\title{
Characterisation of the mitochondrial genome and the population genetics of Polyprion oxygeneios (hapuku) from around New Zealand
}

by

Henry Somerset Lane

A thesis submitted to the Victoria University of Wellington in partial fulfillment of the requirements for the degree of Master of Science

2013

TE WHARE WĀNANGA O TE ŪPOKO O TE IKA A MĀUI

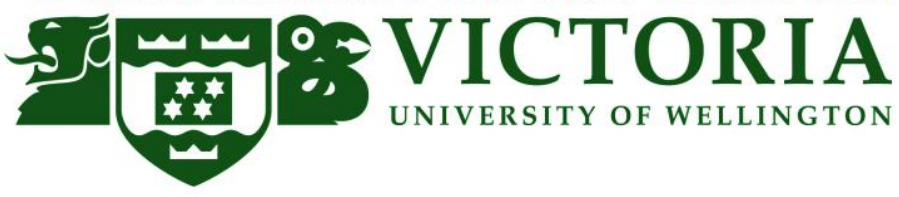




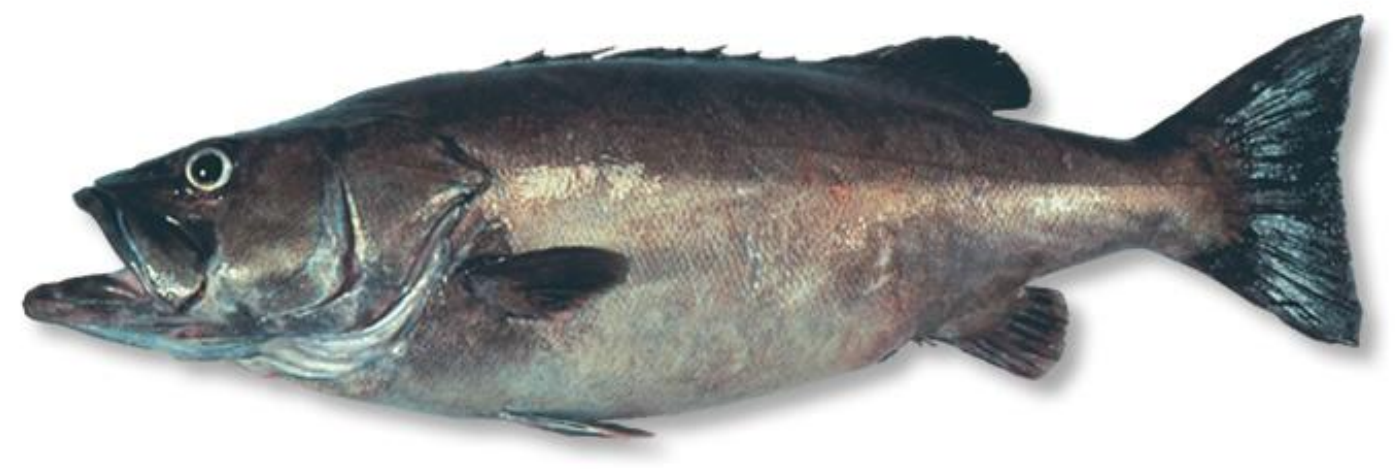

Polyprion oxygeneios (sourced from fishbase.com)

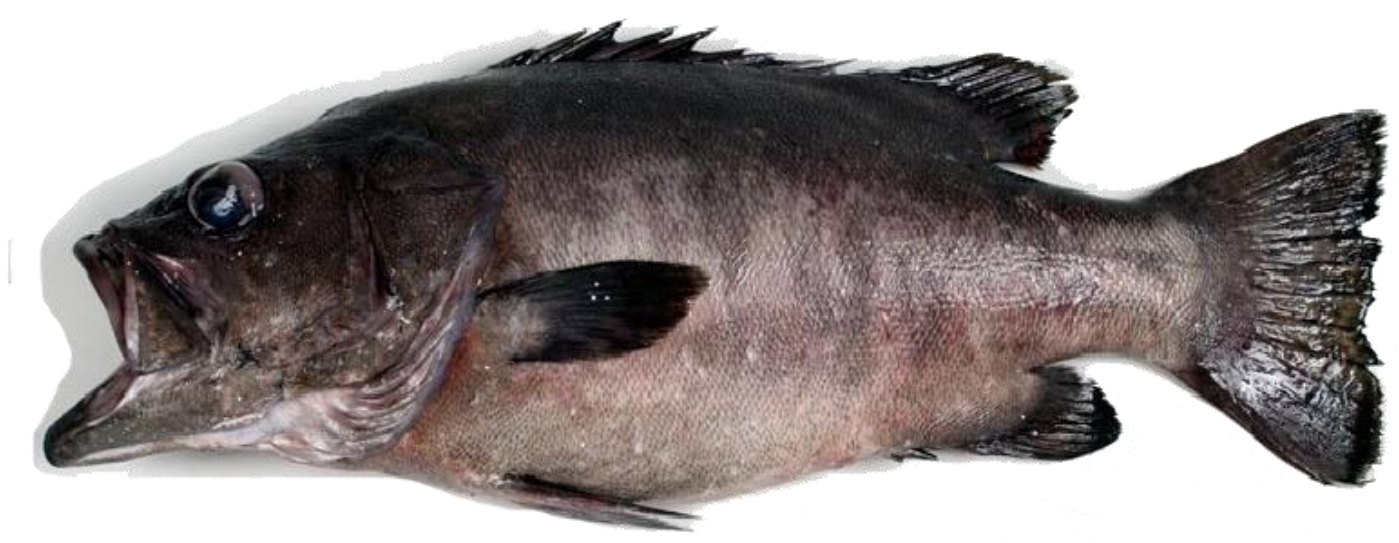

Polyprion americanus (sourced from ladimar.com) 


\section{$\underline{\text { Abstract }}$}

Polyprion oxygeneios (hapuku) is an important commercial and recreational fishery species within New Zealand. Moreover, $P$. oxygeneios are currently being developed as a high-value New Zealand aquaculture species. There have been no previous studies on New Zealand's $P$. oxygeneios that have been able to detect genetic differences among samples, which may be of use to either broodstock or fisheries managers. An understanding of the genetic structure of commercially harvested species maximises the potential for sustainable harvesting through effective management schemes. The primary goal of this thesis was to investigate the population genetic structure of $P$. oxygeneios using molecular markers to analyse samples collected from sites within New Zealand's Exclusive Economic Zone (EEZ).

The DNA sequence of the whole mitochondrial genome of P. oxygeneios was determined and it showed a similar structure and gene organisation to that of other species across a wide range of taxa. A set of species-specific control region primers was developed for P. oxygeneios and Polyprion americanus, and additional primers were designed for the $16 \mathrm{~S}$ and ND6 genes of $P$. oxygeneios. A $\sim 488$ bp portion of the mitochondrial DNA (mtDNA) control region sequence from 274 individuals, and genotypes from 259 individuals using nine polymorphic microsatellite loci, were used to investigate the phylogeography and population genetic structure of P. oxygeneios. The mitochondrial DNA data failed to detect any significant differentiation between sample sites. However, the microsatellite DNA analyses showed that individuals sampled from the west coast of the South Island (Hokitika) were genetically distinct from individuals sampled at all other New Zealand sites. These two groups might be representative of two discrete populations of $P$. oxygeneios within New Zealand's EEZ. These results suggest that the west coast South Island $P$. oxygeneios fishery should continue to be managed as a separate stock, with some possible revision of the Cook Strait fishery required. Analyses of the mtDNA and microsatellite DNA data of P. oxygeneios broodstock held at NIWA's Bream Bay Aquaculture Park showed that they were not significantly differentiated from the wild populations (excluding Hokitika). Simulations also described the appropriate sampling efforts required to capture an appropriate level of genetic diversity when either establishing a new broodstock or supplementing an existing broodstock with new individuals. Continued management of the broodstock will be required to maintain the high levels of genetic diversity that have been captured in the founding broodstock in future generations. 


\section{Acknowledgements}

This thesis would not have been completed without the help and support I have received from a number of different people.

Firstly, and most importantly, I would like to extend an enormous thank you to my supervisors Dr. Peter Ritchie and Dr. Jane Symonds. I consider myself fortunate to have had the opportunity to work under two extremely dedicated and knowledgeable professionals. The support received and the knowledge gained has been invaluable in not only my completion of this thesis but also in my own self-belief as a researcher. Thank you.

To my fellow students within the Peter Ritchie Lab Group, I would like to extend my thanks. In particular, Dave Ashton, Seba 'The Cowboy' Hernandez and Hayden 'Dogs' Smith, are worthy of a mention. It has been a pleasure to work alongside you in the lab and those Wednesday afternoons sampling a few of New Zealand's finest beverages were not too bad either.

The collection of some 300 samples of a middle depth fish is no easy task. The efforts of Greg Bishop and the team at Leigh Fisheries, Rachel Harvie from Waitangi Seafoods, Jude Jamison from Harbour Fish, Marc Ferris from the Ngati Porou Seafood Group and Fraser Smith from The Wellington Trawling Company, made the collection of samples easier than it ought to be! Thanks must be extended to Mary McEwan and the team at GenomNZ as well as Lesley McLeod, Dr. Stephen Brouwer and the MPI Observers. Also, the team at NIWA's Aquaculture Park must be mentioned in their efforts in sample collection.

In the wider world, I would like to acknowledge my parents, Ma and Pa Lane, who taught me the importance of certain geometric shapes; also, to Graham and Ann Haycock for their unwavering support of our family. Last but not least, thanks to all the ladies and gentlemen in Auckland and Wellington (and also to those abroad) who make my life so much fun - you know who you are! 


\section{Table of Contents}

Polyprion oxygeneios and Polyprion americanus ..................................................

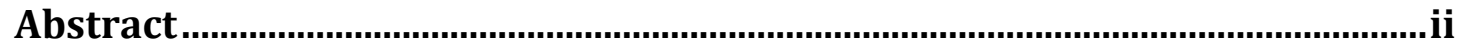

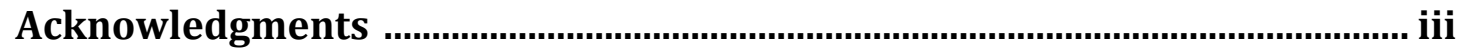

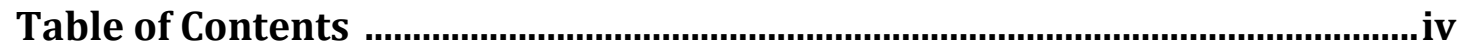

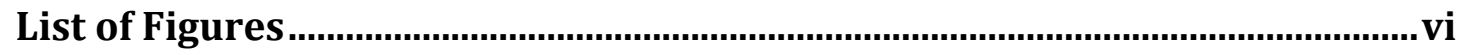

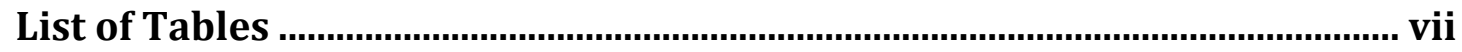

List of abbreviations ........................................................................................... viii

\section{Chapter One: General Introduction}

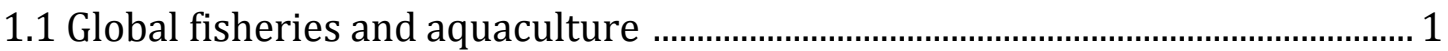

1.2 New Zealand fisheries......................................................................................... 1

1.3 Genetics in fisheries management ........................................................................ 3

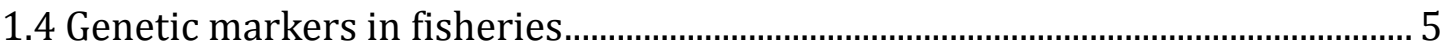

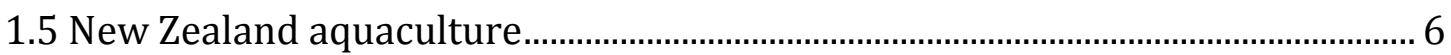

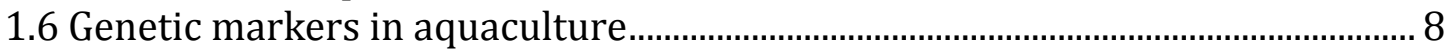

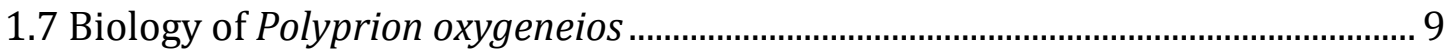

1.8 The New Zealand fishery of Polyprion oxygeneios ..................................................10

1.9 Aquaculture of Polyprion oxygeneios in New Zealand ............................................11

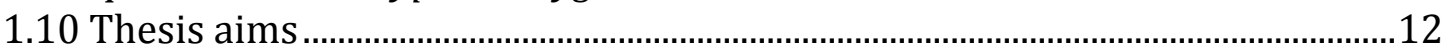

Chapter Two: Characterisation of the whole mitochondrial genome of Polyprion oxygeneios and development of mitochondrial DNA primers

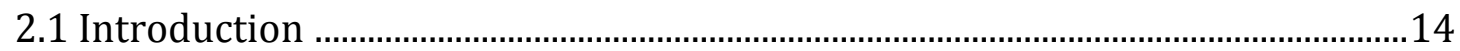

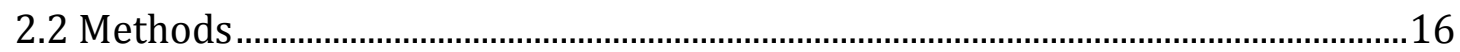

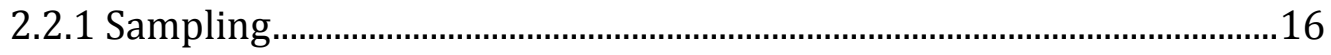

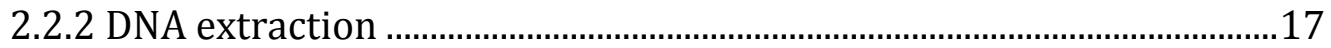

2.2.3 Whole mitochondrial sequencing of Polyprion oxygeneios ..................17

2.2.4 16S and ND6 primer design.....................................................................18

2.2.5 Control region primer design for Polyprion oxygeneios.........................19

2.2.6 Control region primer design for Polyprion americanus .......................19

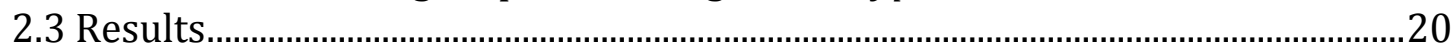

2.3.1 Mitochondrial genome of Polyprion oxygeneios.....................................20

2.3.2 Control region of Polyprion oxygeneios and Polyprion americanus ...21

2.4 Discussion.

Chapter Three: The phylogeography and population genetics of Polyprion oxygeneios inferred from mitochondrial DNA sequences and microsatellite DNA genotyping

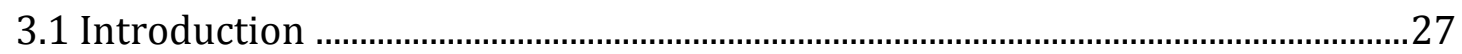

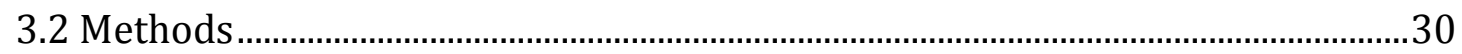

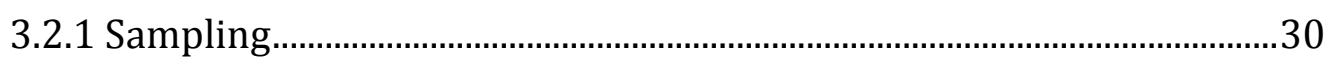

3.2.2 Mitochondrial DNA extraction, amplification and sequencing ...........30

3.2.3 Microsatellite amplification and genotyping ............................................ 31 


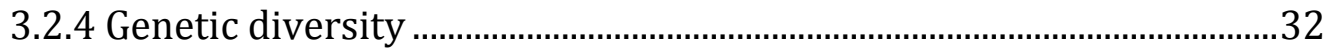

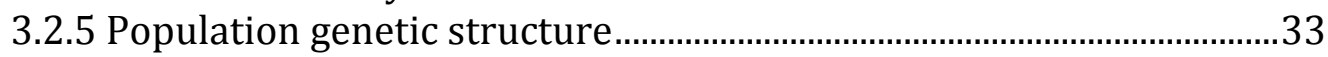

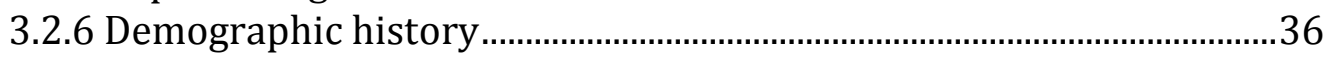

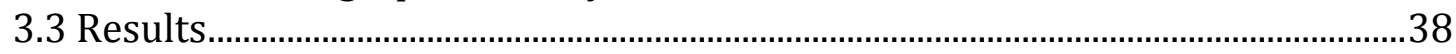

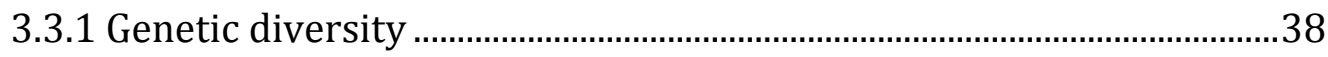

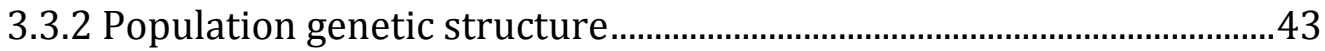

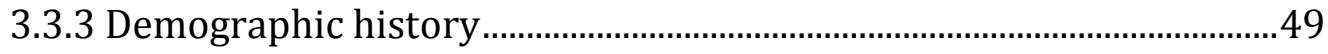

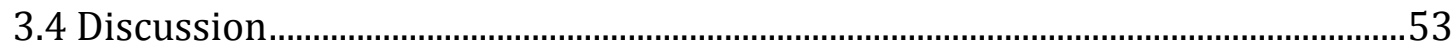

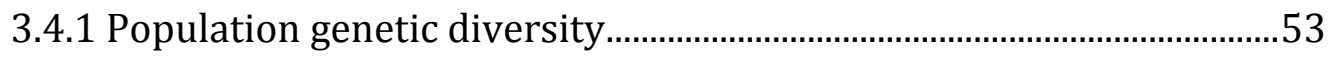

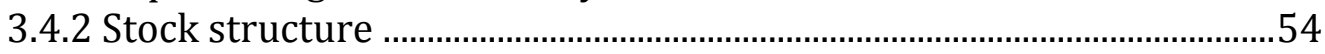

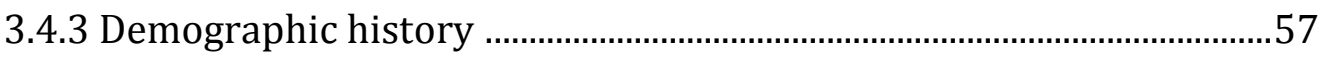

3.4.3 Implications for fisheries management .................................................59

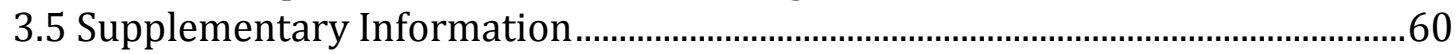

Chapter Four: Genetic variability between hatchery and wild populations of Polyprion oxygeneios based on the mitochondrial DNA control region and nine microsatellites

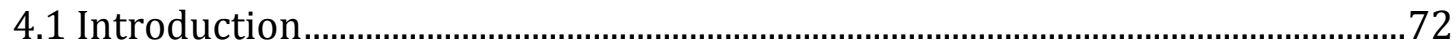

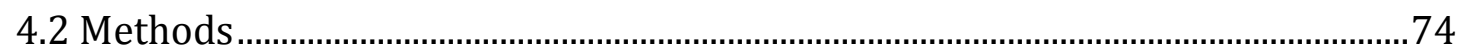

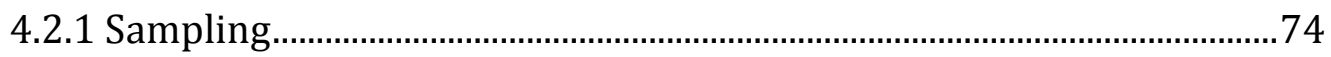

4.2.2 Genetic diversity ........................................................................................ 75

4.2.3 Representation of wild genetic diversity in broodstocks .....................77

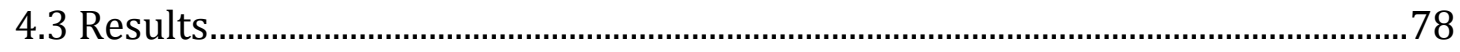

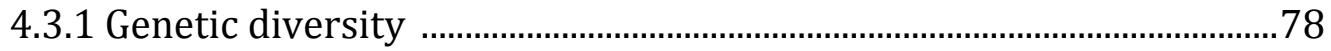

4.3.2 Representation of wild genetic diversity in broodstocks ....................82

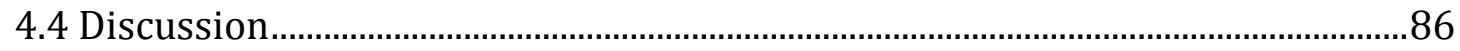

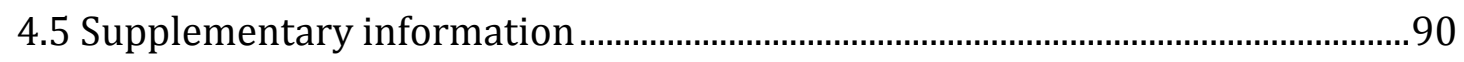

\section{Chapter Five: General Discussion}

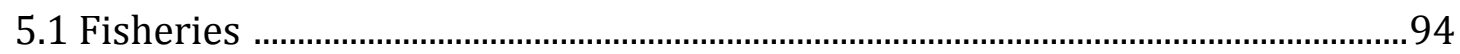

5.2 Management recommendations ............................................................................96

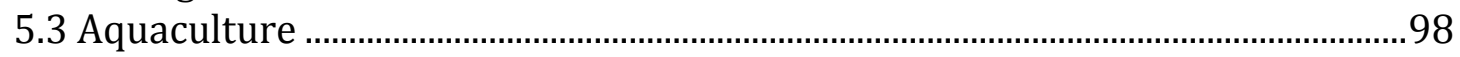

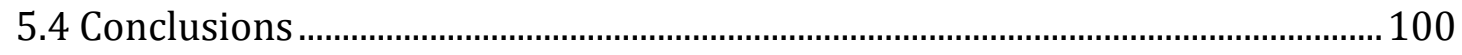

\section{References}




\section{List of Figures}

\section{Chapter One}

1.1 Three classifications of population genetic structure ............................................. 4

1.2 Quota management areas of the hapuku fishery in New Zealand .......................11

\section{Chapter Two}

2.1 Sampling sites for whole genome sequencing and primer design ......................16

2.2 The complete mitochondrial genome of P. oxygeneios ...........................................23

2.3 Control region consensus sequence of $P$. oxygeneios and $P$. americanus .......... 24

\section{Chapter Three}

3.1 Sampling sites for population genetic analyses......................................................

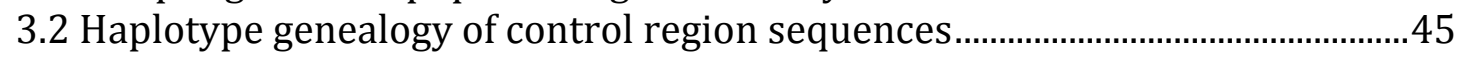

3.3 Haplotype frequencies of each sampling site .........................................................46

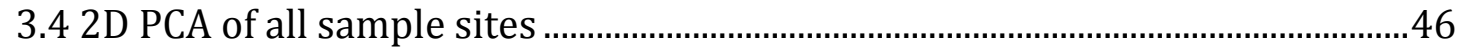

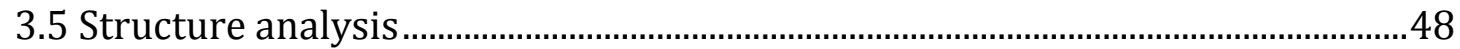

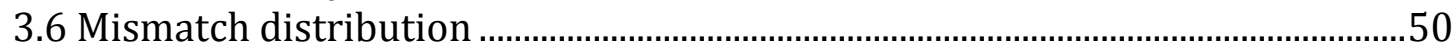

3.7 Bayesian skyline plot at an evolutionary rate of $2.0 \times 10^{-8} \mathrm{~s} / \mathrm{s} /$ year....................52

3.8 Bayesian skyline plot at an evolutionary rate of $3.6 \times 10^{-8} \mathrm{~s} / \mathrm{s} /$ year....................52

3.9 Four classifications of historical demographic processes .....................................58

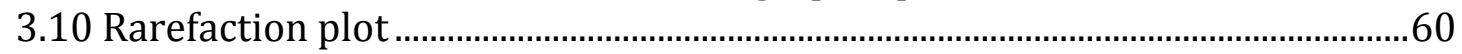

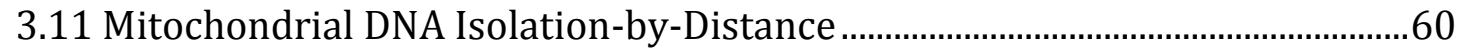

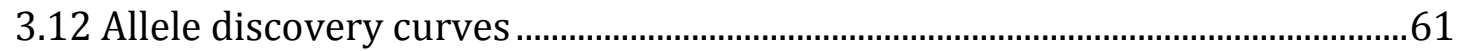

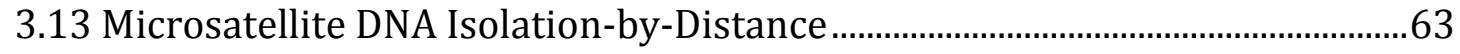

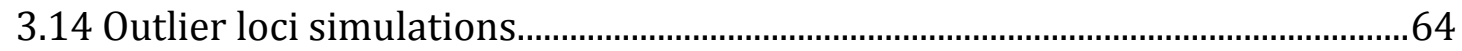

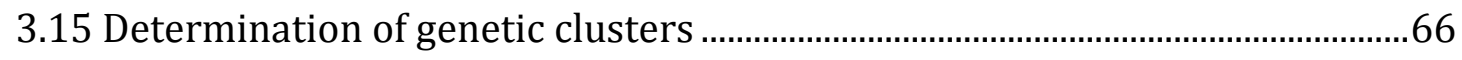

3.16 Neighbour-joining tree of all sampled sites..........................................................66

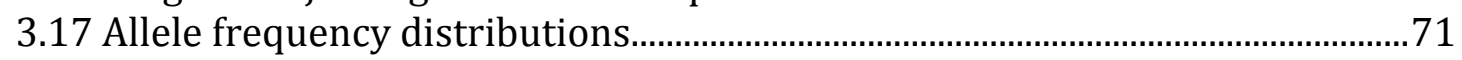

3.18 Rare allele frequency distributions.......................................................................

\section{Chapter Four}

4.1 Location of NIWA's Bream Bay Aquaculture Park ....................................................

4.2 Haplotype frequency of the wild broodstock ........................................................ 79

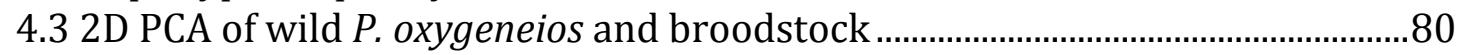

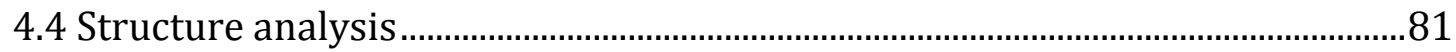

4.5 Wild alleles not represented in the broodstock ...................................................82

4.6 Average percentage of wild alleles not represented in the broodstock............83

4.7 Wild Leigh alleles not represented in an increased broodstock with new

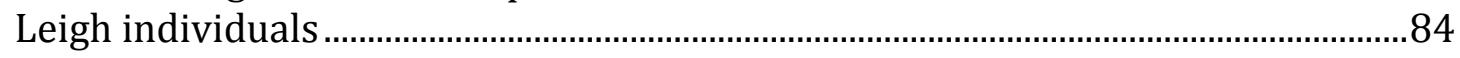

4.8 Wild alleles not represented in an increased broodstock with new Leigh

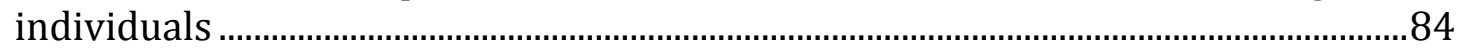

4.9 Wild Otago alleles not represented in an increased broodstock with new Otago individuals .

4.10 Wild alleles not represented in an increased broodstock with new

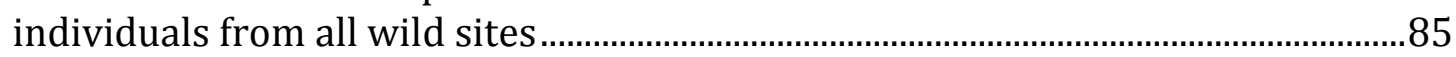

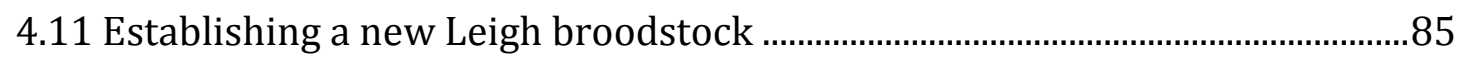

4.12 Establishing a new Marlborough Sounds broodstock .........................................86 
4.13 Establishing a new broodstock from all wild sites

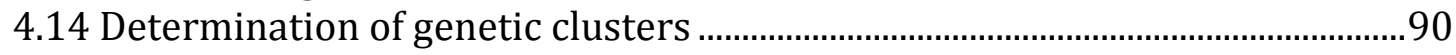

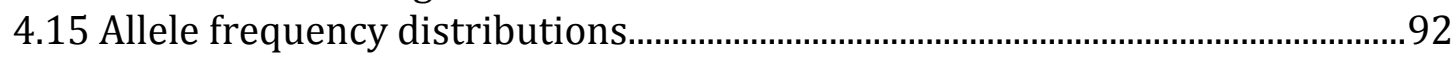

4.16 Rare allele frequency distributions......................................................................

\section{Chapter Five}

5.1 Proposed options for revised management areas in the hapuku fishery.........98

\section{List of Tables}

\section{Chapter Two}

2.1 Gene organisation of the mitochondrial genome of Polyprion oxygeneios.......22

\section{Chapter Three}

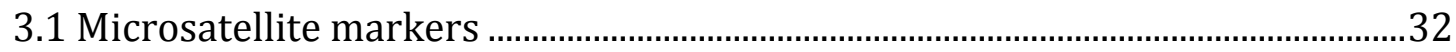

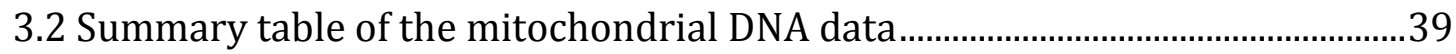

3.3 Summary table of the microsatellite DNA data .........................................................40

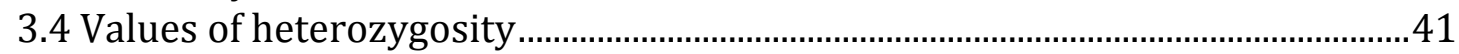

3.5 Pairwise matrix of $F_{s t}$ and genetically differentiated loci ....................................4

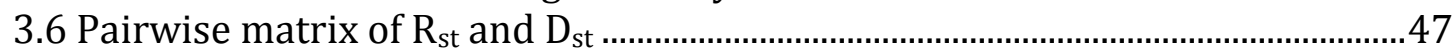

3.7 Pairwise matrix of population assignment............................................................. 48

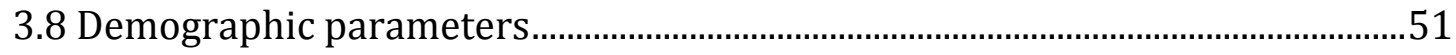

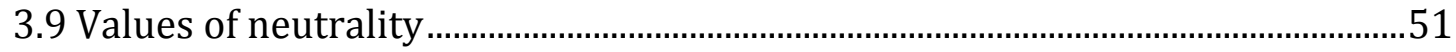

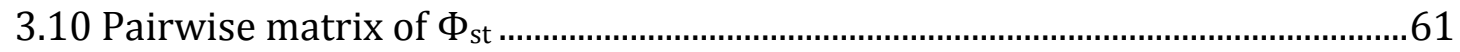

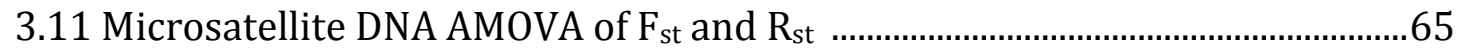

3.12 Genetic bottleneck under the three mutational models ......................................65

\section{Chapter Four}

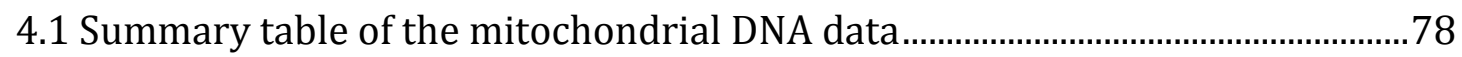

4.2 Summary table of the microsatellite DNA data........................................................8

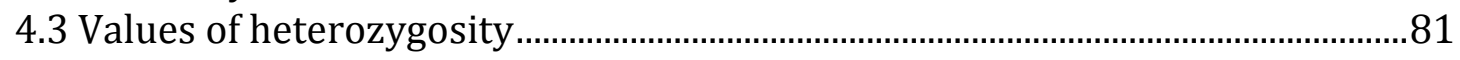

4.4 Genetic bottleneck under the three mutational models.......................................90 


\section{List of abbreviations}

$\begin{array}{ll}\text { AMOVA } & \text { Analysis of molecular variance } \\ \text { BSA } & \text { Bovine serum albumin } \\ \text { BSP } & \text { Bayesian skyline plot } \\ \text { bp } & \text { Base pairs } \\ \text { CCD } & \text { Centrally conserved domain } \\ \text { DNA } & \text { Deoxyribonucleic acid } \\ \text { EEZ } & \text { Exclusive economic zone } \\ \text { ESU } & \text { Evolutionary significant unit } \\ \text { F1 } & \text { Filial 1 } \\ \text { FAO } & \text { Food and Agricultural Organisation } \\ \text { FMA } & \text { Fishery management area } \\ \text { GB } & \text { Gigabyte } \\ \text { HPB } & \text { Hapuku and bass fishery of New Zealand } \\ \text { HWE } & \text { Hardy-Weinberg equilibrium } \\ \text { IAM } & \text { Infinite alleles model } \\ \text { IBD } & \text { Isolation-by-Distance } \\ \text { kya } & \text { Thousand years ago } \\ \text { MCMC } & \text { Markov chain Monte-Carlo } \\ \text { ML } & \text { Maximum likelihood } \\ \text { mtDNA } & \text { Mitochondrial DNA } \\ \text { mtgenome } & \text { Mitochondrial genome } \\ \text { NIWA } & \text { National Institute of Water and Atmospheric Research } \\ \text { PCA } & \text { Principal component analysis } \\ \text { PCR } & \text { Polymerase Chain Reaction } \\ \text { QMA } & \text { Quota management area } \\ \text { QMS } & \text { Quota management system } \\ \text { QTL } & \text { Quantitative trait loci } \\ \text { rRNA } & \text { Ribosomal ribonucleic acid } \\ \text { SMM } & \text { Stepwise mutation model } \\ \text { SNP } & \text { Single nucleotide polymorphism } \\ \text { SSD } & \text { Sum of squared deviations } \\ \text { TACC } & \text { Total allowable commercial catch } \\ \text { TPM } & \text { Two-phase model } \\ \text { tRNA } & \text { Transfer ribonucleic acid } \\ & \end{array}$




\section{Chapter One}

\section{General Introduction}

\section{$\underline{1.1 \text { Global fisheries and aquaculture }}$}

Seafood is a rich source of protein and an essential component of many people's diet. The global seafood industry is worth US $\$ 217.5$ billion and it extracted about 148 million tonnes of product from the oceans in 2010 (FAO 2012). Fish are a limited natural resource (Tidwell and Allen 2001) and since the early 1990s the total production from wild-capture fisheries has plateaued, with $57 \%$ of global fisheries stocks considered fully exploited and 30\% are considered over exploited (FAO 2012). The long-term sustainability of global fisheries is crucial for maintaining food security and socioeconomic benefits for many communities. Maintaining and improving production yields relies on the proper management of existing wild stocks and developing new opportunities for aquaculture.

Over the last three decades, fish production from aquaculture has expanded almost 12-fold with an average annual growth rate of 8.8\% (FAO 2012). Aquaculture production is considered the main future supply of fish products. Preliminary findings of the FAO's 2011 global fisheries overview indicated a total global fish production of 154 million tonnes is primarily driven by a further $6 \%$ increase in aquaculture production during 2010. The increased production from aquaculture is almost entirely for human consumption. With the world's population expecting to near nine billion by mid-century (Godfray et al., 2010), a continued increase in aquaculture production is needed to alleviate the pressure on wild fish stocks and to help fulfill the growing global demand for healthy protein products. 


\section{$\underline{1.2}$ New Zealand fisheries}

New Zealand's Exclusive Economic Zone (EEZ) of 4.4 million $\mathrm{km}^{2}$ is the fourth largest in the world and it supports over 100 different fisheries, which contribute around $\$ 1.5$ billion a year in exports in 2012 (Ministry for Primary Industries). The New Zealand Ministry from Primary Industries defines a fishery as anything to do with fishing for any particular type of fish. With the development of more intensive fishing methods during the 1970s coupled with a rise in the number of fishing vessels, a Quota Management System (QMS) was introduced in 1986 as a management tool to ensure that the annual catch of fish was maintained at sustainable levels.

The QMS has each fishery divided into Fishery Management Areas (FMAs) and each area is allocated a portion, or quota, of the Total Allowable Commercial Catch (TACC). The TACC and the quota for each area can be determined from an estimate of the total stock biomass and the maximum portion of the biomass that can be harvested without having a negative impact on the sustainability of the fishery (Carvalho and Hauser 1994). The high value New Zealand fisheries have had a quantitative stock assessment to determine the maximum sustainable yields for setting their respective TACC. A stock assessment requires a description of the fishery, species life history characteristics, and the population's biomass trends. The accuracy of the assessment needs the boundaries of each stock to be defined.

Numerous stock definitions persist in the literature (Smith et al., 1990; Carvalho and Hauser 1994; Pawson and Jennings 1996; Paul 2002a; Ministry for Primary Industries 2012). In general, a stock is a management unit that can be considered an intraspecific group of randomly mating individuals with temporal and spatial integrity (Ihseen et al., 1981). In a fisheries sense, stocks are usually smaller than natural biological populations (Paul 2002a), but the terms 'stock' and 'population' are typically used interchangeably (Begg and Waldman 1999). The boundaries of a stock have been difficult to define because the marine environment is a large and open system, with few apparent barriers to dispersal. 
Recent studies have suggested that the exchange of individuals in the marine environment often reflects that of a closed system and genetic panmixia is not as common as previously thought (Hauser and Carvalho 2008). Only a few species form single homogenous populations, and many are composed of discrete stocks that respond more or less independently to harvesting pressure (Carvalho and Hauser 1994).

\section{$\underline{1.3 \text { Genetics in fisheries management }}$}

There are a variety of methods available for detecting stock structure (as reviewed by Begg and Waldman 1999; Pawson and Jennings 1996). The most robust approach is to use a suite of techniques that measure multiple biological aspects of the species (Begg and Waldman 1999; Waldman et al., 1997). While a holistic approach is the most effective means, many logistical and financial constraints limit its use (Begg and Waldman 1999). Stock identification methods can be separated into two categories: direct and indirect methods. Direct methods sample the movement of individuals between sites and they include techniques such as mark-recapture (tagging) (Beentjes and Francis 1999; Glover et al., 2008), otolith microchemistry (Ashford et al., 2008) and the evaluation of life-history characteristics (Begg et al., 1999). However, these methods are often unable to determine whether immigrants to a stock will survive and reproduce. Indirect methods sample the effects of individuals moving among sites, with genetic loci being the most common type of marker. Genetic markers sample the inherited characters that are shared by individuals that are part of the same reproductive process (Faurby and Barber 2012). Genetic markers also provide a description of the genetic variation in a population, which is important when considering the long-term persistence and adaptability of a species.

Oceanographic processes, as well as the behavioral and temporal variation of individuals, can all promote subdivision within a population because they influence inbreeding, selection and migration. Population genetic structure provides the right conditions for evolution to occur - commonly referred to as 
evolutionary significant units (ESU) - because subdivided segments can evolve separately and develop adaptive differences and ultimately lead to speciation.

There are several documented cases of overfishing depleting a fishery stock, for example, Atlantic cod (Gadus morhua) (Hutchings 1996), Orange Roughy (Hoplostethus atlanticus) (Smith et al., 1991) and Haddock (Melanogrammus aeglefinus) (Clark et al., 1982). The harvesting that is typical of most industrial scale fishing can cause genetic changes and disrupt genetically subdivided populations that can alter the patterns of genetic variation that naturally fluctuate over time because of the influence of selection, migration and genetic drift (Allendorf et al., 2008). A reduction in the population size of a fishery species will increase the strength of genetic drift, which eliminates genetic variation. A reduction in genetic variation can limit the adaptive potential of a population and its ability to adjust to environmental changes (Allendorf et al., 2008). Moreover, in small populations the chance of closely related individuals mating increases, and if this leads to inbreeding depression it can further reduce the biological productivity of the population (Hoarau et al., 2005). Fishing methods typically select the large individuals in a population. Size-selective harvesting on an industrial scale can change the genetic constitution of the population (if the selected phenotype is heritable) and shift the population to early maturation and smaller individuals (Law 2007).
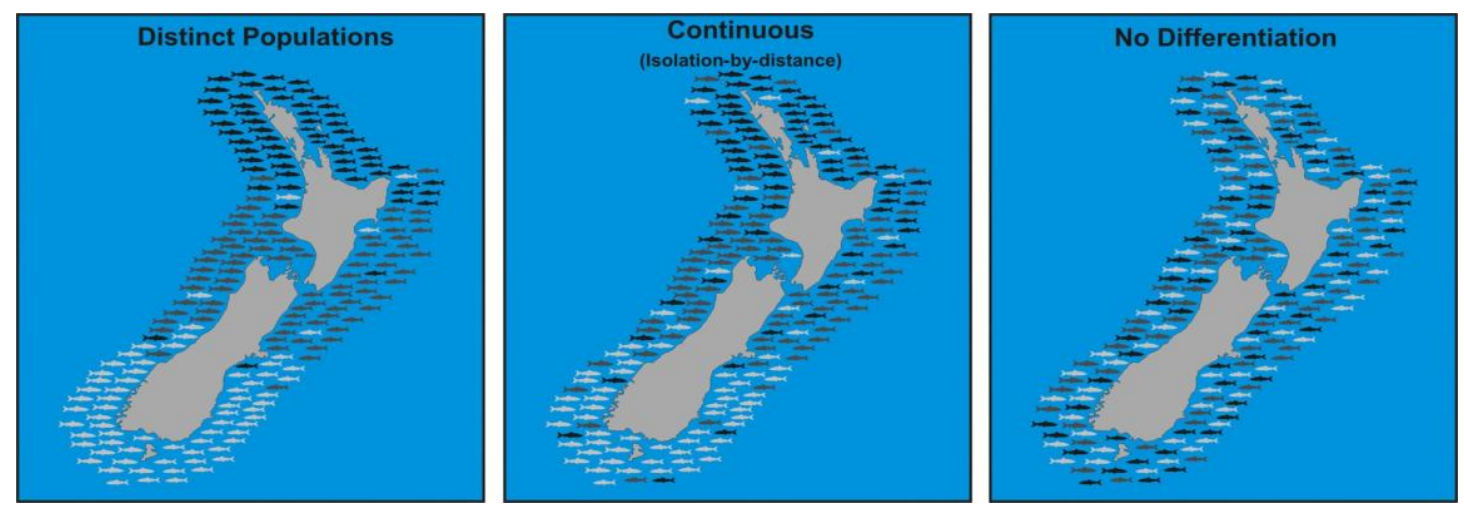

Figure 1.1 Three classifications of population genetic structure of marine fishes as adapted from Laikre et al., (2005). 
An accurate description of the population genetic structure for a fishery species can aid sustainable management of that fishery (Waples and Gaggiotti 2006). As described by Laikre et al., (2005) (figure 1), there are three general categories of genetic structure: 1) distinct populations, gene flow is small enough to permit genetic divergence among closely related populations; 2) continuous change (isolation-by-distance), the genetic composition changes more or less continuously over space; 3) no differentiation (panmixia), genetic homogeneity prevails over the geographic region considered. It may be possible for one species to fit into more than one of these categories. For example, a species that is distributed across a large mainland site and isolated offshore islands may be comprised of a combination of an isolation-by-distance structure on the mainland, but the offshore islands may be genetically distinct from the mainland.

\subsection{Genetic markers in fisheries}

There are several types of genetic markers that can be used to infer population genetic structure, these include: allozymes, mitochondrial DNA (mtDNA), microsatellite DNA, and single nucleotide polymorphisms (SNPs). The most common genetic markers currently in use by fisheries researches are mtDNA and microsatellite DNA. Traditionally, allozymes (protein amino acid variation) were popular, but these markers often lack high levels of variation and hence have low levels of statistical power. Protein-based markers also require very well preserved samples collected using destructive tissue sampling techniques (Smith and Johnson 1985).

Mitochondrial DNA is the most common genetic marker used to survey a fishery species because it is cheap and relatively straightforward to develop (Hurst and Jiggins 2005). The mitochondrial genome (mtgenome) is typically inherited through the maternal line and does not undergo recombination, which means all of the genes act as a single locus and are inherited together. Thus, all genes on the molecule can be assumed to share the same genealogical history. Because mtDNA is maternally inherited it has a quarter of the effective population size of nuclear DNA making mtDNA much more sensitive to demographic changes 
(Hurst and Jiggins 2005). Mitochondrial DNA can be analysed using both population genetic and phylogenetic methodologies. Tree-based evolutionary analyses enable gene lineages to be plotted as distributed across a landscape and provide insight into the demographic history of a population (phylogeography), enabling environmental factors such as climatic changes that can cause populations to either expand or contract to be detected (Gaither et al., 2011; Varela et al., 2012). Most population studies target one or two highly polymorphic gene regions of the mtgenome (e.g. CO1 or the control region) (Freiss and Sedberry 2011; Varela et al., 2012). Nuclear DNA markers, including microsatellites and SNPs, are becoming increasingly common in population genetic studies. Microsatellites are segments of DNA that contain short repeated sequences of 1 - 5 base pairs (bp) (Smith 2008) and these repetitive units are common throughout the genome. These markers provide a greater statistical resolution because they can be developed to sample multiple independent points (loci) on the genome. Most microsatellite loci are non-coding sequences with high mutation rates. Even more genomic loci can be sampled and even high statistical resolution can be obtained using SNPs; however, they are costly and technically difficult to develop.

\subsection{New Zealand aquaculture}

Aquaculture in New Zealand is recognised as the fastest growing industry in the primary sector (MPI 2012). Currently, 19,268 ha of water space is taken up by aquaculture activities and the industry provides around $\$ 350$ million a year to New Zealand's economy; this industry aims to increase this to $\$ 1$ billion by 2025 (Ministry for Primary Industries) Greenshell mussel ${ }^{\mathrm{TM}}$ (Perna canaliculus), Pacific oysters (Crassostrea gigas) and king salmon (Oncorhynchus tshawytscha) are the main species cultured in New Zealand. The development of new high-value species such as hapuku (Polyprion oxygeneios), kingfish (Seriola lalandi) and paua (Haliotis iris) are expected to be key developments that will enable the growth of aquaculture in New Zealand (Bruce 2006). 
Establishing an aquaculture species first requires male and female broodstock that can be bred in captivity to produce domesticated offspring. A major step in aquaculture is the closing of the lifecycle to enable selective breeding from the captive-reared domesticated stock. Selective breeding is the best method for improving the stock performance (Gjedrem 1985). The large wild population sizes of marine organisms enable high levels of genetic variation to be maintained. As the level of genetic variation determines a population's ability to respond to selection, selective breeding in aquaculture is expected to result in greater gains than traditional agriculture (Jackson et al., 2003). In recent review, Gjedrem (2012) notes that the time to produce a standard $4 \mathrm{~kg}$ Atlantic salmon (Salmo salar) has been halved in the last 40 years, and the feed needed to produce $1 \mathrm{~kg}$ of salmon has dropped from $3 \mathrm{~kg}$ to $1.15 \mathrm{~kg}$ (Austreng 1993).

An understanding of the genetic constitution of wild populations is important to ensure that an appropriate level of genetic diversity is captured in the broodstock. Often, there is little or no information on how genetically representative culture populations are relative to their wild progenitors (Liu and Cordes 2004). A lack of understanding of the genetic sources of wild broodstocks can limit the representation of genetic variation and in small captive populations can lead to the development of undesirable genetic traits (Smith 2008).

Inbreeding depression is the reduction in a population's fitness, resulting from the breeding of related individuals that can force deleterious recessive alleles in to homozygotes (Lynch 1991). Marine fish are typically highly fecund, often producing millions of eggs each breeding season (Symonds et al., 2012). Marine populations tend to be large but broodstocks tend to be small by comparison. Thus, ensuring that multiple parents are contributing to the next generation is important to maintaining high levels of genetic variation in the offspring. The strength of inbreeding as well as genetic drift is inversely related to the effective population size (Borrell et al., 2007). A small effective population size can hold comparatively little genetic variation, which restricts the response to selection and increases the risk of inbreeding (Smith 2008). While the detrimental effects of inbreeding are not entirely uniform (Nakadate et al., 2003), simulations have 
highlighted a relationship between a reduction in breeding pairs and a $6-8 \%$ increase in inbreeding per generation (Bentsen et al., 2002).

Outbreeding depression occurs when the fitness of offspring from crosses between individuals from diverged populations is lower than that of offspring formed from crosses between individuals of the same population (Goldberg et al., 2005). This reduction of fitness is thought to arise from the breakdown of coadapted genes that have evolved in the diverged populations (Goldberg et al., 2005). Crosses of the largemouth bass (Micropterus salmoides) from two geographically and genetically distinct populations suffered a 14\% decline in fitness relative to parental populations (Goldberg et al., 2005). It has been shown through various empirical studies, that both inbreeding and outbreeding depression can reduce a population's fitness. Moreover, it may take several generations for these effects to become apparent and even longer to correct (Frost et al., 2006). As such, efforts are made to ensure that the founding broodstock is an appropriate representation of the wild genetic diversity and that this is maintained at acceptable levels through maintenance of the effective population size. Furthermore, consideration is also given to maintaining separate broodstocks when sampling from diverged populations (Smith 2008).

\section{$\underline{1.6 \text { Genetic markers in aquaculture }}$}

In aquaculture, questions arise as to how diverse the genetic background is of the broodstock, and how the cultured populations differ from the wild (Liu and Cordes 2004). Molecular DNA markers have been successfully applied to determine the genetic variation within, and differentiation among, these cultured and wild populations (Smith and Conroy 1992; Norris et al., 2000).

In order to establish a high quality broodstock, it is imperative to determine which individuals are contributing most to the next generation and adjust the parental contribution accordingly, which can be logistically difficult. Typically, small cultured populations only represent a small proportion of the wild genetic diversity. In the absence of reliable pedigree information, certain hatchery 
practices can also reduce this genetic diversity further (Frost et al., 2006). Having access to detailed and reliable pedigree information allows the maintenance of the genetic diversity in culture (Jerry et al., 2004). However, in order to trace parentage effectively in highly fecund species, the appropriate tools are required. Microsatellites are known to provide the best results in culture for parentage assignments (Kim et al., 2007). The large number of alleles and high levels of detectable polymorphism exhibited by microsatellites make obtaining unique genotypes for each individual feasible (Liu and Cordes 2004). There are a number of studies where the application of microsatellites has successfully determined parentage in a variety of species (Norris et al., 2000; Neff 2001; Kim et al., 2007).

\section{$\underline{1.7 \text { Biology of Polyprion oxygeneios }}$}

Current taxonomy of the family Polyprionidae lists two genera: Polyprion and Stereolepis. There is some conjecture about the number of species represented under the genus Polyprion. Roberts (1986) revised the systematics of Polyprion and synonymised around 20 nominal species to two names: $P$. oxygeneios and $P$. americanus. Included in this revision was $P$. moeone, which was previously described from New Zealand and P. americanus being described from the Atlantic. However, Paxton et al., (1989) listed P. oxygeneios and P. moeone as the only valid species occurring in Australian and New Zealand waters. The findings of Ball (2000) are supportive of the suggestion that $P$. moeone is indeed a valid species and suggest that further clarification of the Polyprion genus is required. However, until such a revision of the Polyprion taxonomy is conducted, $P$. oxygeneios and P. americanus are the two species listed under this genus.

The Polyprion spp. are found in waters throughout the temperate and subtropical waters in the southern Indian, Pacific and Atlantic Oceans (Ball et al., 2000). Within New Zealand, P. oxygeneios occur in shelf and slope waters around both the mainland and offshore islands. P. oxygeneios is a demersal fish that is typically found between depths of $50-600$ meters (Francis et al., 1999), and is generally found over rough ground. P. oxygeneios are typically long-lived (up to 
60 years), winter spawning species that are relatively late to mature (seven years) (Beentjes and Francis 1999; Peres and Klippel 2003; Wakefield et al., 2010). It is considered that $P$. oxygeneios form spawning aggregations, but no putative spawning grounds are currently known.

While the adults typically inhabit deeper waters, juveniles are thought to be pelagic, typically associated with floats. This pelagic phase can last up to four years (Francis et al., 1999). Due to the extended nature of this pelagic phase, $P$. oxygeneios have the ability to undergo pan-oceanic mixing (Francis et al., 1999; Ball 2000), although this has not been studied in much detail. In addition to this extended juvenile phase, tagging studies have revealed that adults are highly mobile, possibly related to spawning migrations (Beentjes and Francis 1999). Beentjes and Francis (1999) reported evidence of Cook Strait and Oamaru populations mixing, indicating a single stock. This single stock model is consistent with the genetic study of Smith and Johnson (1985), which found no evidence of multiple stocks in central New Zealand based on allele frequency data of two polymorphic enzyme loci. Smith and Johnson (1985) suggested that when these results are considered with tagging studies, if $P$. oxygeneios stocks are discrete it is probably because of temporal rather than spatial differences. Beentjes and Francis (1999) have also suggested the possibility of a separate stock in eastern Northland, but due to the relatively low numbers of recovered tagged fish the results were inconclusive.

In the tagging study conducted by Beentjes and Francis (1999), it was found that a lot of fish in the Cook Strait region had high site fidelity. Anecdotal evidence suggests that good fishing grounds, particularly pinnacles and ledges, can be fished out quickly and take some time to recover, suggesting high levels of residency. On the other hand, P. oxygeneios have been caught on the open clear ground by trawlers. It is unknown as to whether these fish are moving from one area of rough ground to another, or on a purposeful spawning migration. 


\subsection{The New Zealand fishery of Polyprion oxygeneios}

Since the establishment of the QMS, P. oxygeneios and P. americanus have been managed as a set of pair-species fish stocks (HPB)(Paul 2002a). These are based on the standard QMAs, with QMA 1 and 9 combined into a single northern fish stock: HPB1 (figure 2). The HPB fishery has never been clearly described and the current QMA boundaries were chosen for administrative convenience, rather than stock assessment relevance (Paul 2002b). Moreover, with less than $10 \%$ of the catch recorded under this fishery to the species level, it is difficult to elucidate the stock status for each species from catch data (Paul 2002b).

The New Zealand HPB fishery is relatively small in terms of tonnage. Throughout the 1990 s the landings ranged between 1,100 $t$ and 1,500 $t$, with current landings sitting at 1,635 t. Despite its low tonnage in comparison to other commercial fisheries, i.e. snapper $(6,357 t)$ and hoki $(90,000 t)$, this fishery is considered to be of a high monetary value (Paul 2002b). Therefore, it is important to have an adequate description of this fishery to ensure accurate stock allocation. However, in a review of the HPB fishery, Paul (2002b) notes that there were insufficient data to describe the stock structure, and there were no new data that would suggest that the model needs revision (Smith 2008). 


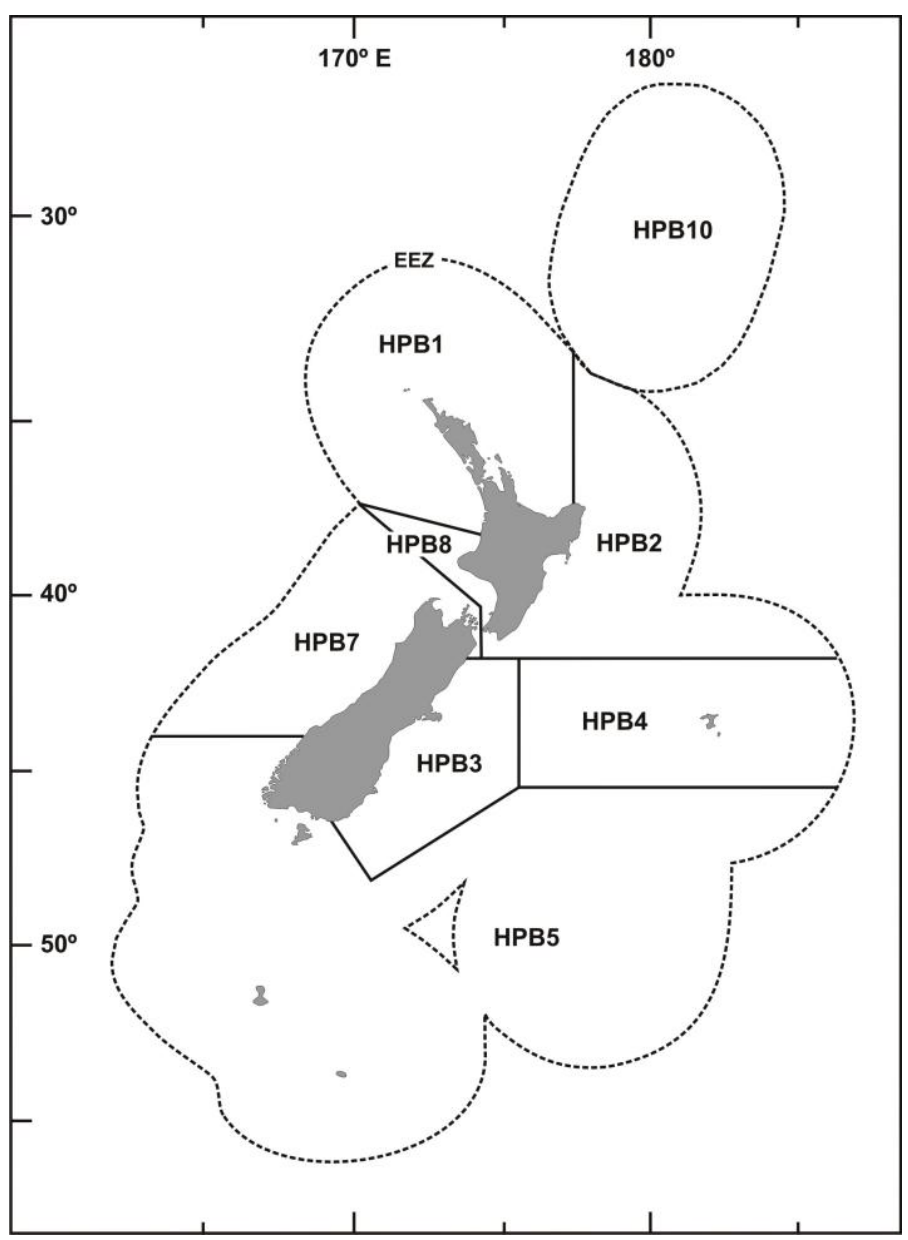

Figure 1.2 Quota management areas of the HPB fishery in New Zealand.

\subsection{Aquaculture of Polyprion oxygeneios in New Zealand}

The National Institute of Water and Atmospheric Research (NIWA) has identified P. oxygeneios as a suitable candidate for New Zealand aquaculture due to its excellent flesh quality and texture (Symonds et al., 2012). The development of this high-value species will not only be important to the growth of New Zealand aquaculture, but also make the industry more secure through diversification by reducing reliance on the established three species (Bruce 2006). Moreover, using higher-value aquaculture species will also allow for greater production from New Zealand's existing farm space (Bruce 2006). The New Zealand Institute of Economic Research (2010) reports that an aquaculture farm producing 8,000 tonne of $P$. oxygeneios per annum would boost New Zealand's gross domestic product by $\$ 200$ million. 
During the past nine years NIWA has undertaken a captive breeding program for wild caught P. oxygeneios at the Bream Bay Aquaculture Park in Northland, with the aim of evaluating the performance of this species for aquaculture (Anderson et al., 2012). This program uses a combination of breeding, genetics and nutrition to develop an elite $P$. oxygeneios broodstock for the future aquaculture industry, and has successfully collected and bred wild P. oxygeneios broodstock in captivity (Symonds et al., 2012). Due to the serial batch spawning behaviour of P. oxygeneios, NIWA and AgResearch have developed microsatellite DNA markers to determine parentage and maximise the parental contribution during spawning (Symonds et al., 2012). These techniques can help ensure a genetically diverse F1 and also identify the best performing individuals for commercial fingerling production (Symonds 2009; Symonds et al., 2012).

\section{$\underline{1.10 \text { Thesis aims }}$}

The overall aim of this thesis is to develop mtDNA markers and use existing microsatellite markers for P. oxygeneios and use them to describe the wild genetic variation and test for differentiation among sampled sites. The genetic data collected from the wild fish population will be compared to the genetic data of $P$. oxygeneios currently in culture. This study will determine how well the captive NIWA broodstock at Bream Bay represents the genetic variation in natural populations. The first component of this thesis (Chapter Two) reports the characterisation of the entire mitochondrial genome of $P$. oxygeneios and the primers that were designed for amplifying the control regions of $P$. oxygeneios and $P$. americanus. Primers were also designed for the ND6 and 16S genes from the mtgenome of P. oxygeneios.

Chapter Three is an investigation of the population genetic structure of $P$. oxygeneios from around New Zealand. Mitochondrial DNA and nine microsatellite DNA markers were used to determine the levels of wild genetic variation, patterns of genetic connectivity, and demographic history. 
Chapter Four is a comparison of genetic variation between wild P. oxygeneios populations and those currently being used in culture. Mitochondrial DNA markers and nine microsatellites were used to compare the two populations; both the wild and F1 broodstocks are analysed.

Chapter Five is a general discussion on the findings of the thesis research and the implication of wild-capture fishery management and the genetic management of the aquaculture broodstock. 


\section{Chapter Two}

\section{Characterisation of the whole mitochondrial genome of}

Polyprion oxygeneios and the development of mitochondrial DNA primers

\section{$\underline{2.1 \text { Introduction }}$}

The mitochondrial genome (mtgenome) is a double-stranded circular molecule that is approximately $16-18$ kilo-bases in length in vertebrates. The first documented sequence of an entire fish mtgenome was the freshwater loach (Crossostoma lacustre) (Tzeng et al., 1992). To date, there are a number of mitochondrial genomes characterised for a variety of fish species. Among these known genomes, the gene content and organisation is highly conserved between taxa, incorporating 13 protein-coding genes, 22 transfer RNAs (tRNA), two ribosomal RNAs (rRNA), and a non-coding region known as the control region or D-loop. Exceptions to this gene composition in fishes have been reported although this is rare (Miya and Nishida 1999).

DNA sequence information is fundamental to our understanding of genome structure, function and evolution. Through recent technological advances in DNA sequencing, there is now an effective way to sequence whole mitochondrial genomes from a range of taxa. Traditional approaches for sequencing genomes have typically relied on the Sanger chain-termination method (Sanger et al., 1977). The development of second-generation sequencing has enabled large numbers of sequence reads to be generated, ranging in length from $35-400$ base pairs (bp), compared to $500-700$ bp for traditional methods (McComish et al., 2010). The sequencing lengths have become shorter, but the numbers of sequences that can be generated in a single run have substantially increased. The large volumes of sequences now possible have enabled the sequencing of extensive areas of a genome to be rapidly covered (Schatz et al., 2010). A single Genomic Analyser can produce 12 - 15 GB of sequence data incorporating 10 
million sequence reads of $75 \mathrm{bp}$ in length (McComish et al., 2010). With the help of previously sequenced genomes held in the GenBank database, de novo sequencing of genomes can be assembled by alignment to the annotated genomes of closely related organisms (see McComish et al., 2010). The advent of second-generation sequencing has allowed the entire mitochondrial genome to be quickly sequenced for a range of marine fishes. This is particularly useful for the elucidation of the evolutionary history of species (Zardoya and Meyer 1996), resolving taxonomic uncertainties (Wang et al., 2012) and designing generic Polymerase Chain Reaction (PCR) primers (Smith 2012).

Population genetic studies often target one or two regions of the mitochondrial genome, i.e. the control region (Freiss and Sedberry 2011) or COI gene (Varela et al, 2012), to determine levels of genetic variation and differentiation.

Mitochondrial DNA (mtDNA) markers represent a good first choice to studying the population genetic structure of a fishery species because developing PCR primers are relatively straight forward, and mtDNA can be analysed using both population genetic and phylogenetic methodologies. DNA sequence data allows genealogical methods to be used, enabling studies into the demographic history of the species. Furthermore, the highly conserved nature of many mtDNA genes means methods can often be transferred and used on a broad range of species (Smith 2012).

The mitochondrial DNA control region is typically the only non-coding region of the genome. It is $\sim 900 \mathrm{bp}$ in length and known for its high rate of mutation. The control region has a tripartite structure with a centrally conserved sequence, referred to as the centrally conserved domain (CCD), flanked by two hypervariable domains at both the 5' and 3' ends (Catanese et al., 2008). Of these two flanking regions, the DNA fragment ranging from tRNA-Pro, through to the CCD, is often recognised as the most variable and is frequently used for population genetic studies (Aboim et al., 2005).

The overall aim of the research reported in this chapter was to determine and characterise, for the first time, the entire mitochondrial genome sequence of 
Polyprion oxygeneios (hapuku). Additionally, PCR primers were designed to amplify the control region of $P$. oxygeneios and subsequently used in population genetic analyses (Chapter Three). The characterisation of the whole mitochondrial genome and the development of new markers for this species will add some important new tools for the management of this fishery and for the development of aquaculture. Moreover, PCR primers designed to amplify the control region of the congeneric, P. americanus, will allow for a comparison of genetic variation between species and provide a DNA sequencing-based species identification tool for the Polyprion fisheries in New Zealand.

\section{$\underline{2.2 \text { Methods }}$}

\subsubsection{Sampling}

A fin clip was taken from a single adult $P$. oxygeneios caught in the Cook Strait and fin clips of $P$. americanus were also taken from adult fish collected off Doubtless Bay, Northland. Fishing-vessel staff made the sample collections during their normal commercial operations. The sampled fin clips were preserved in $70 \%$ ethanol and stored at $4^{\circ} \mathrm{C}$.

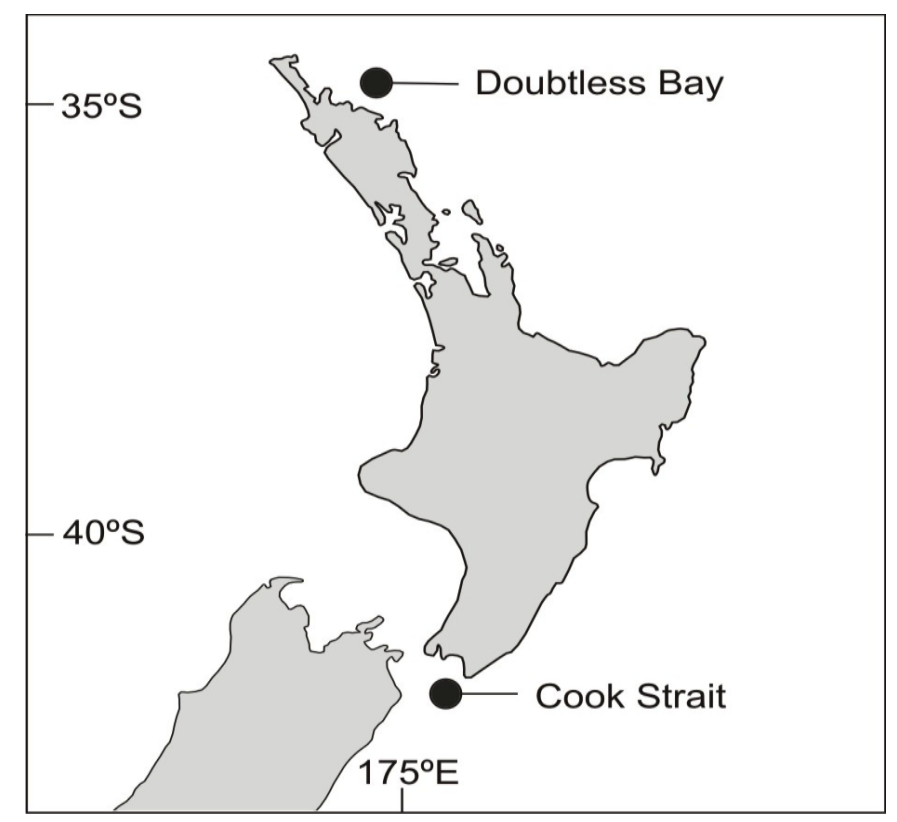

Figure 2.1 Sample sites for $P$. oxygeneios (Cook Strait) and $P$. americanus (Doubtless Bay) 


\subsubsection{Mitochondrial DNA extraction}

Total genomic DNA was extracted using the phenol-chloroform protocol (Sambrook et al., 1989). Each tissue sample was placed in $400 \mu \mathrm{l}$ of extraction buffer (10mM Tris pH 8.0, $50 \mathrm{mM} \mathrm{NaCl}, 10 \mathrm{mM}$ EDTA, and $0.2 \%$ SDS), with 0.5 $\mu \mathrm{g} / \mu \mathrm{l}$ proteinase- $\mathrm{K}$ and incubated for three hours at $50^{\circ} \mathrm{C}$. Following the tissue digestion, DNA was extracted with phenol, followed by chloroform/isoamyl alcohol, and precipitated with 2.5 volumes of ethanol at $-20^{\circ} \mathrm{C}$ for 1 hour. The DNA was pelleted, washed with 70\% ethanol, dried and re-suspended in a TrisEDTA buffer, and stored at $4^{\circ} \mathrm{C}$. DNA concentrations were quantified on a Nanodrop ND-1000 Spectrophotometer, with at least $500 \mathrm{ng} / \mu \mathrm{l}$ of DNA and a high purity level (>2.00) aimed for the extraction used for sequencing the mtgenome.

\subsubsection{Whole mitochondrial genome sequencing of Polyprion oxygeneios}

Second-generation sequencing of the $P$. oxygeneios mitochondrial genome was conducted on an Illumina Genome Analyser IIx at the Beijing Genomics Institute, China. Mate-paired DNA libraries were constructed, each of which had insert sizes of $200 \mathrm{bp}$. The Solexa-Pipeline method was implemented, with $58.37 \mathrm{~GB}$ of raw data generated from a single run. Each of the reads produced by the Illumina machine were $100 \mathrm{bp}$ long, though bases at either end of the read were of lower quality and subsequently trimmed to around $75 \mathrm{bp}$. To minimise the likelihood of incorrectly aligning sequence reads with $\mathrm{N}$ bases (i.e. bases not able to be distinguished), reads with greater than $20 \%$ of bases of low quality, suspected contamination reads, and duplication reads generated by PCR, while constructing the library were all discarded. Following initial filtering as described above, sequence reads were imported as FASTA files into Geneious 5.6.4 (Drummond et al., 2010). Within the final assembly there were two sequence gaps located within the 16S and ND6 genes. There was no DNA sequence produced between the base pairs of $1,954-1,961$, inclusive, within the $16 \mathrm{~S}$ and coverage was very low within the ND6, down to one or two reads, between the base pairs of 13,999-14,088. 


\subsubsection{S and ND6 primer design}

Primers were designed to fill the sequence gaps of 16S and ND6 within the mtgenome of $P$. oxygeneios. To ensure consistency between sequences, DNA was re-extracted from the same piece of tissue, using the same phenol-chloroform extraction procedure as used for the initial sequencing run. Each of the primers was designed in Primer 3 (Rozen and Skaletsky 2000). The PCR was used to amplify a $\sim 400 \mathrm{bp}$ fragment of the 16S using the forward primer F-16S-hapuku (5'-CCGCGAGAGTTAGTCAAAGG-3') and the reverse R-16S-hapuku (5'AGGCGGGACCTCTTATTCAY-3'). A 400 bp fragment of the ND6 was amplified by the forward primer F-ND6-hapuku (5'-CCCGAAATACGGAAAACTCA-3') and the reverse R-ND6-hapuku (5'- TTGCGGTTGCTTCTAATCCT-3'.) To determine the optimum annealing temperature for each primer a PCR gradient was run between $50^{\circ} \mathrm{C}$ and $60^{\circ} \mathrm{C}$. The $15 \mu \mathrm{l}$ PCR reactions performed consisted of $67 \mathrm{mM}$

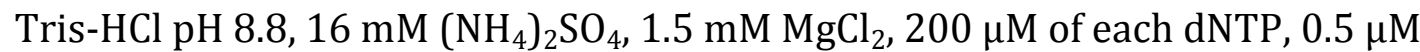
of each primer, $0.6 \mu \mathrm{g} / \mu \mathrm{L}$ Bovine Serum Albumin (BSA), 1 unit of BIOTAQTM DNA Polymerase (Fischer), and $1 \mu \mathrm{L}$ of template DNA ( 50ng). PCR reactions were performed in a TGradient Thermal Block (Biometra, Goettingen, Germany): $95^{\circ} \mathrm{C}$ for $2 \mathrm{~min}$, followed by 36 cycles of $94^{\circ} \mathrm{C}$ for $30 \mathrm{~s}, 50-60^{\circ} \mathrm{C}$ for $30 \mathrm{~s}$ and $74^{\circ} \mathrm{C}$ for $45 \mathrm{~s}$ and a final extension at $74^{\circ} \mathrm{C}$ for $10 \mathrm{~min}$. Amplicons were electrophoresed in 1.5\% agarose gel, stained with ethidium bromide and visualised on a UV-light source. The resultant amplicons from the PCR gradient were adequate for sequencing across all annealing temperatures, with the $60^{\circ} \mathrm{C}$ amplicon chosen for sequencing. PCR products were purified with ExoSAP-IT following manufacturers' instructions and the DNA sequence was determined using an ABI 3730 Genetic Analyser (service provided by Massey University, New Zealand). Once these genes were sequenced they were imported into Geneious 5.6.4 and aligned to the original mitochondrial genome for a complete contiguous genomic sequence. 


\subsubsection{Control region primer design for Polyprion oxygeneios}

Initially, a 900 bp fragment of the control region was amplified by the forward primer H-tRNA-Pro-BCO (5'-GAGCGCCGGTCTTGTAAACCGG-3') and the reverse H-tRNA-Phe-FISH (5'-CTTAACATCTTCAGTGTTATGC-3'). However, most amplification failed during the first PCRs, therefore, new species-specific primers for P. oxygeneios were designed in Primer 3: the forward tRNA-Pro-HPB (5'CCTACСССТАACTCCCAAAGC-3') and the reverse tRNA-Phe-HPB (5'TGCGGAGCTTTCTAGGGCTC-3'). More consistent amplifications were observed using the second set of primers, however, an additional reverse primer was designed in Primer 3 for within the CCD. This enabled a shorter fragment of the control region to be amplified. The forward primer tRNA-Pro-HPB was paired with the newly developed reverse primer CCD-HPB (5'CCCCTTGCCCCTTAGAAAGAG-3'), which amplified 550bp of the control region. All $25 \mu \mathrm{l}$ PCR reactions consisted of the same mastermix ingredients as used with the 16 S and ND6 reactions. Thermal Cycling was performed on a TGradient Thermal Block: $95^{\circ} \mathrm{C}$ for $2 \mathrm{~min}$, followed by 30 cycles of $94^{\circ} \mathrm{C}$ for $30 \mathrm{~s}, 61^{\circ} \mathrm{C}$ for 30 $\mathrm{s}$ and $74^{\circ} \mathrm{C}$ for $45 \mathrm{~s}$ and a final extension at $74^{\circ} \mathrm{C}$ for $10 \mathrm{~min}$. The resultant amplicons were electrophoresed in 1.5\% agarose gel, stained with ethidium bromide, visualised under a UV-light source and purified using ExoSAP-IT as per the manufacturers' instructions. The DNA sequence was determined using an ABI 3730 Genetic Analyser (service provided by Massey University, New Zealand).

\subsubsection{Control region primer design for Polyprion americanus}

A species-specific reverse primer for P. americanus was designed in Primer 3 to amplify the DNA fragment ranging from tRNA-Pro to within the CCD. The forward primer tRNA-Pro-HPB was paired with the reverse primer CCD-Bass (5'AAGAGAACCCCTTGCTCGCTG-3'), which amplified a 500 bp fragment of the control region from P. americanus. All PCR reactions were $15 \mu \mathrm{l}$, consisting of the same mastermix as described above. The same PCR protocol used to amplify the control region of $P$. oxygeneios was implemented for $P$. americanus. The 
amplicons were electrophoresed, stained, visualised and purified in the same method as described above. The DNA sequence was again determined using an ABI 3730 Genetic Analyser (service provided by Massey University, New Zealand).

\section{$\underline{2.3 \text { Results }}$}

\subsubsection{Whole mitochondrial genome of Polyprion oxygeneios}

The assembled mtgenome of $P$. oxygeneios was $16,509 \mathrm{bp}$ in length with a base frequency composition of $\pi_{\mathrm{A}}=0.28, \pi_{\mathrm{C}}=0.297, \pi_{\mathrm{G}}=0.166$ and $\pi_{\mathrm{T}}=0.257$, with an overall GC content of 0.463 . The molecule contains 13 protein-coding genes, 2 rRNA genes and 22 tRNA genes and a non-coding control region (table 2.1 and figure 2.2)

The common start codon ATG was found in all protein-coding genes except in the C01 gene, which uses GTG. Open reading frames of $P$. oxygeneios ended with a stop codon of TAA (ND1, C01, ATPase8, ND4L and ND5). The remaining genes had an incomplete stop codon TA (ATPase6, CO3) and T (ND2, CO2, ND3, ND4, ND6, and Cyt b). Furthermore, the paired genes of ATPase8-ATPase6, ND4L-ND4 and ND65-ND6 overlapped 10, seven and four nucleotides, respectively.

The two rRNA subunits, 12S and 16S, were 948 and 1,696 nucleotides long, respectively. There was an initial $8 \mathrm{bp}$ gap in the sequence of $16 \mathrm{~S}$ that was filled by sequencing a $\sim 400 \mathrm{bp}$ region of the $16 \mathrm{~S}$ from the same individual. As in other vertebrates, these genes were located between tRNA-Phe and tRNA-Leu, being separated by tRNA-Val. The mtgenome of $P$. oxygeneios has 22 tRNA genes interspersed by the rRNA and protein-coding genes, with lengths ranging in size from $66-74 \mathrm{bp}$. The lengths of the tRNA genes are long enough so that the encoded tRNA can fold into the cloverleaf structure characteristic of tRNA (Inoue et al., 2001). 


\subsubsection{Control region of Polyprion oxygeneios and Polyprion americanus}

The major non-coding region of the control region of $P$. oxygeneios was $849 \mathrm{bp}$ long and located between tRNA-Pro and tRNA-Phe. The forward primer (tRNAPro HPB) and the reverse primer (CCD-HPB) amplified a $488 \mathrm{bp}$ fragment from the control region of $P$. oxygeneios. The length of the control region fragment of $P$. americanus was $494 \mathrm{bp}$.

A comparison between the consensus sequences of $294 P$. oxygeneios and $25 P$. americanus revealed a sequence match of $88 \%(436 / 494 \mathrm{bp})$; a consensus sequence is the calculated order of the most frequent nucleotide bases found at each position in a sequence alignment. There were also six insertions in the $P$. americanus sequence. The consensus sequences were used, as this allowed for the average base composition that best represented the sequence of each respective species. The base composition of the consensus sequence for $P$. oxygeneios was: $\pi_{\mathrm{A}}=0.328, \pi_{\mathrm{C}}=0.191, \pi_{\mathrm{G}}=0.156$ and $\pi_{\mathrm{T}}=0.326$. The base composition for the consensus $P$. americanus sequence was $\pi_{\mathrm{A}}=0.338, \pi_{\mathrm{C}}=$ $0.206, \pi_{\mathrm{G}}=0.140$ and $\pi_{\mathrm{T}}=0.314$, with an undefined base $\pi_{\mathrm{Y}}=0.02$. This base is undefined because of the high level of polymorphism at this site, with 14 and 11 individuals having the pyrimidine base $\mathrm{T}$ or $\mathrm{C}$, respectively. The GC content for $P$. americanus and $P$. oxygeneios was 0.346 and 0.343 , respectively. 
Table 2.1 Gene content and organisation for the mitochondrial genome of Polyprion oxygeneios

\begin{tabular}{|c|c|c|c|c|}
\hline Region & Start & Finish & Length (bp) & Gene product \\
\hline tRNA-Phe & 1 & 68 & 68 & tRNA-Phe \\
\hline 12S rRNA & 69 & 1016 & 948 & $12 \mathrm{~S}$ ribosomal RNA \\
\hline tRNA-Val & 1017 & 1088 & 72 & tRNA-Val \\
\hline 16S rRNA & 1089 & 2784 & 1696 & $16 \mathrm{~S}$ ribosomal RNA \\
\hline tRNA-Leu & 2785 & 2858 & 74 & tRNA-Leu \\
\hline ND1 & 2859 & 3833 & 975 & NADH dehydrogenase subunit 1 \\
\hline tRNA-Ile & 3838 & 3907 & 70 & tRNA-Ile \\
\hline tRNA-Gln & 3907 & 3977 & 71 & tRNA-Gln \\
\hline tRNA-Met & 3977 & 4045 & 69 & tRNA-Met \\
\hline ND2 & 4046 & 5090 & 1045 & NADH dehydrogenase subunit 2 \\
\hline tRNA-Trp & 5091 & 5161 & 71 & tRNA-Trp \\
\hline tRNA-Ala & 5163 & 5231 & 69 & tRNA-Ala \\
\hline tRNA-Asn & 5233 & 5305 & 73 & tRNA-Asn \\
\hline tRNA-Cys & 5339 & 5404 & 66 & tRNA-Cys \\
\hline tRNA-Tyr & 5405 & 5474 & 70 & tRNA-Tyr \\
\hline COI & 5476 & 7026 & 1551 & cytochrome c oxidase subunit I \\
\hline tRNA-Ser & 7027 & 7097 & 71 & tRNA-Ser \\
\hline tRNA-Asp & 7101 & 7172 & 72 & tRNA-Asp \\
\hline COII & 7180 & 7870 & 691 & cytochrome c oxidase subunit II \\
\hline tRNA-Lys & 7871 & 7944 & 74 & tRNA-Lys \\
\hline ATPase 8 & 7946 & 8113 & 168 & ATPase subunit 8 \\
\hline ATPase 6 & 8104 & 8786 & 683 & ATPase subunit 6 \\
\hline COIII & 8787 & 9571 & 785 & cytochrome c oxidase subunit III \\
\hline tRNA-Gly & 9572 & 9643 & 72 & tRNA-Gly \\
\hline ND3 & 9644 & 9992 & 349 & NADH dehydrogenase subunit 3 \\
\hline tRNA-Arg & 9993 & 10061 & 69 & tRNA-Arg \\
\hline ND4L & 10062 & 10358 & 297 & NADH dehydrogenase subunit 4L \\
\hline ND4 & 10352 & 11732 & 1381 & NADH dehydrogenase subunit 4 \\
\hline tRNA-His & 11733 & 11801 & 69 & tRNA-His \\
\hline tRNA-Ser & 11802 & 11869 & 68 & tRNA-Ser \\
\hline tRNA-Leu & 11876 & 11948 & 73 & tRNA-Leu \\
\hline ND5 & 11949 & 13787 & 1839 & NADH dehydrogenase subunit 5 \\
\hline ND6 & 13784 & 14305 & 522 & NADH dehydrogenase subunit 6 \\
\hline tRNA-Glu & 14306 & 14374 & 69 & tRNA-Glu \\
\hline Cyt b & 14379 & 15519 & 1141 & Cytochrome b \\
\hline tRNA-Thr & 15520 & 15591 & 72 & tRNA-Thr \\
\hline tRNA-Pro & 15591 & 15660 & 70 & tRNA-Pro \\
\hline ontrol region & 15661 & 16509 & 849 & Non-coding \\
\hline
\end{tabular}




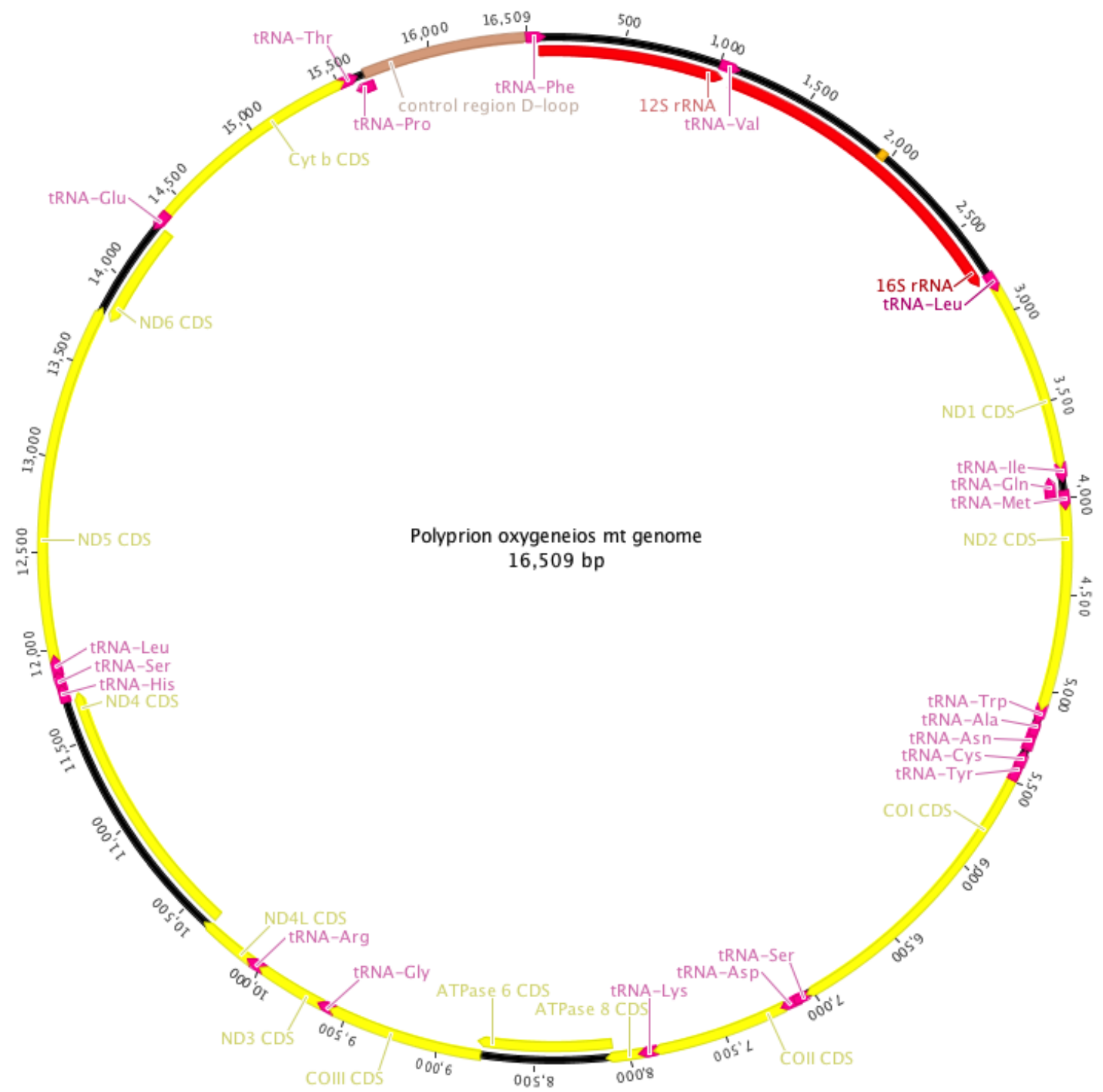

Figure 2.2 Complete mitochondrial genome of Polyprion oxygeneios. Protein coding genes are yellow; tRNAs are purple; rRNAs are red; the control region is brown. The arrowhead on each respective gene is the direction of transcription. 
$P$. americanus consensus sequence

P. oxygeneios consensus sequence

$P$. americanus consensus sequence

P. oxygeneios consensus sequence

$P$. americanus consensus sequence

P. oxygeneios consensus sequence

P. americanus consensus sequence

P. oxygeneios consensus sequence

P. americanus consensus sequence

$P$. oxygeneios consensus sequence

$P$. americanus consensus sequence

$P$. oxygeneios consensus sequence

$P$. americanus consensus sequence

P. oxygeneios consensus sequence

P. americanus consensus sequence

P. oxygeneios consensus sequence

$P$. americanus consensus sequence

P. oxygeneios consensus sequence
1 TATATGTTTCAAAATACATATATGTATTAACACCATACATTTATATTAACCATATCATAT 60 T T TGTT C AAATACATATATGTATTAACACCATACATTTATATTAACCATATCA AT 1 TGTGTGTTGC-AAATACATATATGTATTAACACCATACATTTATATTAACCATATCA-AT 58

61 AGCATTCAAGTACAATACATGTTTAATCAACATTGTCAGGCCTCAAACCCCTCACATATC 120 AGCATTCAAGTACA TAC TGTTTAATCAACATT AGG CT AC TCA ATATC

59 AGCATTCAAGTACA-TACCTGTTTAATCAACATTAATAGGACTTCCACA-TTCATATATC 116

121 ACAGCAATCACTAAGAGTTCCATAACCCATATAYTATTAAATAAATGACATACTAACCGA 180 A A AATCA TA GAGTT CATAACCCATATA+T A A AA TGACATA AA GA

117 AAAATAATCATTAGGAGTTACATAACCCATATATTTGCATACAATTGACATATAAAATGA 176

181 ATTCAGGTATTAACGAAACTTAAGACCGAACACTTACCTTCATTAGTTAAGATATACCAA 240 ATT A GTATTA CGAAACTTAAGACCGAACAC TACCTT ATT GTTAAGATATACCAA

177 ATT-AAGTATTAGCGAAACTTAAGACCGAACACCTACCTTAATTGGTTAAGATATACCAA 235

241 GTACCCAACATTCTATTATATATCACAATCTTAATGTAGTAAGAGCCTACCAACAGATGA 300 GTAC CA CATTCTATTATA TCA A TCTTAATGTAGTAAGAGCCTACCAACA TGA

236 GTACTCACCATTCTATTATACTTCAGAGTCTTAATGTAGTAAGAGCCTACCAACAAGTGA 295

301 TTTCTTAATGCATACTGTTATTGATGGTGAGGGACAACTATTGTGGGGGTTTCACTTAGT 360 TTTCTTAATGCATACT TTATTGA GGTGAGGGACAACTATTGTGGGGGTTTCACTT GT

296 TTTCTTAATGCATACTCTTATTGAAGGTGAGGGACAACTATTGTGGGGGTTTCACTTGGT 355

361 GAACTATTCCTGGCATTTGGTTCCTACTTCAGGGTCAATTATTGATATTATTCCTCAAAC 420 GAACTATTCCTGGCATTTGGTTCCTACTTCAGGGTCAATTATTGATATTATTCCTCAAAC

356 GAACTATTCCTGGCATTTGGTTCCTACTTCAGGGTCAATTATTGATATTATTCCTCAAAC 415

421 TTTCCCTAACGCTGACATAAGTTAATGGTGGAGTACATAGTACGAGATAACCCAGTATGC 480 TTTCCCTAACGCTGACATAAGTTAATGGTGGAGTACAT GT GAGATAACCCAG ATGC

416 TTTCCCTAACGCTGACATAAGTTAATGGTGGAGTACATGGTCTGAGATAACCCAGCATGC 475

481 CGGGCGTTCTCTCC 494 CGGGCG TCT TC

476 CGGGCGC

Figure 2.3 Consensus sequence of the control region of $P$. oxygeneios and $P$. americanus. The numbers represent the number of nucleotide bases along the sequence; dashes represent indels. The undefined base of the $P$. americanus sequence is highlighted red 


\subsection{Discussion}

The mitochondrial genome of $P$. oxygeneios is similar in structure and gene arrangement to that found in many other fish species (Inoue et al., 2001; Catanese et al., 2008; Wang et al., 2012). The sequence length of the final genomic assembly was 16,509 bp and consisted of 13 protein-coding genes, 22 tRNAs, 2 rRNAs, and a non-coding region. The gene orders of mitochondrial genomes are generally conserved across taxa, as exemplified in humans and mice (Anderson et al., 1981; Bibb et al., 1981), although, structural rearrangements of tRNA genes, in the deep-sea fish, Gonostroma gracile (Miya and Nishida 1999), have been noted. While these features have been reported in fishes, there are few other examples within the literature and not observed within the mitochondrial genome of $P$. oxygeneios.

This study describes, for the first time, the whole mitochondrial genome for a species of the family Polyprionidae. Future analyses of related species from this family may uncover some interesting phylogenetic patterns and taxonomic changes. Taxonomy of the family Polyprionidae lists two genera: Polyprion and Stereolepis. Current systematics lists two species under the genus Polyprion: P. oxygeneios and P. americanus, however, there is some contention about the number of species represented under this genus. Genetic investigations into $P$. americanus have been reported in the literature, though none of these have sequenced the entire mitochondrial genome (Sedberry et al., 1996; Ball et al., 2000). Previously, a separate species, P. moeone, was described from New Zealand, with P. americanus being described from the Atlantic. However, a revision of the systematics of Polyprion synonymised around 20 nominal species to two; including P. moeone (Roberts 1986). Studies of Paxton (1989) and Ball (2000) support the suggestion that $P$. moeone is indeed a valid species and suggests that further clarification of the Polyprion genus is required. The sequencing of mitochondrial genomes have become useful genetic tools in resolving controversies over phylogenetic relationships in many marine fishes (Lavoue et al., 2005; Catanese et al., 2008), and it may be possible through the 
sequencing of the whole mitochondrial genome of $P$. americanus to resolve the taxonomic uncertainty of Polyprion spp.

The mitochondrial control region is thought to be selectively neutral and thus, mutations that arise persist in a population. The hyper-variable domain at the $5^{\prime}$ end of the control region is typically viewed as the most polymorphic fragment of this region (Nagata et al., 1998; Aboim et al., 2005). The development of primers for this region should provide sequences that contain enough polymorphic DNA sites to allow for statistically robust inferences about population genetic structure (see Chapter Three). The additional development of primers for the control region of $P$. americanus highlights the areas of genetic difference between the two species. These two species, P. oxygeneios and $P$. americanus, were genetically similar and showed an $88 \%$ sequence match. This level of interspecific genetic similarity is observed in control region sequences of other species including tuna (Auxis thazard and A. rochei)(Catanese et al., 2008) and freshwater gobies (Rhinogobius maculafasciatus and R. giurinus)(Chen et al., 1998).

The New Zealand hapuku fishery (HPB) lands both P. oxygeneios and $P$. americanus, but less than $10 \%$ of the catch is recorded by species (Paul 2002b). In a review of the hapuku fishery, Paul (2002b) estimates that approximately one quarter of the catch is $P$. americanus and three quarters is P. oxygeneios. However, it is not possible to analyse catch data for each species separately, which may be of use to the management of this fishery (Paul 2002a). The development of mitochondrial DNA primers for these two species has established a new set of genetic markers for researchers to use and possibly clarify instances of incorrect identification in catch records and during scientific research. This genetic data will enable each species to be accurately distinguished and the population genetic structure of each one to be determined. 


\section{Chapter Three}

\section{The phylogeography and population genetics of Polyprion oxygeneios inferred from mitochondrial DNA sequences and microsatellite DNA genotyping}

\section{$\underline{3.1 \text { Introduction }}$}

The identification of genetic structure is vital to effective fisheries management because the level of fisheries-induced mortality needs to be balanced by withinstock recruitment and immigration from other stocks (Carvalho and Hauser 1994; Laikre et al., 2005). Given the potential for dispersal within the marine environment, populations have historically been viewed as open, characterised by high levels of demographic connectivity and gene flow (Hauser and Carvalho 2008). As many pelagic fishes are highly fecund and highly dispersive, one could a priori expect panmixia across large geographic scales (Garcia De Leon et al., 1997; Dammannagoda et al., 2011). However, evidence of varying levels of structure for wide-ranging and dispersive fish has increased in recent times (Bentzen et al., 1996; Ruzzante et al., 1998; Aboim et al., 2005). Physical oceanographic factors (Rogers et al., 2006) and behavioral influences (Dammannagoda et al., 2011) can work to limit gene flow, developing genetic clines over relatively small geographic scales if sustained over long periods of time. Therefore, simplistic assumptions of dispersal, based on species' lifehistory traits may not accurately reflect actual population connectivity and can potentially mislead management decisions (Dammannagoda et al., 2011).

Historically, non-genetic markers have been used to manage fish stocks and understand the population structure of exploited species. Some of these direct methods include parasitic tags, otolith microchemistry, and meristic and morphometric data (Paul 2002a). However, these markers are strongly influenced by the environment and reflect where the fish have lived rather than the population they are sourced from and reproduce within (Garcia De Leon et 
al., 1997). The advent of molecular markers in fisheries science has played an important role in defining stock structure because they directly sample inherited characters that are shared by individuals that are part of the same reproductive process (Faurby and Barber 2012). Mitochondrial DNA (mtDNA) has been one of the most popular markers because it is relatively cheap and easy to collect data. Certain regions of the mitochondrial genome are often hyper-variable and selectively neutral (i.e. the control region), making it a good first choice for a genetic assessment of a fisheries stock structure. Furthermore, matrilineal inheritance of mtDNA reduces the effective population size making it a suitable candidate for detecting demographic change through phylogenetic methodologies. Microsatellites are highly variable regions of DNA that are characterised by short tandem repeats of nucleotides at high frequency along the nuclear genome. Due to the high frequency at which they occur within the genome, microsatellite DNA markers can be developed to sample multiple independent loci along the genome. This provides a greater statistical resolution, which may enable microsatellites to be a more powerful marker for elucidating finer scale population genetic structure than mtDNA (Bentzen et al., 1996). Studies utilizing more than one DNA marker have the ability to describe the stock structure more fully than those studies utilizing only one ( $\mathrm{O}^{\prime}$ Connell and Wright 1997). The comparison of mtDNA and microsatellite DNA data among the same populations allows for the phylogeography to be discerned and the population genetics validated.

Polyprion oxygeneios (hapuku) is a long-lived species, able to live in excess of 60 years, with sexual maturation being reached around seven years of age (Wakefield et al., 2010). P. oxygeneios are believed to be winter spawning with no confirmed spawning locations, but extensive movements of $P$. oxygeneios inferred from tagging studies suggest the formation of spawning aggregations (Beentjes and Francis 1999). Juveniles have an extended pelagic phase of up to four years and are associated with floating material i.e. seaweed (Francis et al., 1999). Due to the extended nature of this pelagic phase, P. oxygeneios have the ability to undergo pan-oceanic mixing between populations (Francis et al., 1999), 
although this has not been studied in much detail. In fact, juveniles are rarely caught and information on them is scarce.

To date there has been no genetic research focusing on P. oxygeneios; they have only been incorporated in studies as an outgroup to P. americanus (Ball et al., 2000). Mitochondrial and microsatellite DNA markers have distinguished between three discrete populations of P. americanus: the North Atlantic and Mediterranean, Brazil and the South Pacific (Sedberry et al., 1996; Ball et al., 2000). Genetic differentiation was only found at the inter-oceanic scale, with no evidence for stock separation within a region spatially equivalent to New Zealand. Within New Zealand's waters, tagging studies (Beentjes and Francis 1999) and allele frequency data of two polymorphic enzyme loci (Smith and Johnson 1985) reported evidence of Cook Strait and eastern South Island populations of $P$. oxygeneios mixing, with a possible separate stock in Northland. Unfortunately, this data has been ineffective in describing the genetic stock structure of P. oxygeneios from around New Zealand. Current stock boundaries of the hapuku fishery (HPB) are based on quota management areas (QMA) and are not reflective of the natural stock boundaries of this species (Paul 2002a). Existing data cannot describe the stock structure of New Zealand P. oxygeneios (Paul 2002b), and that there is no new data that would suggests this needs revision (Smith 2008).

The aim of this study was, for the first time, to determine the level of genetic diversity and differentiation among populations of $P$. oxygeneios using samples collected from a range of locations throughout New Zealand's Exclusive Economic Zone (EEZ). We used DNA sequences from the mitochondrial control region and genotypes from nine microsatellite DNA markers to test the null hypothesis of panmixia among New Zealand's stocks of P. oxygeneios; which would be consistent with the tagging and allozyme studies as well as the population genetic work on P. americanus. Moreover, it is important to understand the genetic constitution of the fishery species because over-fishing can deplete genetic variation, drive selective genetic change, and alter genetic structure (Allendorf et al., 2008). 


\section{$\underline{3.2 \text { Methods }}$}

\subsubsection{Sampling}

Tissue samples of $P$. oxygeneios were taken from adult fish collected at eight sites around New Zealand (figure 3.1). Seven of the sampling sites were off the coast of mainland New Zealand (North and South Island) and one site was in the Chatham Island area, approximately $770 \mathrm{~km}$ to the east of mainland New Zealand. Sample collections were made during fisheries surveys or broodstock collection trips undertaken by the National Institute of Water and Atmospheric Research (NIWA) and from commercial fishing operations. Fin clips or muscle tissue samples were taken and preserved in $70 \%$ ethanol and stored at $4{ }^{\circ} \mathrm{C}$.

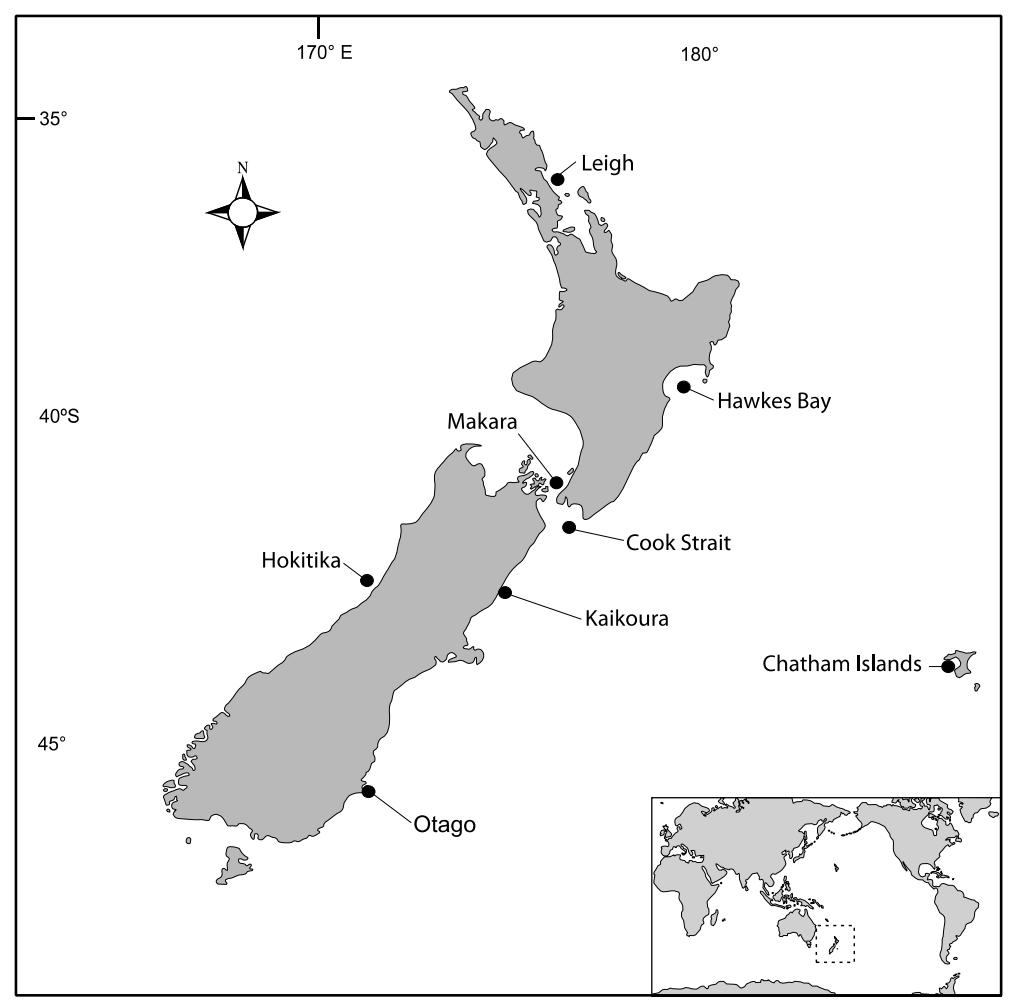

Figure 3.1 Sampling sites of $P$. oxygeneios from around New Zealand

\subsubsection{Mitochondrial DNA extraction, amplification and sequencing}

Genomic DNA was extracted from 294 wild P. oxygeneios samples using a phenolchloroform protocol (Sambrook et al., 1989). Each tissue sample was placed 
separately in $400 \mu \mathrm{l}$ of extraction buffer $(10 \mathrm{mM}$ Tris pH 8.0, $50 \mathrm{mM} \mathrm{NaCl}, 10 \mathrm{mM}$ EDTA, and $0.2 \%$ SDS) with $0.5 \mu \mathrm{g} / \mu \mathrm{l}$ proteinase-K and incubated for three hours at $50^{\circ} \mathrm{C}$. Following the tissue digestion, DNA was extracted with phenol, followed by chloroform/isoamyl alcohol, and precipitated with 2.5 volumes of ethanol at $20^{\circ} \mathrm{C}$ for 1 hour. The DNA was pelleted, washed with $70 \%$ ethanol, dried and resuspended in a Tris-EDTA buffer and stored at $4^{\circ} \mathrm{C}$.

The Polymerase Chain Reaction (PCR) was used to amplify 550 base pairs (bp) portion of the mtDNA control region using the forward primer tRNA-Pro-HPB (5'-CCTACCCCTAACTCCCAAAGC-3') and the reverse primer CCD-HPB (5'CCCCTTGCCCCTTAGAAAGAG-3'). All PCRs consisted of 67 mM Tris-HCl pH 8.8, $16 \mathrm{mM}\left(\mathrm{NH}_{4}\right)_{2} \mathrm{SO}_{4}, 1.5 \mathrm{mM} \mathrm{MgCl}_{2}, 200 \mu \mathrm{M}$ of each dNTP, $0.5 \mu \mathrm{M}$ of each primer, $0.6 \mu \mathrm{g} / \mu \mathrm{L}$ Bovine Serum Albumin (BSA), 1 unit of BIOTAQTM DNA polymerase (Fischer), and $1 \mu \mathrm{L}$ of template DNA ( $\sim 50 \mathrm{ng}$ ). Thermal Cycling was performed on a TGradient Thermal Block (Biometra, Goettingen, Germany): $95^{\circ} \mathrm{C}$ for $2 \mathrm{~min}$, followed by 30 cycles of $94^{\circ} \mathrm{C}$ for $30 \mathrm{~s}, 61^{\circ} \mathrm{C}$ for $30 \mathrm{~s}$ and $74^{\circ} \mathrm{C}$ for $45 \mathrm{~s}$ and a final extension at $74^{\circ} \mathrm{C}$ for $10 \mathrm{~min}$. The resultant amplicons were electrophoresed in 1.5\% agarose gel, stained with ethidium bromide and visualised on a UV-light source. PCR products were purified with ExoSAP-IT following manufacturers' instructions and the DNA sequence was determined using an ABI 3730 Genetic Analyser (service provided by Massey University, New Zealand and Macrogen Incorporated, Korea). Initially, the DNA sequence of each amplicon was determined from both directions, which enabled any ambiguous DNA sequence positions to be properly resolved, and subsequently, only the forward primer was used for determining the DNA sequence of the amplicons. The DNA sequences were aligned using the software Geneious 5.6.4 using the default parameters (Drummond et al., 2010).

\subsubsection{Microsatellite amplification and genotyping}

GenomNZ (AgResearch) in Invermay, New Zealand, conducted all microsatellite genotyping in this study. Nine pairs of microsatellite primers (table 3.1) were used to determine the genotypes of 259 wild $P$. oxygeneios individuals from 
seven sampling sites. To ensure consistency, the same tissue used for mtDNA sequencing was also used for microsatellite genotyping. Genomic DNA was extracted using a Chelex ${ }^{\circledR} 100$ procedure (Bio-Rad Laboratories). A combination of five published microsatellite loci, previously reported by Ball et al. (2000)(Pam010, Pam017, Pam021, Pam025 and Pam035), and four propriety loci developed by AgResearch using 454 sequencing (GGOQ6A, GH0OIK, GJLKPX, and GJSLB2) were used in a multiplex genotyping panel. The multiplex was conducted with an annealing temperature of $56^{\circ} \mathrm{C}$ and a $\mathrm{MgCl}$ concentration of $2.0 \mathrm{mM}$. The primer concentrations ranged from $0.1 \mu \mathrm{M}$ to $0.6 \mu \mathrm{M}$. One of the primers in each pair was fluorescently labeled and an ABI3730 Genetic Analyser (Applied Biosystems) was used to determine the allele sizes.

Table 3.1 Nine microsatellite DNA markers and type of repeat.

\begin{tabular}{cc}
\hline Marker & Nucleotide Repeat \\
\hline Pam010 & Di (GT) \\
Pam017 & Di (GT) \\
Pam021 & Di (AC) \\
Pam025 & Di (CA) \\
Pam035 & Di (GT) \\
GJLKPX & Di (AC) \\
GJSLB2 & Di (AG) \\
GG0Q6A & Di (TC) \\
GH0OIK & Tri (TTG) \\
\hline
\end{tabular}

\section{$\underline{3.2 .4 \text { Genetic diversity }}$}

\section{Mitochondrial DNA data}

The summary statistics of the level of genetic diversity in each population, which included the number of polymorphic (segregating) sites $(S)$, the number of haplotypes $\left(N_{h}\right)$, haplotype diversity $(h$, measure of the frequencies and number of haplotypes among individuals), nucleotide diversity ( $\pi$, averaged weighted sequence divergence between haplotypes) and the number of private haplotypes $\left(P_{h}\right.$, haplotypes restricted to a single sample and not found anywhere else) were calculated using DnaSP 5.10.01 (Librado and Rozas 2009). HP-RARE 1.1 (Kalinowski 2005) was used to calculate the standardised haplotypic richness, 
and a rarefaction curve was constructed by plotting the cumulate haplotypic richness against the number of individuals sampled when drawn at random.

\section{Microsatellite DNA data}

Micro-checker 2.2.3 (Oosterhout et al., 2004) was used to identify any deviations from the Hardy-Weinberg Equilibrium (HWE) by either large allele drop-out, scoring errors due to stuttering, or the presence of null alleles. Tests for linkage disequilibrium and exact tests for HWE were performed by Genepop 4.0.10 (Raymond and Rouset 1995). The levels of observed $\left(\mathrm{H}_{\mathrm{o}}\right)$ and expected $\left(\mathrm{H}_{\mathrm{e}}\right)$ heterozygosity were calculated in Arlequin 3.1.1 (Excoffier et al., 2005). The total number of alleles, private alleles and allele frequency distributions for each population and locus were generated in Genalex 6.5b3 (Peakall and Smouse 2012). The allelic and private allelic richness was determined in HP-RARE 1.1, with the inbreeding coefficients $\left(F_{\text {is }}\right)$ being calculated in FSTAT 2.9.3 (Goudet 1995). In order to determine whether the sample sizes for each population were large enough to capture the respective population's allelic diversity, allele discovery curves were constructed for all loci and populations using the PopGenKit (Rioux-Paquette 2011) in R 2.15 (Ihaka and Gentleman 1996; R Development Core Team 2011).

\subsubsection{Population genetic structure}

\section{Mitochondrial DNA}

Pairwise genetic differences $\left(\phi_{\text {st }}\right)$ were estimated as indicators of gene flow between all sampled sites. Conventional $\phi_{\text {st }}$ were calculated based on haplotype frequencies using Arlequin 3.1.1 and the significance were assessed using 1,000 permutations. A Bonferroni correction to the significance level was estimated to minimise the chance of type 1 errors (probability of incorrectly rejecting the null hypothesis of panmixia) among a large number of pairwise comparisons (Rice 1989). A test for Isolation-by-Distance (IBD) was conducted using the regression of $\phi_{s t}$ and measurements of geographic distance between sites (m). Geographic 
distances between sites were estimated by ruler option using Google Earth 6.2.2 (Google Inc.). The distances calculated was the shortest marine distance between any two sampling sites. Significance was evaluated for each site using a Mantel's test implemented in Arlequin 3.1.1 and using 1,000 permutations. IBD plots were constructed using Microsoft Excel.

A haplotype genealogy of the mtDNA sequences was estimated using the maximum-likelihood (ML) method implemented in the program PhyML3.0 (Guindon et al. 2010), which enables the relationships among haplotypes to be determined without ambiguities or unresolved connections (Salzburger et al., 2011). The K80 substitution model was chosen according to the highest loglikelihood as indicated by jModelTest 0.1.1 (Posada 2008) and the proportion of invariant sites was fixed $(0.8420)$, the other parameters on tree searching and branch support were set as defaults. The ML tree was then converted into a haplotype genealogy using Haplo.launch 1.0 (Salzburger et al., 2011). Haplotype frequencies were calculated as a proportion of the total number of haplotypes within each sampled site, graphed in Microsoft Excel and visually represented in CorelDRAW.

\section{Microsatellite DNA}

POWSIM 4.1 (Ryman and Palm 2006) was used to assess the statistical power of the utilized loci under different combinations of sample sizes, number of loci and alleles, and allele frequencies. The statistical power and alpha values were assessed using the Chi-squared and Fisher's exact tests under a specified level of population divergence $\left(\mathrm{F}_{\mathrm{st}}\right)$. Two sets of simulations of 1,000 replications were run assessing two combinations of $N_{e f} / t$ : 500/50 and 2000/205, respectively.

Levels of genetic differentiation between populations were estimated by three approaches. Firstly, a test for differences in allele frequency distribution between all pairs of populations was conducted using GENEPOP 4.0.10. Unbiased $P$ values were computed for each population pair at each locus using an Exact $G$ test (Goudet et al., 1996). Moreover, $P$ values for each population pair across all 
loci were also calculated by Fisher's exact probability test (Rousset and Raymond 1995). Secondly, population differentiation was measured using $\mathrm{F}_{\text {st }}$ (Weir and Cockerham 1984) and $\mathrm{R}_{\mathrm{st}}$ in Arlequin 3.1.1 and significance was tested using 1,000 permutations. Both fixation indices were incorporated because there is uncertainty about which one is the best mutational model for microsatellite loci: $F_{\text {st }}$ measures the variation in allele frequencies across populations assuming the Infinite Allele Model (IAM) and $\mathrm{R}_{\mathrm{st}}$ uses the Stepwise Mutation Model (SMM). Pairwise $P$ values were adjusted using the sequential Bonferroni correction to minimise the chance of a type 1 error. Thirdly, genetic differentiation between sites was also calculated using an unbiased estimator of $D_{\text {st }}$ (Jost 2008) as implemented in SMOGD 1.2.5 (Crawford 2010) with 1,000 bootstrap iterations (http://www.ngcrawford.com/django/jost/).

IBD plots were produced from Slatkin's linear $F_{\text {st }}$ and $R_{s t}$ values as a function of oceanographic distance between sampling sites. A Mantel's test with 1,000 permutations was used to test for a correlation (Arlequin 3.1.1) and IBD plots were constructed using Microsoft Excel. An analysis of molecular variance (AMOVA) was conducted on clusters of sampling sites to determine the maximum proportion of the total genetic variation that could be attributed to differences between groups. Clusters were based on pairwise comparisons of variation in allele frequency as well as the geographic region of samples.

A coalescent simulation approach was used to discover outlier loci, implemented in LOSITAN (Antao et al., 2008). The distribution of loci was simulated based on $F_{\text {st }}$ values and heterozygosity using the method of Beaumont and Nichols (1996). Outlier simulations of $10^{4}$ steps were conducted using a 'neutral mean $\mathrm{F}_{\mathrm{st}}$ ' then by a 'forced mean $\mathrm{F}_{\mathrm{st}}$ '. The overall $\mathrm{F}_{\mathrm{st}}$ was used to estimate the upper and lower $\mathrm{F}_{\mathrm{st}}$ limits at $99 \%$ confidence intervals. Both the IAM and SMM mutation models were used in this analysis.

A Bayesian approach was used to test for population structure. The program STRUCTURE 2.3.2 (Pritchard et al., 2000) was used to minimise Hardy-Weinberg and linkage disequilibrium in the genotype data and assign individuals to a 
'population' cluster ( $\mathrm{K}=$ the number of genetically distinct clusters) without reference to sample site information. A Markov Chain Monte Carlo (MCMC) simulation was run for $10^{6}$ steps with a burn-in period of $10^{4}$ steps. The K value ranged form 1 - 7 and the admixture model was used with correlated allele frequencies among clusters and uninformed priors. STRUCTURE Harvester 0.6.92 (Earl and von Holdt 2012) was used to estimate the optimum number of $\mathrm{K}$ by using the Delta K estimator.

Assignment tests were carried out using a Bayesian approach (Piry et al., 2004). The software GENECLASS2 was used to develop a reference genotype for each population and then, based on the 'leave one out' methodology of Paetkau et al., (2004), it attempted to assign each sample to a population based on the highest probability of a genotypic match to one of the reference populations. This program has been shown to outperform STRUCTURE in situations when gene flow is high (Waples and Gaggiotti 2006). Probability computations were based on 10,000 simulated individuals with an exclusion threshold $(P>0.05)$.

A Principle Component Analysis (PCA) was used to examine the genetic relationships among the sites sampled using Genalex 6.5b3 with the standardised covariance method. The PCA finds correlated statistical patterns of variation within the data set that are major contributors to the variance of the data as a whole. Population 1.2.31 (Langella 2010) was used to visualise the patterns of variance between populations. An unrooted neighbour-joining tree was built based on Nei's minimum distance and 1,000 Bootstrap replicates were used to determine the level of support for clusters.

\subsubsection{Demographic history}

\section{Mitochondrial DNA}

Three different approaches were used to search for a signature of population expansion based on the mtDNA control region data set: neutrality tests, mismatch distribution and Bayesian skyline plots (BSP). 1. Tajima's D (Tajima 
1989) and Fu's $F_{\mathrm{s}}$ (Fu 1997) statistics were calculated using an infinite sites model in Arlequin 3.1.1. Assuming neutrality, these two test statistics are expected to be negative in cases of population expansion. 2. A mismatch distribution (Rogers and Harpending 1992) was constructed using DnaSP 5.10.01. Population history can influence the shape of the distribution: a population that has undergone a recent size contraction will have a uni-modal and smooth distribution; whereas a population that has been at a constant size for a long period of time will have a multi-modal distribution. The observed mismatch distribution was tested against the model of constant population size and population growth-decline. In order to distinguish between these two types of distribution, the raggedness $\left(\mathrm{H}_{\mathrm{r}}\right)$ index and sum of squared deviations (SSD) were estimated in Arlequin 3.1.1. The time $(t)$ since population expansion occurred could then be estimated under the equation $\tau=2 \mu t$ (Rogers and Harpending 1992), where $\mu$ is the mutation rate of the mtDNA sequence and $\tau$ is the age of expansion expressed in a unit of mutational time. The $\mu$ was defined as $2 \mu k$, where $k$ was the number of nucleotide bases analysed. The mutation rate of $2.0 \times 10^{-8}$ proposed by Brown et al., (1979) for the vertebrate mitochondrial genome based on mammalian data and $3.6 \times 10^{-8}$ calibrated by Donaldson and Wilson Jr. (1999) for snook (Percoidei: Centropomidae), was used in this study because a rate of mutation has not been estimated for P. oxygeneios. Furthermore, the effective population size $\left(N_{e f}\right)$ was calculated using the estimates of co-ancestry coefficient $\left(\theta_{s}\right)$ calculated in Arlequin 3.1.1. The equation $N_{e f}=\theta_{s} / 2 \mu$ was used with the same mutation rates as described above.

Additionally, changes in the effective population size through time were examined using a BSP constructed using BEASTv1.7.3 (Drummond and Rambaut 2007). Different XML files were created in BEAUti 1.7.2. The HKY substitution model was used because it was the closest approximation available in BEAST to the best model selected by jModelTest 0.1.1. A strict molecular clock was applied and two mutation rates of $3.6 \times 10^{-8}$ (Donaldson and Wilson 1999) and $2.0 \times 10^{-8}$ (Brown et al., 1979) were used. A MCMC simulation was run for $50^{7}$ steps with the first $10 \%$ discarded as the burn-in time. Genealogies were sampled every $10^{3}$ iterations, and all other parameters remained in their default settings. 
Inspections of the results and construction of the BSP were conducted using Tracer 1.5.0 (Rambaut and Drummond 2007).

\section{Microsatellite DNA}

The program BOTTLENECK 1.2.02 (Piry et al., 1999) was used to investigate whether there was evidence of a recent genetic bottleneck by assessing the microsatellite data for an excess of heterozygotes. The expected heterozygosity was calculated from the observed alleles at each locus and a distribution of heterozygosity was generated based on a simulated coalescence of nine loci under the SMM, IAM and the two-phase model (TPM). The interpretation of results focused on the TPM of mutation because it is recommended as the best model for microsatellite loci and gave a better fit with observed allele frequency data than the IAM and SMM (Piry et al., 1999). The TPM option was set in BOTTLENECK 1.2.02 at 95\% SMM and 5\% IAM. The average expected equilibrium heterozygosity for each locus was compared to the $\mathrm{H}_{\mathrm{e}}$ under HWE and used to assess whether there was an excess or deficit in heterozygotes at each locus using the Wilcoxon's test and 1,000 replications.

\section{$\underline{3.3 \text { Results }}$}

\section{$\underline{3.3 .1 \text { Genetic diversity }}$}

\section{Mitochondrial DNA}

DNA sequences obtained from 294 individuals were aligned and trimmed to a length of $488 \mathrm{bp}$. The aligned sequences had asymmetric base frequencies of $\pi_{\mathrm{A}}=$ $0.328, \pi_{C}=0.19, \pi_{G}=0.155$ and $\pi_{T}=0.327$. There were 51 polymorphic sites and the overall $\pi$ was 0.01136 . A total of 47 haplotypes were recorded with a diversity of 0.861 . Across all sites, 21 private haplotypes were found. The highest number of private haplotypes was four at the Hokitika, Hawkes Bay and Cook Strait sites. Nucleotide and haplotype diversity were similar across all sample 
sites, but the Chatham Islands and Hokitika showed reduced levels of nucleotide diversity and Hawkes Bay had a higher level of haplotype diversity (table 3.2).

Table 3.2 Sample sites, number of individuals sampled $(N)$, the average number of nucleotide differences $(S)$, the number of haplotypes $\left(N_{h}\right)$, haplotype diversity $(h)$, nucleotide diversity $(\pi)$, and number of private haplotypes $\left(P_{h}\right)$

\begin{tabular}{ccccccc}
\hline Location & $\boldsymbol{N}$ & $\boldsymbol{S}$ & $\boldsymbol{N}_{\boldsymbol{h}}$ & $\boldsymbol{h}$ & $\boldsymbol{\pi}$ & $\boldsymbol{P}_{\boldsymbol{h}}$ \\
\hline Leigh & 49 & 30 & 19 & 0.894 & 0.01153 & 2 \\
Hawkes Bay & 22 & 27 & 15 & 0.957 & 0.01370 & 4 \\
Cook Strait & 25 & 28 & 13 & 0.880 & 0.01170 & 4 \\
Makara & 21 & 19 & 8 & 0.805 & 0.01131 & 1 \\
Kaikoura & 39 & 29 & 16 & 0.853 & 0.01258 & 1 \\
Otago & 49 & 32 & 18 & 0.808 & 0.01216 & 3 \\
Hokitika & 45 & 23 & 17 & 0.822 & 0.00928 & 4 \\
Chatham Island & 44 & 28 & 17 & 0.878 & 0.00934 & 2 \\
\hline Total & 294 & 51 & 47 & 0.861 & 0.01136 & 21 \\
\hline
\end{tabular}

\section{Microsatellite DNA}

Across seven sample sites throughout New Zealand, 259 individuals were genotyped across nine microsatellites. Linkage disequilibrium was not consistently observed for any loci pairs and no loci were found to be under the influence of selection. The Micro-checker analysis showed no evidence of large allele drop-out or scoring errors due to stuttering, but null alleles were present in the Hokitika population at five loci; this finding was attributed to an excess of homozygotes. The loci suggested to have null alleles present were: GG0Q6A, GH0OIK, GJLSB2, Pam017, Pam025. The Pam021 locus in the Otago site also showed null alleles, and because these were only found within these sample sites they were not excluded from the data set. All analyses were conducted with and without the null alleles to determine whether they were influencing the significance of the results. From hereafter, any significant results reported were found to be significant with null alleles included and excluded unless otherwise stated.

Significant deviations from HWE were observed only at the Otago and Hokitika sites (table 3.4). All of the nine loci at Hokitika deviated from HWE, while eight out of the nine loci at Otago deviated from HWE; GH0OIK was the only locus in 
HWE. The observed and expected heterozygosity at each locus ranged from 0.327 (GH0OIK) to 1.000 (Pam010) and 0.931 (Pam010) to 0.606 (GG0Q6A), respectively. Across all populations there was a significant deficit in heterozygotes $(P=0.0018)$ with Hokitika being the only significant sample site $(P<0.001)$. With null alleles removed, Hokitika was still found to have a heterozygote deficiency $(P=0.0164)$, but this was no longer the case across all populations $(P=0.3975)$.

The nine microsatellites showed a wide range of polymorphism. The number of alleles per locus per site ranged from five at loci Pam017 and GH0OIK for Cook Strait and Hawkes Bay, to 22 for locus Pam010 at Hokitika. Private alleles were present in all sites apart from Otago; Hokitika had the highest recording of 18 private alleles. To reduce the effect of sample size bias, allelic richness was calculated with values ranging from 6.06 to 7.18 for Otago and Hokitika, respectively. Moreover, private allelic richness ranged from 0.12 to 1.45 for the same two respective sites. The total number of alleles discovered at each site ranged from 75 for Otago and Hawkes Bay to 104 for Hokitika. The allele discovery curves showed that the number of alleles for each microsatellite locus begins to plateau around 30 individuals. This suggests that the sample sizes were sufficient to capture most of the alleles at each site. The inbreeding coefficients ranged from -0.057 (Makara) to 0.237 (Hokitika) (table 3.5).

Table 3.3 Sampled sites; number of individuals sampled $(N)$; total number of alleles (a); average number of alleles per locus $(\mathrm{Na})$; allelic richness $\left(\mathrm{A}_{\mathrm{r}}\right)$; private alleles $(\mathrm{P})$; private allelic richness $\left(\mathrm{PA}_{\mathrm{r}}\right)$; inbreeding coefficient $\left(\mathrm{F}_{\text {is }}\right)$

\begin{tabular}{cccccccc}
\hline Location & $\boldsymbol{N}$ & $\mathbf{a}$ & $\mathbf{N a}$ & $\mathbf{A}_{\mathbf{r}}$ & $\mathbf{P}$ & $\mathbf{P A}_{\mathbf{r}}$ & $\mathbf{F}_{\text {is }}$ \\
\hline Leigh & 49 & 88 & 9.7 & 6.38 & 3 & 0.25 & -0.011 \\
Hawkes Bay & 21 & 75 & 8.3 & 6.43 & 2 & 0.48 & -0.022 \\
Cook Strait & 25 & 82 & 9.1 & 6.93 & 3 & 0.35 & -0.026 \\
Makara & 22 & 77 & 8.5 & 6.49 & 2 & 0.27 & -0.057 \\
Otago & 48 & 75 & 8.3 & 6.06 & 0 & 0.12 & -0.017 \\
Hokitika & 49 & 104 & 11.5 & 7.18 & 18 & 1.45 & 0.237 \\
Chatham Island & 43 & 86 & 9.5 & 6.46 & 4 & 0.28 & 0.056 \\
\hline
\end{tabular}


Table 3.4 numbers of individuals genotyped $(N)$; number of alleles found (a); observed heterozygosity $\left(\mathrm{H}_{0}\right)$; expected heterozygosity $\left(\mathrm{H}_{\mathrm{e}}\right) ; P$, bold values sig $<0.05$ across nine microsatellites for each sampled site

\begin{tabular}{|c|c|c|c|c|}
\hline $\begin{array}{l}\text { Site, } \\
\text { Locus }\end{array}$ & GJLKPX & Pam010 & Pam021 & Pam035 \\
\hline \multicolumn{5}{|l|}{ Leigh } \\
\hline$N$ & 49 & 49 & 49 & 49 \\
\hline $\mathbf{a}$ & 18 & 15 & 14 & 6 \\
\hline $\mathbf{H}_{\mathbf{o}}$ & 0.898 & 0.898 & 0.857 & 0.735 \\
\hline $\mathbf{H}_{\mathbf{e}}$ & 0.884 & 0.912 & 0.776 & 0.734 \\
\hline$P$ & 0.282 & 0.962 & 0.611 & 0.867 \\
\hline \multicolumn{5}{|c|}{ Hawkes Bay } \\
\hline$N$ & 21 & 21 & 21 & 21 \\
\hline $\mathbf{a}$ & 13 & 15 & 12 & 6 \\
\hline $\mathbf{H}_{\mathbf{o}}$ & 0.952 & 0.952 & 0.810 & 0.810 \\
\hline $\mathrm{H}_{\mathbf{e}}$ & 0.893 & 0.913 & 0.819 & 0.749 \\
\hline $\boldsymbol{P}$ & 0.576 & 0.281 & 0.619 & 0.840 \\
\hline \multicolumn{5}{|c|}{ Cook Strait } \\
\hline$N$ & 25 & 25 & 25 & 25 \\
\hline $\mathbf{a}$ & 14 & 16 & 12 & 6 \\
\hline $\mathrm{H}_{\mathbf{o}}$ & 0.960 & 0.960 & 0.840 & 0.840 \\
\hline $\mathrm{H}_{\mathrm{e}}$ & 0.897 & 0.927 & 0.850 & 0.767 \\
\hline $\boldsymbol{P}$ & 0.958 & 0.509 & 0.797 & 0.866 \\
\hline \multicolumn{5}{|c|}{ Makara } \\
\hline$N$ & 22 & 22 & 22 & 22 \\
\hline $\mathbf{a}$ & 13 & 15 & 12 & 6 \\
\hline $\mathrm{H}_{\mathbf{o}}$ & 0.909 & 1.000 & 0.773 & 0.818 \\
\hline $\mathrm{H}_{\mathbf{e}}$ & 0.883 & 0.903 & 0.847 & 0.742 \\
\hline$P$ & 0.539 & 0.509 & 0.281 & 0.578 \\
\hline \multicolumn{5}{|l|}{ Otago } \\
\hline$N$ & 48 & 48 & 48 & 48 \\
\hline $\mathbf{a}$ & 13 & 16 & 12 & 6 \\
\hline $\mathbf{H}_{\mathbf{o}}$ & 0.917 & 0.937 & 0.542 & 0.875 \\
\hline $\mathrm{H}_{\mathbf{e}}$ & 0.853 & 0.931 & 0.652 & 0.752 \\
\hline$P$ & $<0.001$ & $<0.001$ & 0.012 & 0.010 \\
\hline \multicolumn{5}{|c|}{ Hokitika } \\
\hline$N$ & 49 & 49 & 49 & 49 \\
\hline $\mathbf{a}$ & 18 & 22 & 13 & 10 \\
\hline $\mathrm{H}_{\mathbf{o}}$ & 0.837 & 0.857 & 0.796 & 0.694 \\
\hline $\mathbf{H}_{\mathbf{e}}$ & 0.917 & 0.915 & 0.792 & 0.798 \\
\hline $\boldsymbol{P}$ & $<0.001$ & $<0.001$ & 0.004 & $<0.001$ \\
\hline \multicolumn{5}{|c|}{ Chatham Islands } \\
\hline$N$ & 43 & 43 & 43 & 43 \\
\hline $\mathbf{a}$ & 14 & 15 & 16 & 8 \\
\hline $\mathbf{H}_{\mathbf{o}}$ & 0.860 & 0.860 & 0.884 & 0.651 \\
\hline $\mathrm{H}_{\mathrm{e}}$ & 0.882 & 0.907 & 0.821 & 0.770 \\
\hline $\boldsymbol{P}$ & 0.346 & 0.475 & 0.765 & 0.422 \\
\hline
\end{tabular}


Table 3.4 numbers of individuals genotyped $(N)$; number of alleles found (a); observed heterozygosity $\left(\mathrm{H}_{0}\right)$; expected heterozygosity $\left(\mathrm{H}_{\mathrm{e}}\right)$; $P$, bold values sig $<0.05$ across nine microsatellites for each sampled site

\begin{tabular}{|c|c|c|c|c|c|}
\hline $\begin{array}{l}\text { Site, } \\
\text { Locus }\end{array}$ & GG0Q6A & GH00IK & GJSLB2 & Pam017 & Pam025 \\
\hline \multicolumn{6}{|l|}{ Leigh } \\
\hline$N$ & 49 & 49 & 49 & 49 & 49 \\
\hline $\mathbf{a}$ & 10 & 6 & 6 & 5 & 8 \\
\hline $\mathrm{H}_{\mathbf{o}}$ & 0.714 & 0.776 & 0.796 & 0.571 & 0.694 \\
\hline$H_{e}$ & 0.729 & 0.747 & 0.765 & 0.644 & 0.712 \\
\hline$P$ & 0.189 & 0.867 & 0.287 & 0.079 & 0.277 \\
\hline \multicolumn{6}{|c|}{ Hawkes Bay } \\
\hline$N$ & 21 & 21 & 21 & 21 & 21 \\
\hline $\mathbf{a}$ & 8 & 4 & 7 & 5 & 7 \\
\hline $\mathbf{H}_{\mathbf{o}}$ & 0.714 & 0.714 & 0.762 & 0.619 & 0.714 \\
\hline $\mathbf{H}_{\mathbf{e}}$ & 0.782 & 0.668 & 0.783 & 0.612 & 0.678 \\
\hline$P$ & 0.287 & 0.731 & 0.442 & 1.000 & 0.449 \\
\hline \multicolumn{6}{|c|}{ Cook Strait } \\
\hline$N$ & 25 & 25 & 25 & 25 & 25 \\
\hline $\mathbf{a}$ & 10 & 5 & 7 & 4 & 8 \\
\hline $\mathrm{H}_{\mathbf{O}}$ & 0.800 & 0.680 & 0.880 & 0.600 & 0.760 \\
\hline $\mathbf{H}_{\mathbf{e}}$ & 0.795 & 0.655 & 0.828 & 0.664 & 0.758 \\
\hline$P$ & 0.682 & 0.920 & 0.994 & 0.713 & 0.278 \\
\hline \multicolumn{6}{|c|}{ Makara } \\
\hline$N$ & 22 & 22 & 22 & 22 & 22 \\
\hline $\mathbf{a}$ & 5 & 7 & 7 & 5 & 7 \\
\hline $\mathbf{H}_{\mathbf{o}}$ & 0.636 & 0.818 & 0.681 & 0.818 & 0.636 \\
\hline $\mathbf{H}_{\mathbf{e}}$ & 0.606 & 0.749 & 0.761 & 0.618 & 0.611 \\
\hline$P$ & 0.440 & 0.767 & 0.792 & 0.224 & 0.914 \\
\hline \multicolumn{6}{|l|}{ Otago } \\
\hline$N$ & 48 & 48 & 48 & 48 & 48 \\
\hline $\mathbf{a}$ & 5 & 5 & 7 & 5 & 6 \\
\hline $\mathbf{H}_{\mathbf{o}}$ & 0.750 & 0.667 & 0.896 & 0.604 & 0.646 \\
\hline $\mathrm{H}_{\mathbf{e}}$ & 0.663 & 0.694 & 0.807 & 0.682 & 0.728 \\
\hline$P$ & 0.006 & 0.444 & $<0.001$ & 0.010 & 0.004 \\
\hline \multicolumn{6}{|c|}{ Hokitika } \\
\hline$N$ & 49 & 49 & 49 & 49 & 49 \\
\hline $\mathbf{a}$ & 11 & 6 & 8 & 7 & 9 \\
\hline $\mathbf{H}_{\mathbf{o}}$ & 0.510 & 0.327 & 0.510 & 0.531 & 0.531 \\
\hline $\mathbf{H}_{\mathbf{e}}$ & 0.831 & 0.720 & 0.789 & 0.769 & 0.780 \\
\hline$P$ & $<0.001$ & $<0.001$ & $<0.001$ & $<0.001$ & $<0.001$ \\
\hline \multicolumn{6}{|c|}{ Chatham Islands } \\
\hline$N$ & 43 & 43 & 43 & 43 & 43 \\
\hline $\mathbf{a}$ & 9 & 5 & 7 & 5 & 7 \\
\hline $\mathrm{H}_{\mathbf{o}}$ & 0.698 & 0.581 & 0.744 & 0.674 & 0.605 \\
\hline $\mathbf{H}_{\mathbf{e}}$ & 0.715 & 0.715 & 0.756 & 0.640 & 0.738 \\
\hline $\boldsymbol{P}$ & 0.729 & 0.045 & 0.619 & 0.599 & 0.052 \\
\hline
\end{tabular}




\subsubsection{Population genetic structure}

\section{Mitochondrial DNA}

Comparison of pairwise $\phi_{\text {st }}$ values showed some significance between the sample sites of Hokitika-Hawkes Bay, Makara, and Otago and between Chatham IslandsHawkes Bay, Makara and Otago at $P<0.05$. However, none of these comparisons were significant after the Bonferroni correction $(P=0.0017)$. Mantel's test indicated that there was no significant relationship between genetic distance and geographic distance for all sites $\left(\mathrm{r}^{2}=0.007, P=0.31\right)$. No AMOVAs were implemented because no significant genetic structure was observed.

The haplotype genealogy showed a complex pattern of a stable historical population (figure 3.2). The most common haplotype is found in all populations. No discernable pattern was evident in the distribution of sites throughout the genealogy or via an examination of the distribution of haplotype frequencies by sample site (figure 3.3). The general trend of the genealogical pattern was one of a lack of genetic structure.

\section{Microsatellites}

The POWSIM analysis indicated that the nine loci from all sample sites showed that each site's respective sample size was capable of detecting a true $\mathrm{F}_{\mathrm{st}}$ value down to the value of 0.05 with a probability of $100 \%$ from both Fisher's exact test and chi-squared (data not shown) from two different $N_{e f} / t$ combinations simulated.

Pairwise comparisons of $\mathrm{F}_{\text {st }}$ showed significant differentiation among three pairwise comparisons following the Bonferroni correction $(P=0.0023)$ (table 3.5): Hokitika, which had significant $F_{\text {st }}$ values with Leigh (0.05468), Otago (0.06052) and the Chatham Islands (0.05370). Similar results were found with $R_{s t}$ values, with a significant level of differentiation between Hokitika-Leigh (0.09660) and Hokitika-Otago (0.12037) but no significant differentiation was 
found between Hokitika-Chatham Islands (table 3.6). Rst values were generally higher than their $F_{\text {st }}$ equivalent. These results were supported by high $D_{\text {st }}$ values among all pairwise comparisons including Hokitika (table 3.6). When populations are significantly differentiated, genetic distances among populations can be overestimated when there are null alleles, however, significant differences were detected at eight out of nine loci (table 3.5). Between the comparisons of Hokitika-Leigh and Hokitika-Otago the locus GJLKPX was not significant while the locus Pam021 was not significant between HokitikaChatham Islands. The unrooted tree of genetic relatedness based on Nei's (1972) Minimum distance also showed that Hokitika was the most genetically distinct site of all sites sampled (figure 3.16).

There was no significant IBD $(P=0.29)$ among all sites, excluding Hokitika (fig 3.13). An AMOVA determined the highest proportion of total variance attributed to variation between groups occurred when Hokitika was separated from the other populations forming its own cluster (5.4\% and 8.8\% for $\mathrm{F}_{\mathrm{st}}$ and $\mathrm{R}_{\mathrm{st}}$, respectively). However, this high percentage of variation attributed to Hokitika was not statistically significant $(P=0.143)$. There was no further explanation as to the levels of genetic variation assessed when other clusters were formed.

The sample site PCA showed that the first two axes explained $85.12 \%$ and $11.13 \%$ of the total genetic variance, respectively, with over three-quarters of the genetic variation found attributed to Hokitika (figure 3.4). 

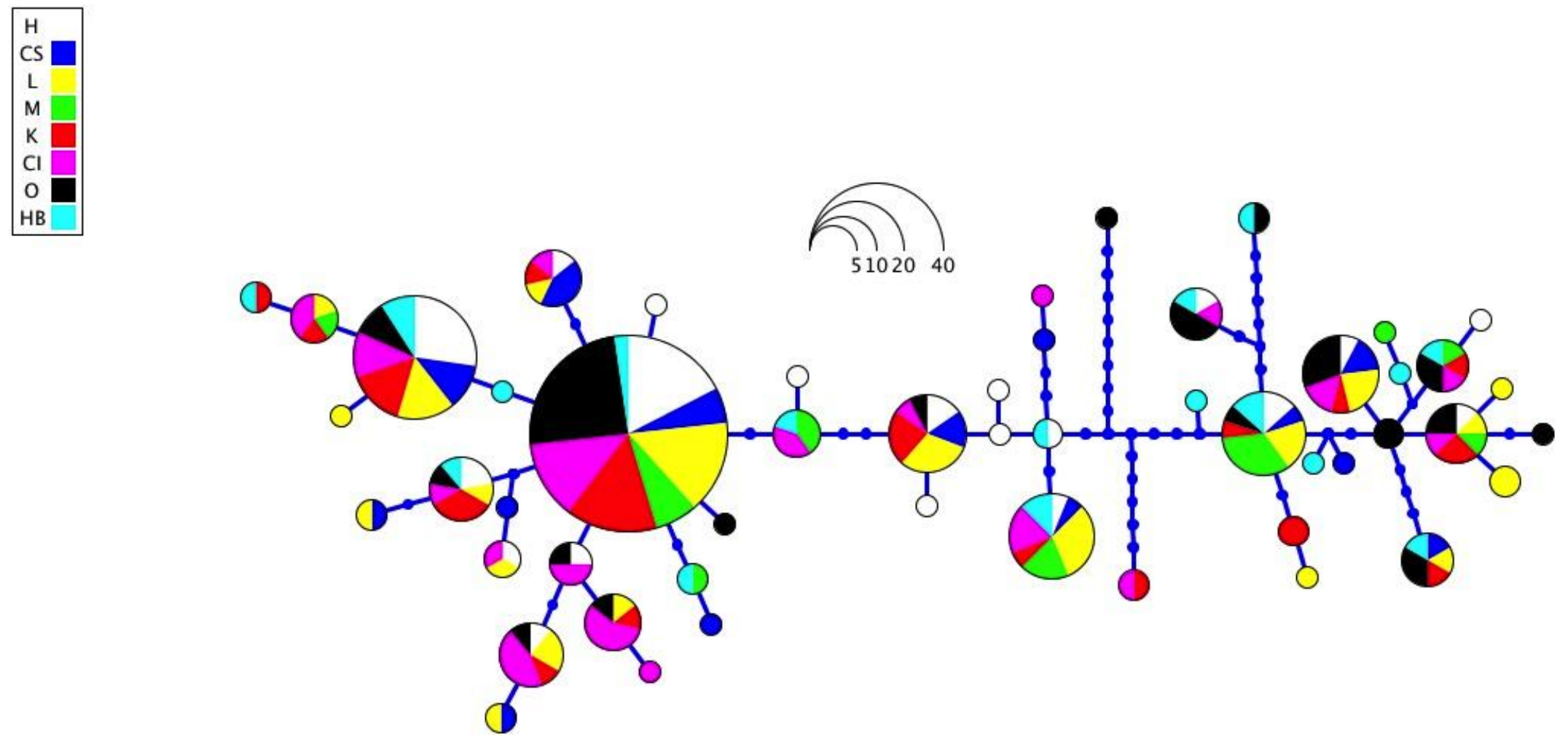

Figure 3.2 Haplotype genealogy from ML tree of the control region sequences of 294 individuals. The circles represent the haplotypes. The scale shown indicates the relationship between the circle sizes and the frequency of haplotypes. Lines connecting the circles represent a mutational step, and dots in the line represent a putative mutational step between haplotypes. H, Hokitika; CS, Cook Strait; L, Leigh; M, Makara; K, Kaikoura; CI, Chatham Islands; 0, Otago; H, Hawkes Bay 


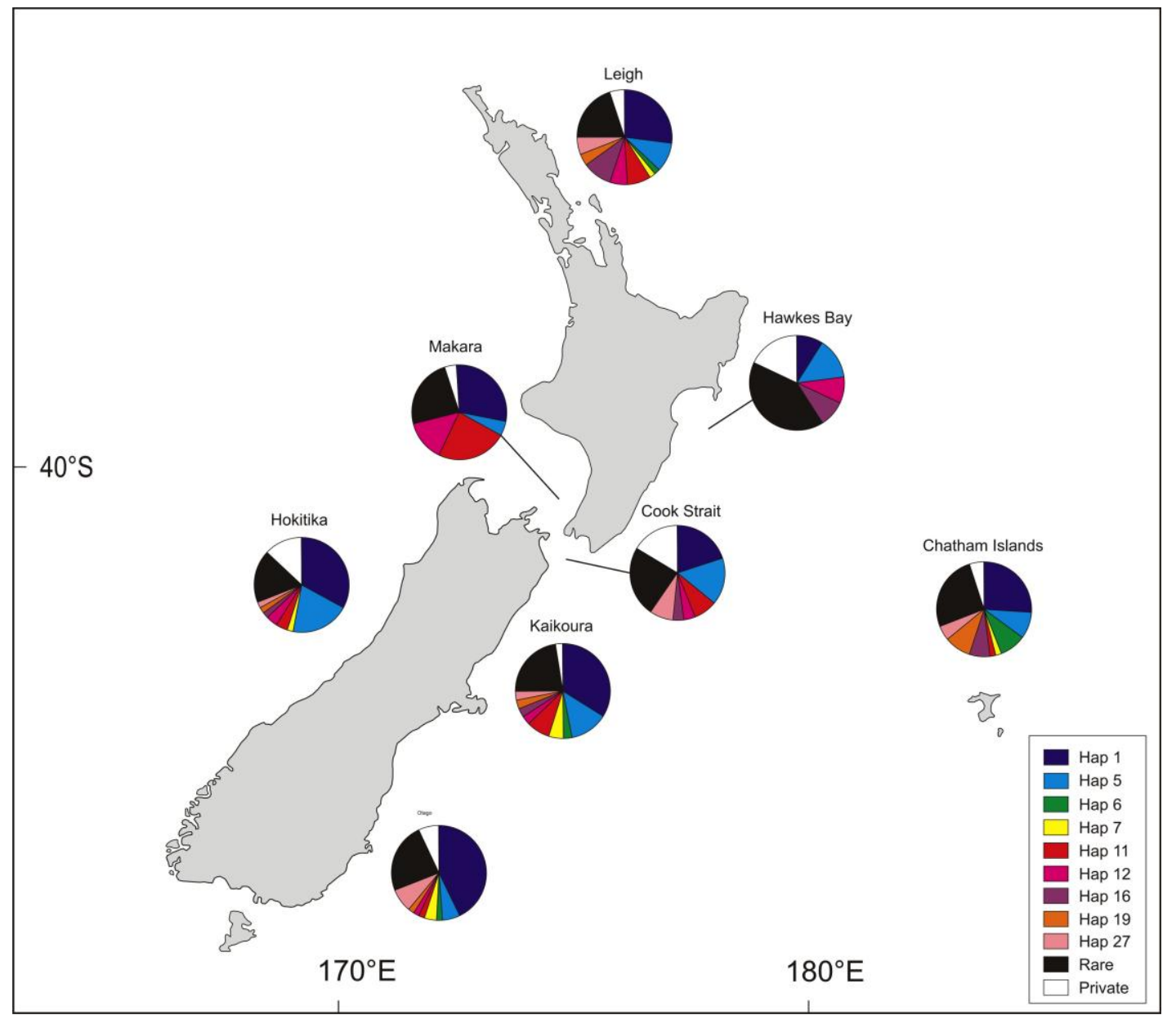

Figure 3.3 The frequency of the $\mathbf{1 1}$ most common haplotypes as discovered at each sample site. Rare haplotypes (not in the 11 most common) and private haplotypes also shown

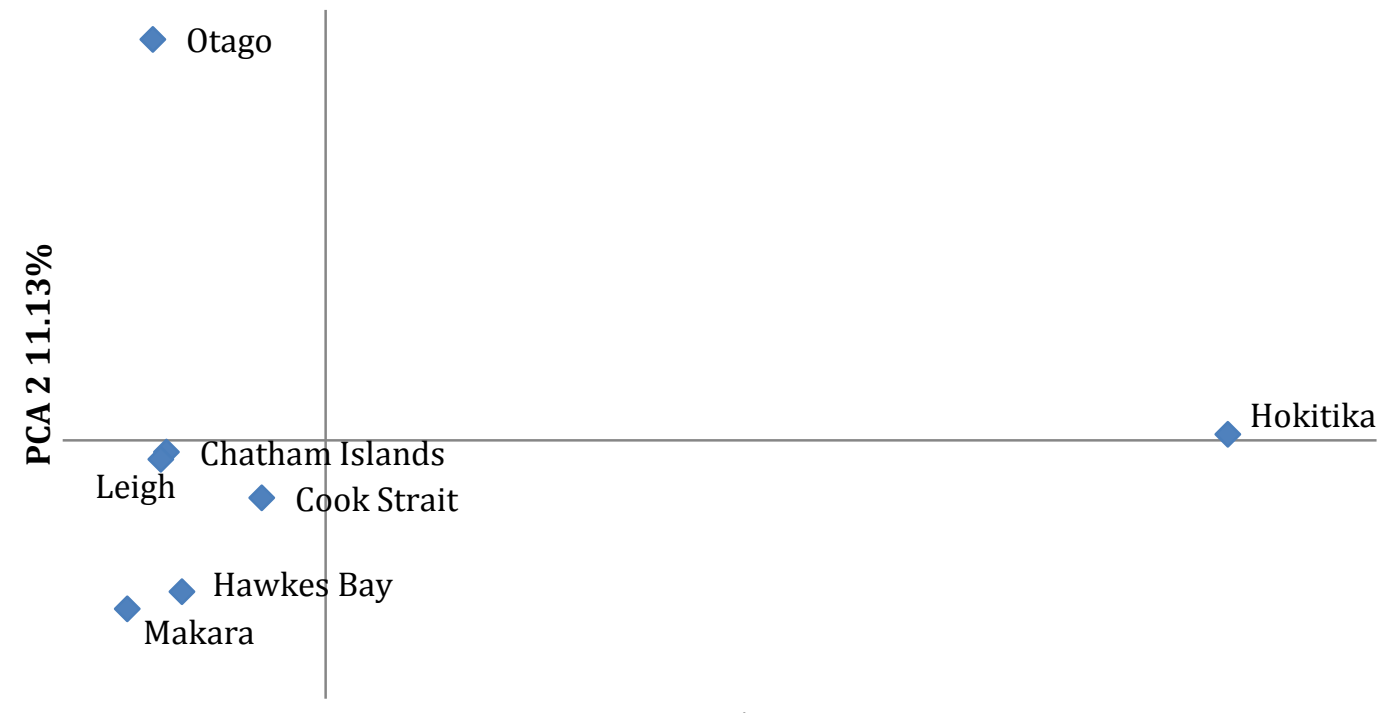

PCA $185.12 \%$

Figure 3.4 2D plot of the first two PCA axes of genotype frequencies of all sampled sites 
Table 3.5 Matrix of pairwise comparisons of population genetic structure using $F_{\text {st }}$ (below diagonal) values at seven sample sites across nine microsatellites. Bold values, sig $P<0.05$; $*$ sig at $P<0.0023$ (Bonferroni correction). Above the diagonal are the numbers of loci significant at $P<0.0023$ with superscripted numbers listed corresponding to each of the significant nine loci. 1, GG0Q6A; 2, GH00IK; 3, GJLKPX; 4, GJSLB2; 5, Pam010; 6, Pam017; 7, Pam021; 8, Pam025; 9, Pam035

\begin{tabular}{|c|c|c|c|c|c|c|c|}
\hline & Leigh & Hawkes Bay & Cook Strait & Makara & Otago & Hokitika & Chatham Islands \\
\hline Leigh & & - & - & - & - & $\mathbf{8}^{1,2,4,5,6,7,8,9}$ & - \\
\hline Hawkes Bay & -0.003 & & - & - & - & $5^{2,4,6,8,9}$ & - \\
\hline Cook Strait & 0.001 & -0.006 & & - & - & $6^{2,4,5,6,8,9}$ & - \\
\hline Makara & 0.002 & -0.002 & -0.001 & & - & $71,2,4,5,6,8,9$ & - \\
\hline Otago & 0.005 & 0.008 & 0.005 & 0.009 & & $8^{1,2,4,5,6,7,8,9}$ & - \\
\hline Hokitika & $0.055^{*}$ & 0.051 & 0.043 & 0.058 & $0.061 *$ & & $8^{1,2,3,4,5,6,8,9}$ \\
\hline Chatham Islands & -0.004 & -0.003 & -0.001 & 0.002 & 0.005 & $0.054^{*}$ & \\
\hline
\end{tabular}

Table 3.6 Matrix of pairwise comparisons of population genetic structure using $\mathbf{R}_{\text {st }}$ (below diagonal) values at seven sample sites across nine microsatellite loci. Bold

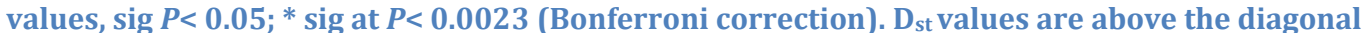

\begin{tabular}{cccccccc}
\hline & Leigh & Hawkes Bay & Cook Strait & Makara & Otago & Hokitika & Chatham Islands \\
\hline Leigh & & -0.001 & -0.001 & 0.001 & 0.008 & 0.172 & -0.002 \\
Hawkes Bay & -0.007 & & -0.012 & -0.001 & 0.011 & 0.162 \\
Cook Strait & -0.007 & -0.019 & & -0.002 & 0.004 & 0.125 & -0.001 \\
Makara & -0.008 & -0.014 & -0.012 & & 0.009 & 0.172 \\
Otago & -0.002 & -0.002 & -0.006 & 0.001 & 0.001 & 0.001 \\
Hokitika & $\mathbf{0 . 0 9 *}$ & $\mathbf{0 . 0 6 9}$ & $\mathbf{0 . 0 6 9}$ & $\mathbf{0 . 0 7 1}$ & $\mathbf{0 . 1 2 0}$ & 0.008 \\
Chatham Islands & 0.008 & -0.001 & 0.008 & -0.004 & $\mathbf{0 . 0 3 4}$ & $\mathbf{0 . 0 6 1}$ \\
\hline
\end{tabular}




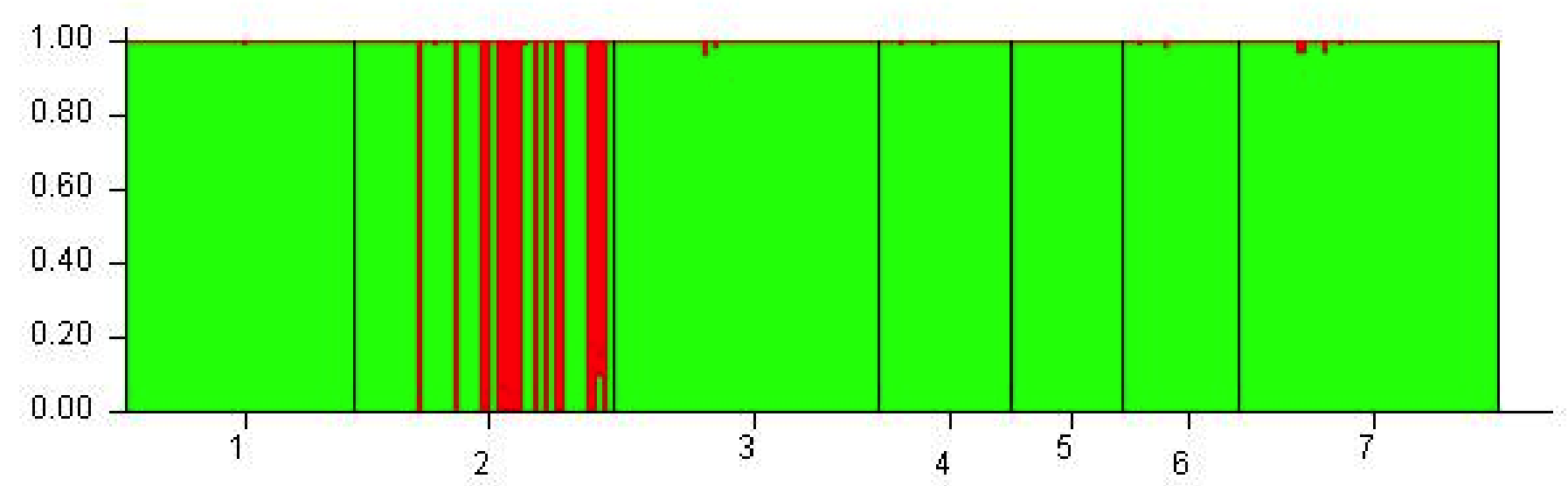

Figure 3.5 Structure analysis of $\mathrm{K}=2$; each individual is represented by a single vertical line. Cluster two is represented by red and includes only individuals from 2 , Hokitika. Cluster one is represented by green and includes: 1, Chatham Islands; 3, Leigh; 4, Cook Strait; 5, Hawkes Bay; 6, Makara; 7, Otago and some individuals from 2 , Hokitika.

Table 3.7 Assignment tests for individuals from each sampling site (rows) assigned back to each site (columns). Numbers represent percentages of individuals assigned to each site and values in bold are correct assignments

\begin{tabular}{|c|c|c|c|c|c|c|c|}
\hline & Leigh & Hawkes Bay & Cook Strait & Makara & Otago & Hokitika & Chatham Islands \\
\hline Leigh & 67 & 14 & 16 & 0 & 16 & 12 & 7 \\
\hline Hawkes Bay & 4 & 81 & 0 & 14 & 0 & 10 & 4 \\
\hline Cook Strait & 4 & 0 & 76 & 0 & 6 & 8 & 4 \\
\hline Makara & 12 & 0 & 4 & 82 & 0 & 8 & 7 \\
\hline Otago & 10 & 5 & 0 & 4 & 71 & 6 & 9 \\
\hline Hokitika & 0 & 0 & 0 & 0 & 0 & 39 & 0 \\
\hline Chatham Islands & 2 & 0 & 8 & 0 & 8 & 16 & 67 \\
\hline
\end{tabular}


The Bayesian cluster analysis performed in STRUCTURE 2.3.3 showed that the data set was structured (figure 3.5). Two clusters were identified from the New Zealand sample sites using the Delta K estimator. The Hokitika samples were assigned to one cluster, with the samples from the remaining six sample sites being assigned to the second cluster. Based on the Bayesian assignment tests (Rannala and Mountain 1997), 64\% of individuals across all sites were correctly assigned to their actual sample site. Makara had the highest percentage of individuals correctly assigned with $82 \%$, while Hokitika had the lowest with 39\% (table 3.7). The probability simulation algorithm by Paetkau et al., (2004) further indicated that all individuals had probability values above the exclusion threshold $(P>0.05)$ for their correct site. However, considering all sites together, only 21 individuals were below the exclusion threshold for three or more sites. This suggests that many of the sampled individuals were assigned probability values that were above the exclusion threshold for other sites too. However, of the $39 \%$ of individuals assigned to Hokitika, all of them (19 individuals) could not be assigned to any other site.

\subsubsection{Demographic history}

\section{Mitochondrial DNA}

The mismatch distribution for the data set deviated significantly from the expected distribution under the population expansion model (figure 3.6). It was represented by a poor fit of the observed pairwise differences and expected distribution model. Similarly there was a lack of statistical significance of Tajima's $D$ test $(P=0.132)$, and a non-significant SSD $(\mathrm{P}=0.84)$ and $\mathrm{H}_{\mathrm{r}}$ indices $(P$ $=0.55$ ). However, the model of population expansion was not rejected by Fu's $F_{S}$ values, which were significant at Hawkes Bay $(P=0.009)$, Hokitika $(P=0.001)$, Chatham Islands $(P=0.032)$ and across all samples sites $(P=0.001)$. Fu's $F_{s}$ test is more sensitive than other tests at detecting the signal of population expansion (Fu 1997; Ramos-Onsins and Rozas 2002). Using both mutation rates, and estimates of $\tau$ by population, the time since the last recent expansion of the sampled locations was Hokitika, which was estimated between 32 kya and 17.8 
kya for the slower and faster mutation rates, respectively. For all other populations, an expansion event has been estimated to take place between 40 kya and 173k ya for the slower mutation rate and 22 kya and 96 kya for the faster mutation rate. Effective population sizes were found to be similar across all populations. Additionally, the BSPs showed that P. oxygeneios has had a stable historical population size with a small recent expansion event occurring between 20kya and ca. $15 \mathrm{kya}$ (figures $3.7 \& 3.8$ ).

\section{Microsatellite DNA}

The BOTTLENECK analysis did not show any evidence of the genetic effects of a contraction of a population size across all sites. All sites were in equilibrium under the three mutational models.

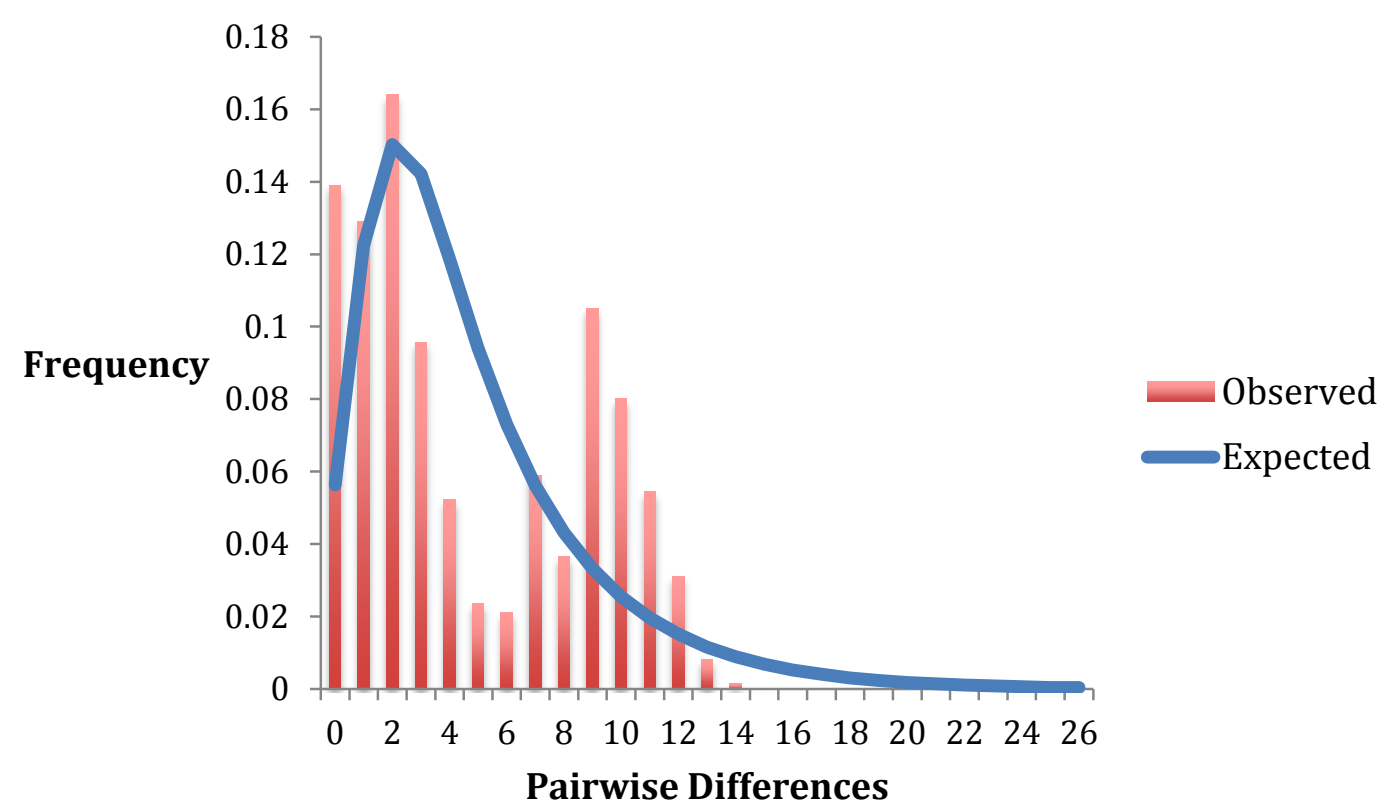

Figure 3.6 Mismatch distribution of the frequency of pairwise differences from 294 control region sequences 
Table 3.8 Demographic parameters from 294 control region sequences; $\tau$, age of mutational time; $t$, time since population expansion for mutation rates of $2.0 \times 10^{-8}$ and $3.6 \times 10^{-8} ; \theta_{s}$, co- ancestry coefficient; $N_{e f}$, effective female population sizes for each respective mutation rate.

\begin{tabular}{ccccc}
\hline \multicolumn{5}{c}{ Demographic Parameters } \\
\hline Location & $\tau$ & $\boldsymbol{t}$ & $\boldsymbol{\theta}_{\mathrm{s}}$ & $\boldsymbol{N}_{\boldsymbol{e f}}$ \\
\hline Leigh & 1.559 & $44,400-79,900$ & 6.504 & $185,000-333,000$ \\
Hawkes Bay & 3.372 & $96,000-173,000$ & 7.132 & $203,000-276,000$ \\
Cook Strait & 1.530 & $43,500-78,400$ & 7.151 & $204,000-430,000$ \\
Makara & 1.785 & $50,800-91,400$ & 5.003 & $142,000-256,000$ \\
Kaikoura & 1.258 & $35,800-64,400$ & 6.623 & $188,000-339,000$ \\
Otago & 2.091 & $59,500-107,000$ & 7.177 & $204,000-368,000$ \\
Hokitika & 0.625 & $17,800-32,000$ & 5.031 & $143,000-258,000$ \\
Chatham Islands & 0.796 & $22,700-40,800$ & 6.207 & $177,000-396,000$ \\
\hline
\end{tabular}

Table 3.9 Neutrality tests from 294 control region sequences * represents significant at $P<0.05$

\begin{tabular}{ccccc}
\hline & \multicolumn{2}{c}{ Neutrality tests } & \multicolumn{2}{c}{ Goodness of fit } \\
\hline Location & Fu's $\boldsymbol{F}_{\boldsymbol{s}}$ & Tajima's D & $\mathbf{H}_{\mathbf{r}}$ & SSD \\
\hline Leigh & -4.068 & -0.685 & 0.024 & 0.017 \\
Hawkes Bay & $\mathbf{- 6 . 1 0 9 *}$ & -0.303 & 0.026 & 0.014 \\
Cook Strait & -2.787 & -1.133 & 0.038 & 0.019 \\
Makara & 0.780 & 0.231 & 0.122 & 0.045 \\
Kaikoura & -3.132 & -0.782 & 0.058 & $\mathbf{0 . 8 4 4}$ \\
Otago & -2.231 & -0.584 & 0.040 & 0.031 \\
Hokitika & $\mathbf{- 8 . 1 6 3 *}$ & -0.995 & 0.049 & 0.022 \\
Chatham Islands & $\mathbf{- 5 . 2 0 4 *}$ & -1.160 & 0.026 & 0.017 \\
\hline Mean & -3.864 & -0.676 & 0.048 & 0.126 \\
\hline All individuals & $\mathbf{- 2 0 . 5 4 9 *}$ & -1.059 & 0.031 & 0.018 \\
\hline
\end{tabular}




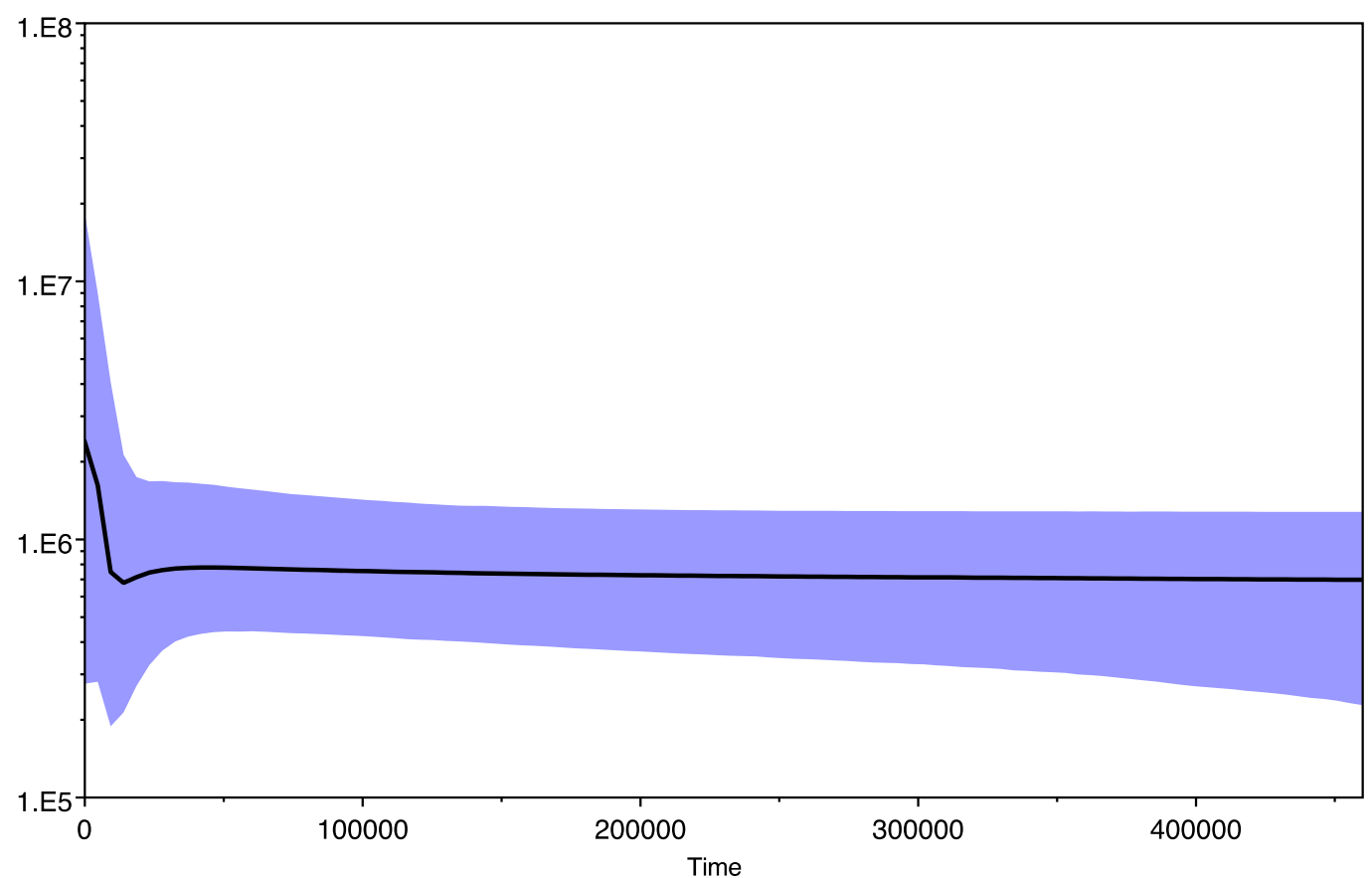

Figure 3.7 Bayesian skyline plots permuted 500 million times at an evolutionary rate of $2.0 \times 10^{-8}$ s/s/year

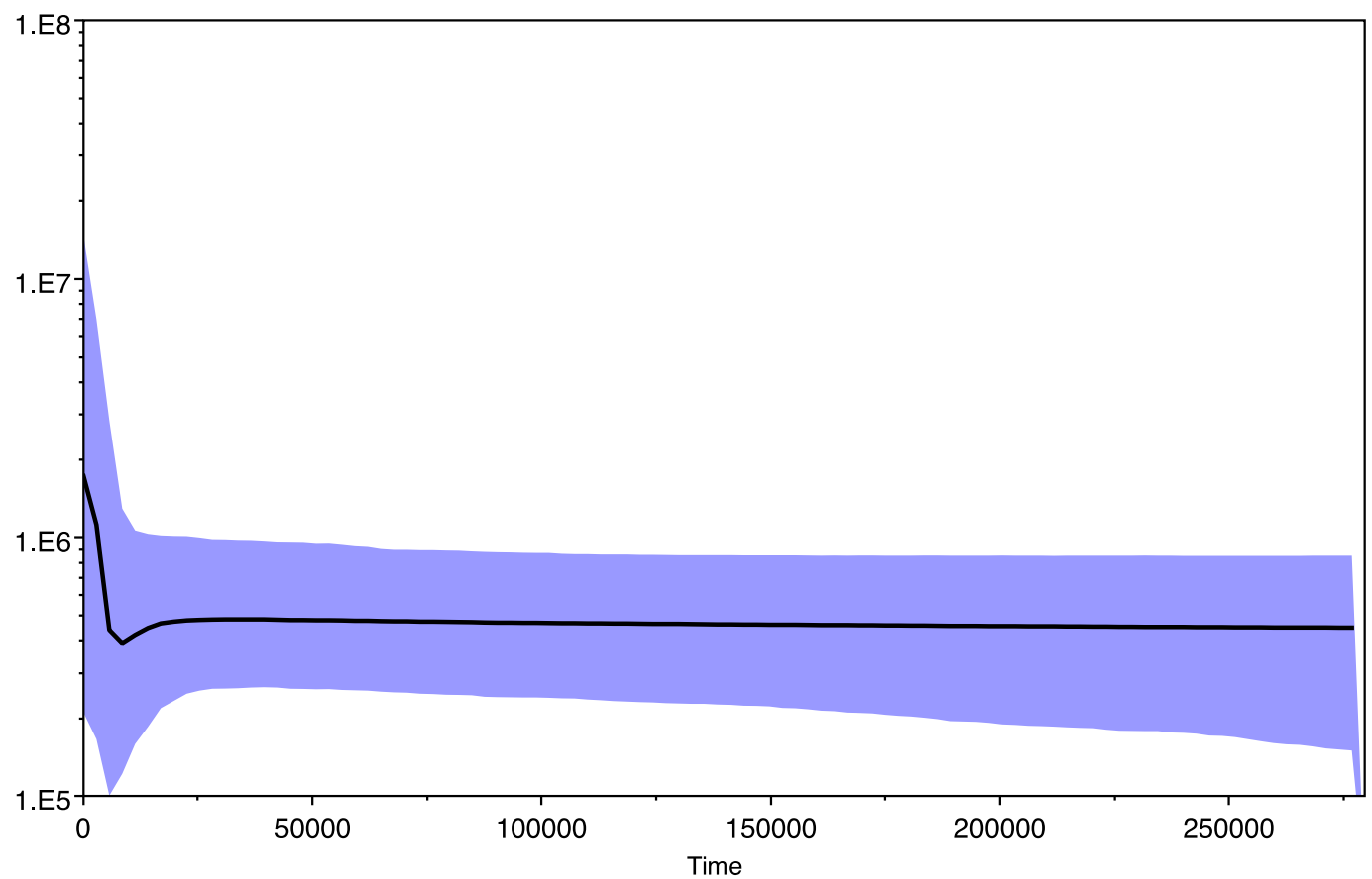

Figure 3.8 Bayesian skyline plots permuted 500 million times at an evolutionary rate of $3.6 \times 10^{-8}$ s/s/year 


\section{$\underline{\text { 3.4 Discussion }}$}

This study was the first to investigate the genetic structure of P. oxygeneios within New Zealand's waters. The mtDNA data showed little evidence of genetic differentiation of $P$. oxygeneios among sample sites, but the microsatellite DNA data suggested that the samples collected at the Hokitika site were from a population that was genetically distinct from samples collected at all other New Zealand sites. Previous tagging and allozymes studies in New Zealand have suggested that $P$. oxygeneios are likely to be mainly a single stock and there could be a separate Northland population (Smith and Johnson 1985; Beentjes and Francis 1999). Polyprion spp. are considered to be highly mobile as adults, particularly during the spawning season (Beentjes and Francis 1999), and have a unique life-history strategy of an extended juvenile phase of up to four years (Wakefield et al., 2010). P. americanus has a similar life history as P. oxygeneios, and it has been found to be genetically homogenous across ocean basins (Ball et al., 2000). This finding was attributed to the long period that juveniles spend in the pelagic environment (Ball et al., 2000). Thus, a priori expectation would be for $P$. oxygeneios to exhibit panmixia across the relatively small geographic scale of New Zealand.

\subsubsection{Genetic diversity}

All loci were included in the analyses despite the presence of null alleles. Of the nine microsatellites used within this study, null alleles, due to an excess of homozygotes at five loci (GG0Q6A, GH00IK, GJSLB2, Pam017, Pam025), were found in samples genotyped from Hokitika; an additional locus (Pam021) was also found to have null alleles at Otago. Although null alleles are often considered a technical problem, they are still considered relevant to the population genetic data because they are typically caused by a mutation within the primer site of that particular microsatellite (Chapius and Estoup 2006), which means they can be defined as an allele. Moreover, because these null alleles were most often found in samples from the Hokitika site it could indicate a significant level of 
population genetic differentiation between Hokitika and all other New Zealand sites. It is known that the presence of null alleles in a data set can inflate the levels of genetic differentiation (Chapius and Estoup 2006), however, analyses conducted excluding the loci with null alleles produced the same pattern of genetic differentiation as when they were included.

A deficiency of heterozygotes in marine species is common, especially in species with large effective population sizes, and it is most often attributed to the presence of null alleles (Li et al., 2003). It is known that null alleles in a data set significantly reduce the number of heterozygotes. However, the samples genotyped from the Hokitika site had a deficiency of heterozygotes when the loci with null alleles were included $(P<0.001)$ and when they were excluded $(P=$ 0.0164 ) in the analyses. There are various population processes that can reduce heterozygosity, including inbreeding and the Wahlund effect (Wahlund 1928). The Wahlund effect is the recent mixing of two differentiated populations, which can lead to a deficiency of heterozygotes when samples are taken at random from the combined populations. The Hokitika samples were collected from a small area over a short period of time, which might not reflect the known dispersal patterns and travelling distances of $P$. oxygeneios, hence the result is unlikely to be caused by the Wahlund effect. Elevated levels of inbreeding $\left(\mathrm{F}_{\text {is }}=\right.$ 0.237) and a reduction in heterozygosity may be a consequence of over-fishing, which has been shown to reduce the levels of genetic diversity in a population, as exemplified in the snapper (Pagrus auratus) Tasman Bay population (Hauser et al., 2002). However, no reports in the catch data suggest that over-fishing occurs in this area (Paul 2002b), suggesting it could possibly be a consequence of null alleles in the Hokitika data set (Chybicki and Burczyk 2009).

\section{$\underline{3.4 .2 \text { Stock structure }}$}

The mitochondrial DNA analyses exhibit some significant pairwise comparisons of genetic differentiation - $\Phi_{\text {st }}$ - between sampled sites of Hokitika-Hawkes Bay, Makara and Otago, and also Chatham Islands-Hawkes Bay, Makara and Otago (table 3.11). Unlike the microsatellite DNA data, the mtDNA analyses did not 
provide conclusive evidence of population structure. This may be attributed to a small sample size (figure 3.10), the patterns of population differentiation being somewhat sex biased i.e. because of the matrilineal inheritance of mtDNA, or the number of microsatellite loci sampled were better able to detect genetic differentiation (e.g. Bentzen et al., 1996). There is evidence from the analyses of the microsatellite DNA data to suggest that the Hokitika site contains individuals from a genetically distinct population when compared to individuals from all other sites sampled in New Zealand. The significant level of population differentiation - based on $\mathrm{F}_{\mathrm{st}}, \mathrm{R}_{\mathrm{st}}$ and $\mathrm{D}_{\mathrm{st}}$ analyses - indicated restricted gene flow between Hokitika and Leigh, Otago and Chatham Islands. It is well known that the hapuku fishery is composed of two species (P. oxygeneios and P. americanus), which are phenotypically similar and ecologically overlapping congeneric species. It was possible that the genetic differences detected using microsatellite DNA markers was because the Hokitika site was dominated by samples of $P$. americanus, and not the main study species P. oxygeneios. However, the mixture of species within the samples was most likely not the case because the mtDNA sequencing and microsatellite DNA genotyping were conducted using the same tissue samples. In every sample from the Hokitika site, the mtDNA control region sequences obtained were clearly from $P$. oxygeneios; the mtDNA sequence from P. americanus is easily distinguishable from P. oxygeneios (see Chapter Two). The mtDNA data rejected the suggestion that the difference detected by microsatellite DNA at the Hokitika site was because of a misidentification with $P$. americanus.

There has been no prior suggestion of a discrete population along the west coast of the South Island other than a slight decline and peak in catch landings in the eastern HPB fisheries (HPB 2 and 3) that are absent in HPB 7 (Paul 2002a). Studies of $P$. oxygeneios within New Zealand have only sampled sites that are within the main area of fishing activity - Cook Strait and the eastern South Island (Smith and Johnson 1985; Beentjes and Francis 1999). Hokitika (HPB7) may not have been included in any of the previous studies because it is not regarded as one of the main supporting areas of the fishery. 
A genetically distinct west coast South Island fishery stock has never been reported for any other species. The New Zealand hoki (Macruronus novaezelandiae), the black oreo and smooth oreo (Allocytus niger; Pseudocyttus maculatus), and the kingfish (Seriola lalandi) are all high-mobile and wide ranging species (Smith et al., 1996; Smith et al., 2002; Miller et al., 2011), but genetic studies have concluded that they are panmictic throughout New Zealand and with sites within the Tasman Sea (Smith et al., 1996; Smith et al., 2002a; Miller et al., 2011). Furthermore, despite the shorter pelagic larval duration of orange roughy (Hoplostethus atlanticus) 10 days, the high capacity for active migration as adults is thought to provide enough gene flow, even at large geographic scales, to genetically homogenise global populations (Varela et al., 2012). Therefore, with $P$. oxygeneios possessing a long pelagic larval duration and highly mobile adults, it was unexpected to a find a genetically distinct population at Hokitika. Although only $39 \%$ of the individuals sampled from Hokitika could be correctly assigned back to their site of capture, they could not be assigned to any other site sampled.

There is increasing evidence that suggests many pelagic fishes are comprised of heterogeneous populations, which are largely the result of behavioural or oceanographic factors (Aboim et al., 2005; Rogers et al., 2006; Dammannagoda et al., 2011; Miller et al., 2011). New Zealand has a complex marine current system, and taking into consideration the circulation patterns of surface currents around New Zealand, it is possible that population connectivity can be maintained by passive larval dispersal facilitated by the circulation of ocean currents. There is no apparent pattern of oceanographic currents that might act as a retention mechanism for larvae within the Hokitika region (Heath 1985).

It has been reported that $P$. oxygeneios fishing areas can be sensitive to overfishing and take some time for the population size to recover, which suggests a high level of residency at sites except during the spawning season (Paul 2005). The Hokitika population could mix with individuals from the other New Zealand population during summer months, and return to their own separate spawn area in the winter (Wakefield et al., 2010). There are no data on 
the genetic structure of Australian P. oxygeneios populations and whether they are a genetically distinct population. The Hokitika population could be genetically similar and connected to the Australian population. Although genetic homogeneity has been reported between Australian and New Zealand populations of $P$. americanus (Ball et al., 2000), this does not necessarily mean similar results will be found for P. oxygeneios. Aboim (2005), utilizing both mtDNA and microsatellite DNA markers, found that two congeneric species of Beryx splendens and B. decadactylus, despite possessing similar biological traits and sampled over the same geographic space, revealed a striking pattern of genetic difference.

Equal levels of genetic heterogeneity have been found between individuals sampled at different times within the Cook Strait and individuals sampled from different locations (Smith and Johnson 1985). Moreover, tagging studies (Beentjes and Francis 1999) also suggested that if there were different stocks they would probably be separated temporally rather than spatially (Smith and Johnson 1985). However, the allozyme markers used by Smith and Johnson (1985), and the extended pelagic phase of juveniles, may be subject to selection and not reflect the processes of gene flow.

\subsubsection{Demographic history}

The analysis of mtDNA sequences allows marine fishes to be categorised into four groups (figure 3.9) based on different combinations of small and large values of haplotype and nucleotide diversity (Grant and Bowen 1998); for an explanation of each category refer to the figure legend. The high levels of haplotype diversity versus moderate levels of nucleotide diversity would place $P$. oxygeneios within group 4, which is categorised by a large stable population with a long evolutionary history. The high number of mutational steps between haplotypes exhibited in the genealogy of $P$. oxygeneios suggests that these arose some time ago and is supportive of a historically stable population. Conversely, a population having undergone recent expansion events will typically exhibit a star-like pattern in haplotype genealogies (Xiao et al., 2010; Varela et al., 2012). 


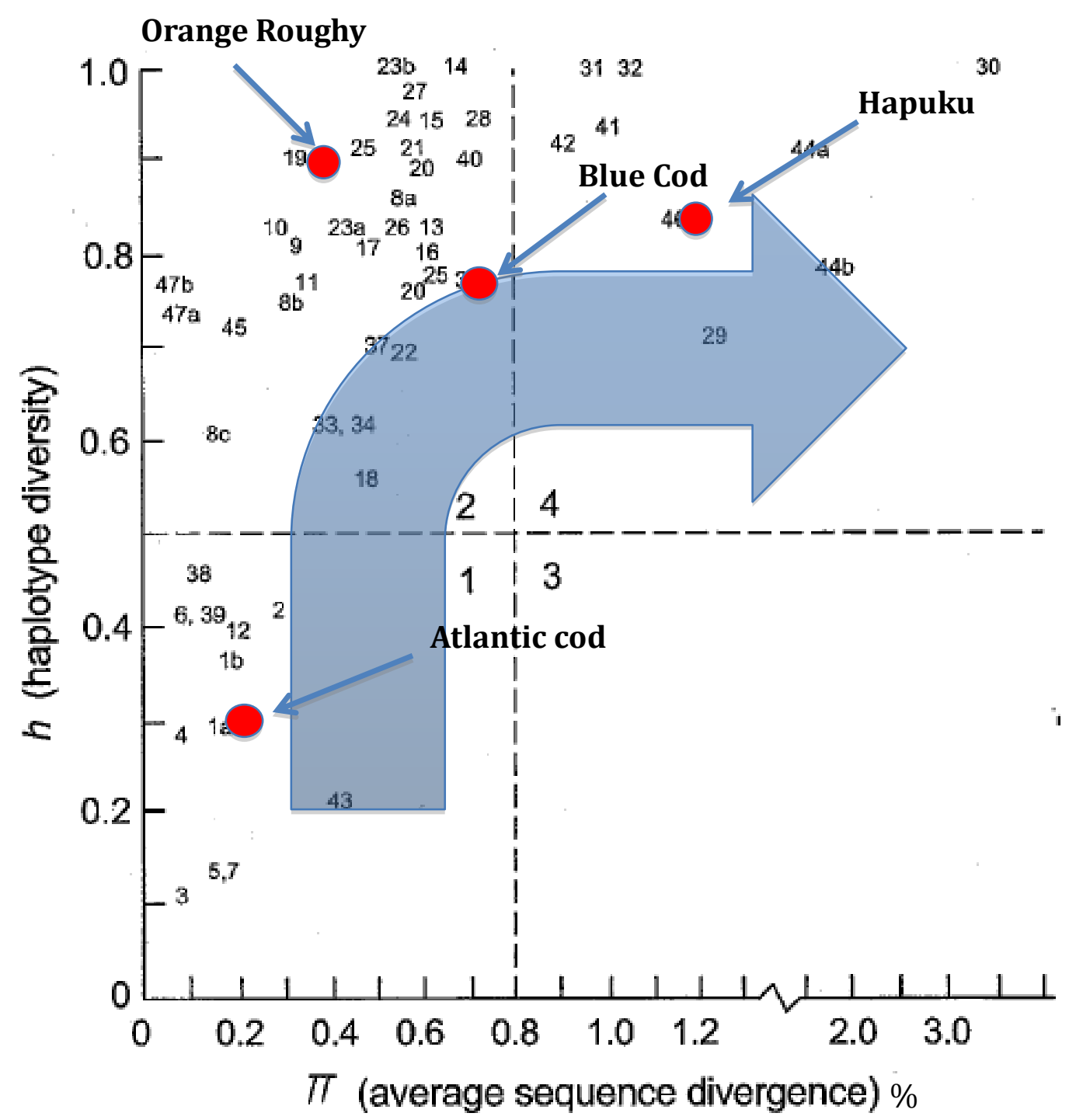

Figure 3.9 Classification of historical demographic processes in marine populations (adapted from Grant and Waples 2000). Group 1 is characterised by low $h$ and low $\pi$ and is representative of a population having undergone a recent bottleneck. Group 2 is characterised by high $h$ and low $\pi$ and is representative of a recent expansion in the population size. Group 4 is characterised by high $h$ and high $\pi$ and is representative of an older, historically stable population size. Group 3 is characterised by a low $h$ and a high $\pi$ however there are few examples of this among fish species. Orange roughy

(Varela et al., 2012); blue cod (Smith 2012); Atlantic cod (Carr et al., 1995)

The mismatch distribution also shows that there appears to have been a constant population size. Populations of deep-water species may be less likely to be affected by the large environmental upheavals experienced during glacial cycles (Gaithier et al., 2011). It is interesting to note, however, that results of Fu $F_{S}$ reveal significant negative $F_{s}$ values for all pooled sample sites, as well as individual sites of Hokitika, Chatham Islands and Hawkes Bay. It is recognised 
that $\mathrm{Fu} F_{s}$ is much more sensitive to demographic change than other statistical tests, particularly at higher sample numbers (Ramos-Onsins and Rozas 2002). Although the BSP of both mutation rates show a historical population size that is stable, it is characterised by a small increase in size $\sim 17-20$ kya. The demographic trends exhibited in the BSP are similar to the estimates of population expansion from $\tau$ for Hokitika and Chatham Islands. The timing of these events largely depend on the mutation rate used (Varela et al., 2012), therefore, the precise timing of these events is uncertain, but most likely occurred towards the end of the Pleistocene Period after the last glacial maximum. During the last glacial maximum sea levels dropped, meaning all three main islands in New Zealand were all connected. As sea levels began to rise, this would have opened up new ecological niches, allowing a possible population expansion into shallower waters. While evidence is inconclusive, anecdotal and historical information has suggested that $P$. oxygeneios have once occupied shallower waters (Maxwell 2011).

\section{$\underline{\text { 3.4.4 Implications for fisheries management }}$}

The current QMA boundaries for the HPB fishery were setup without a description of the population structure. When implementing a management strategy it is important to utilize information from genetic, demographic and ecological studies (Begg and Waldman 1999). A genetic study may need to be conducted on P. americanus to ensure the coordination of the management plans for both species. This study has provided the first description of the population genetic variation of $P$. oxygeneios from around New Zealand. The genetic data reported in this study supports the separate management of the HPB7 fishery and there is no evidence for splitting the other HPB fishing areas into separate management stocks. More genetic data are needed to determine whether there is temporal variation among $P$. oxygeneios stocks and to describe the genetic structure of $P$. americanus stocks. Also, resampling along the west coast of the South Island would provide further confidence to the results of this research. 


\section{Supplementary Information}

\section{Mitochondrial DNA}

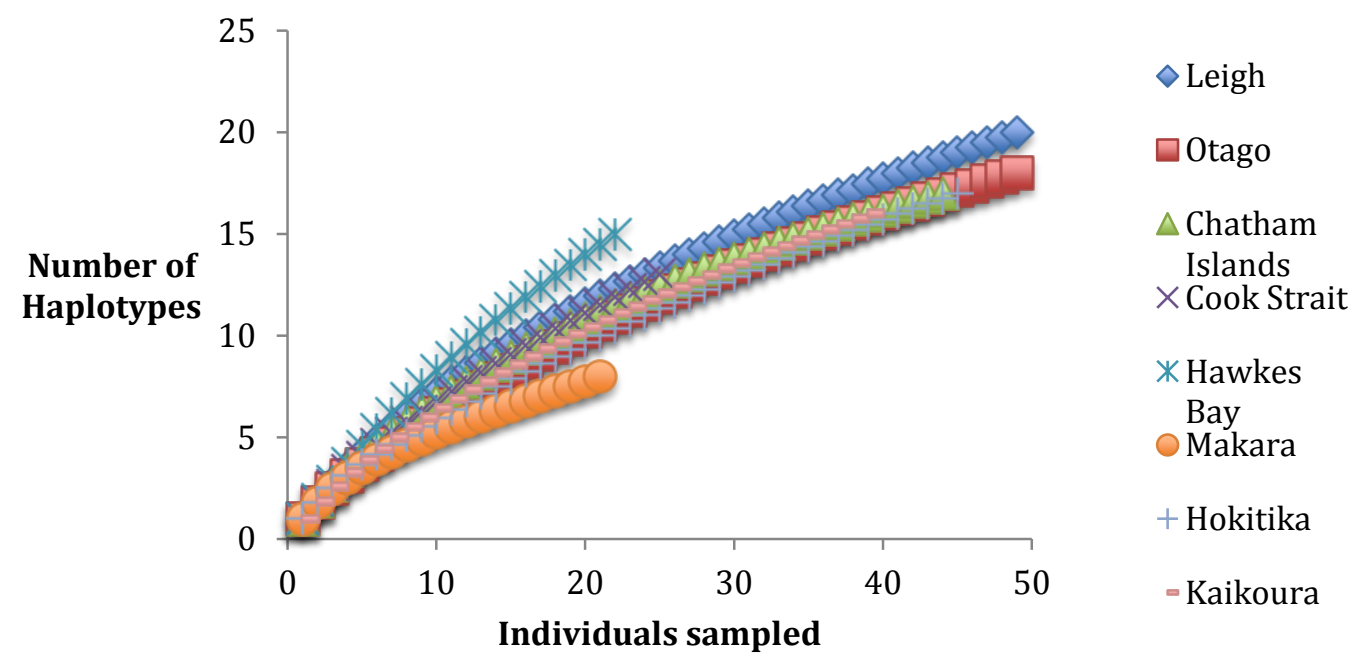

Figure 3.10 Rarefaction curve of each sample site, plotting the cumulate haplotypic richness against the number of individuals sampled

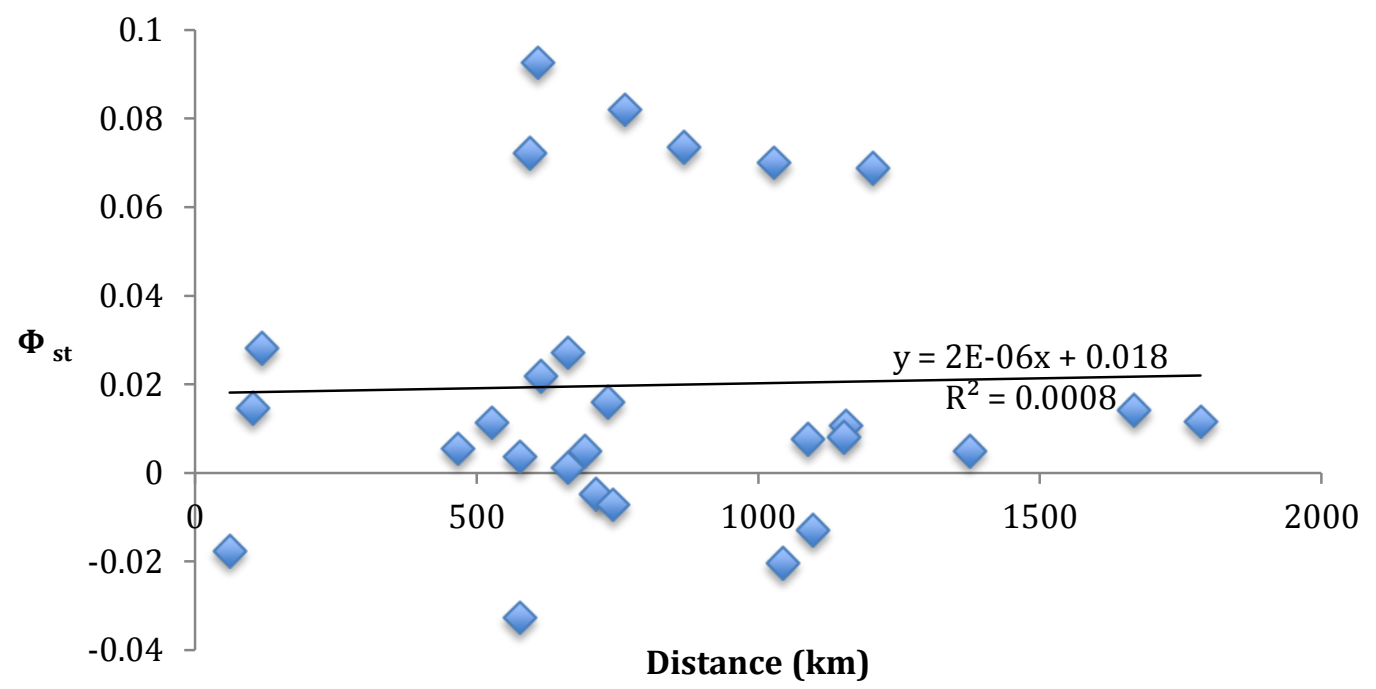

Figure 3.11 IBD plot of the regression of $\Phi_{\text {st }}$ and geographic distance between sampling sites 
Table 3.10 Pairwise matrix of $\Phi$ st (below diagonal) based on haplotype frequencies and the $P$ values (above the diagonal). Bold values are sig $P$ 0.05

\begin{tabular}{ccccccccc}
\hline & Leigh & Hawkes Bay & Cook Strait & Makara & Kaikoura & Otago & Hokitika & Chatham Islands \\
\hline Leigh & & 0.298 & 0.929 & 0.237 & 0.843 & 0.139 & 0.163 & 0.167 \\
Hawkes Bay & 0.004 & & 0.293 & 0.945 & 0.214 & 0.244 & $\mathbf{0 . 0 1 9}$ & $\mathbf{0 . 0 1 1}$ \\
Cook Strait & -0.020 & 0.005 & & 0.212 & 0.849 & 0.101 & 0.474 & 0.347 \\
Makara & 0.008 & -0.033 & 0.015 & & 0.121 & 0.193 & $\mathbf{0 . 0 0 9}$ & $\mathbf{0 . 0 1 1}$ \\
Kaikoura & -0.013 & 0.011 & -0.018 & 0.028 & & 0.103 & 0.587 & 0.263 \\
Otago & 0.014 & 0.008 & 0.027 & 0.016 & 0.022 & & $\mathbf{0 . 0 0 7}$ & $\mathbf{0 . 0 0 5}$ \\
Hokitika & 0.012 & $\mathbf{0 . 0 6 8}$ & -0.005 & $\mathbf{0 . 0 9 3}$ & -0.007 & $\mathbf{0 . 0 7 4}$ & 0.251 \\
Chatham Islands & 0.011 & $\mathbf{0 . 0 7 3}$ & 0.001 & $\mathbf{0 . 0 8 2}$ & 0.005 & $\mathbf{0 . 0 7 1}$ & 0.005 & \\
\hline
\end{tabular}

Microsatellite DNA

A

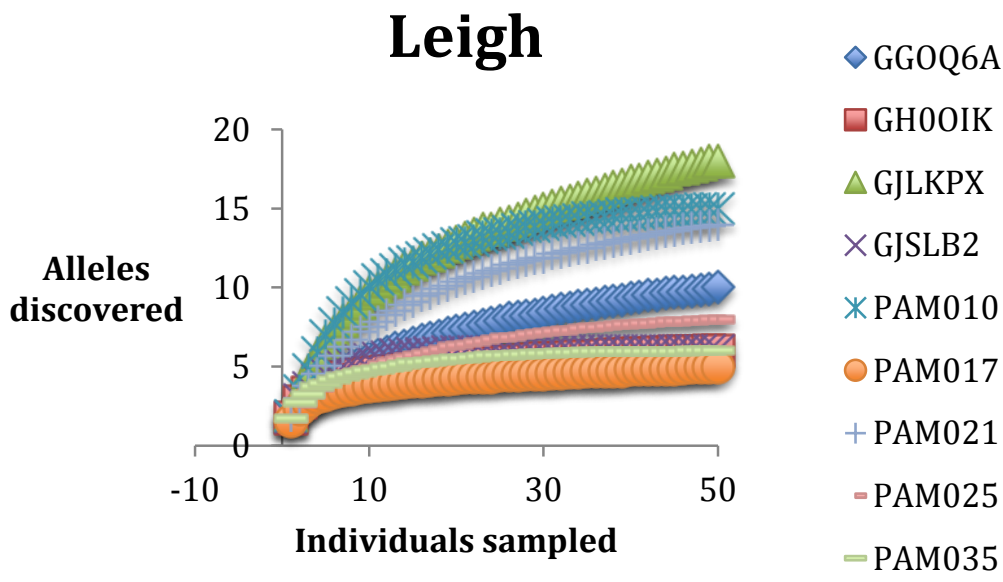

B

Hawkes Bay

Alleles
discovered

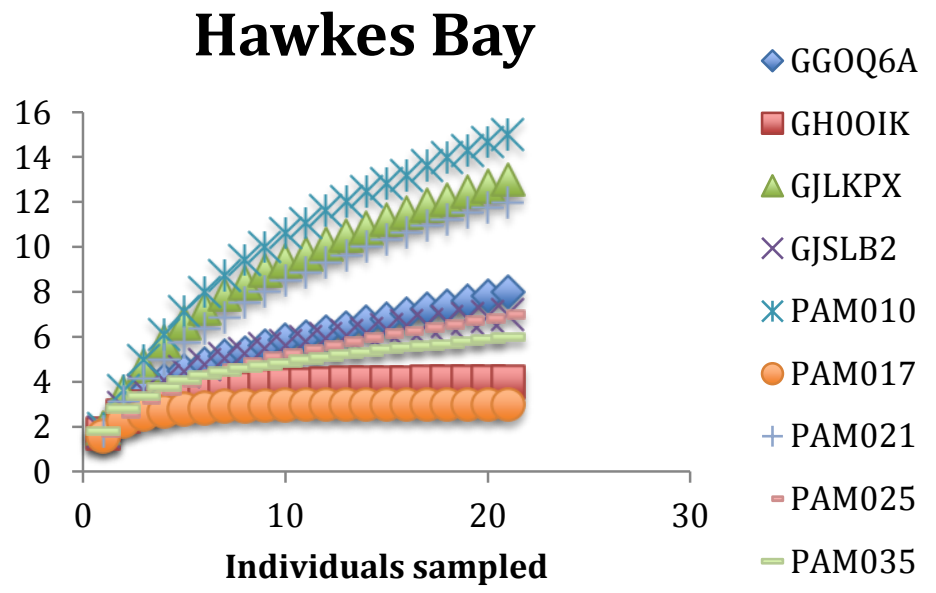


C
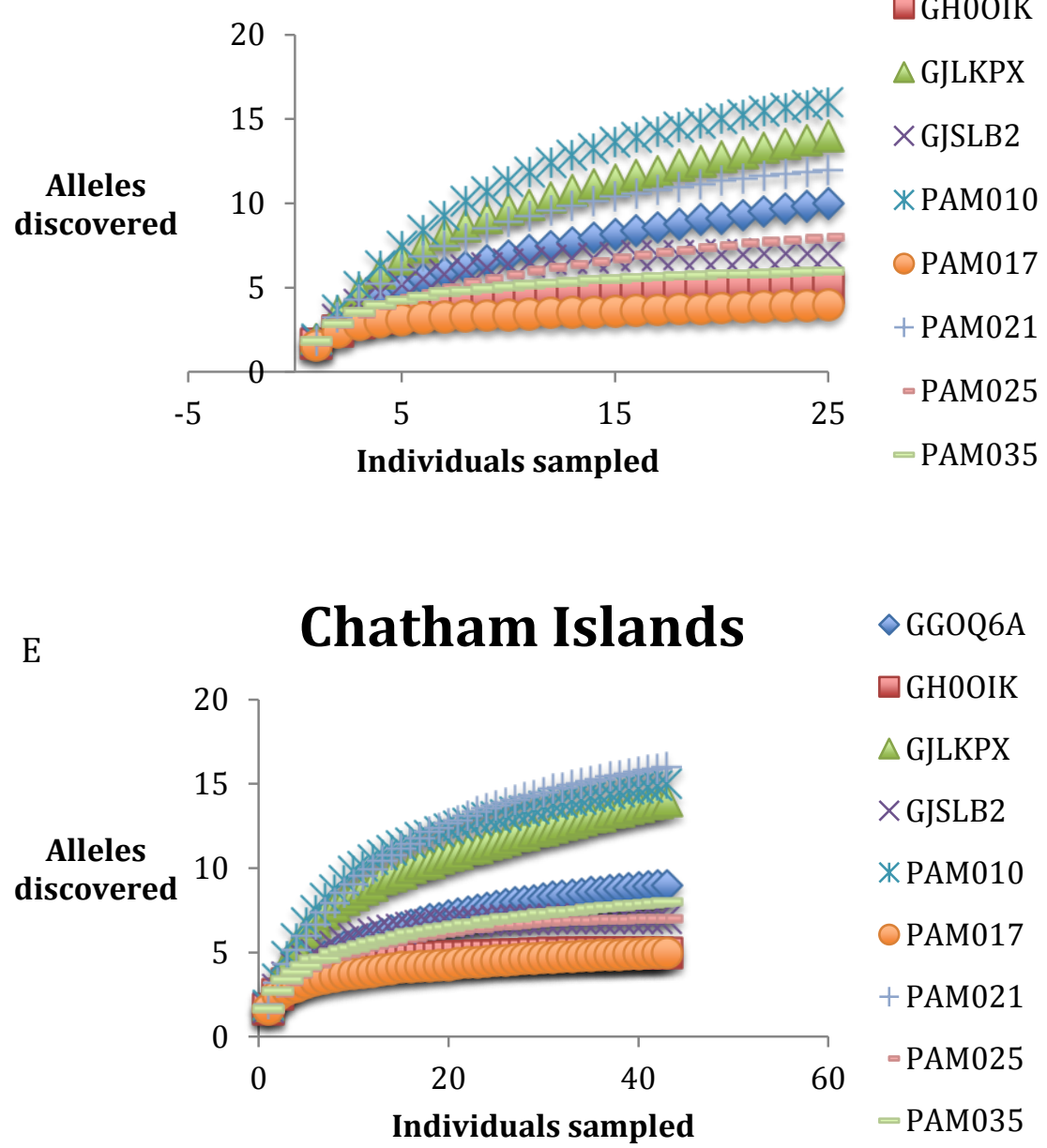

$\square$ GH0OIK

$\triangle$ GJLKPX

$\times$ GJSLB2

* PAM010

- PAM017

+ PAM021

- PAM025

- PAM035

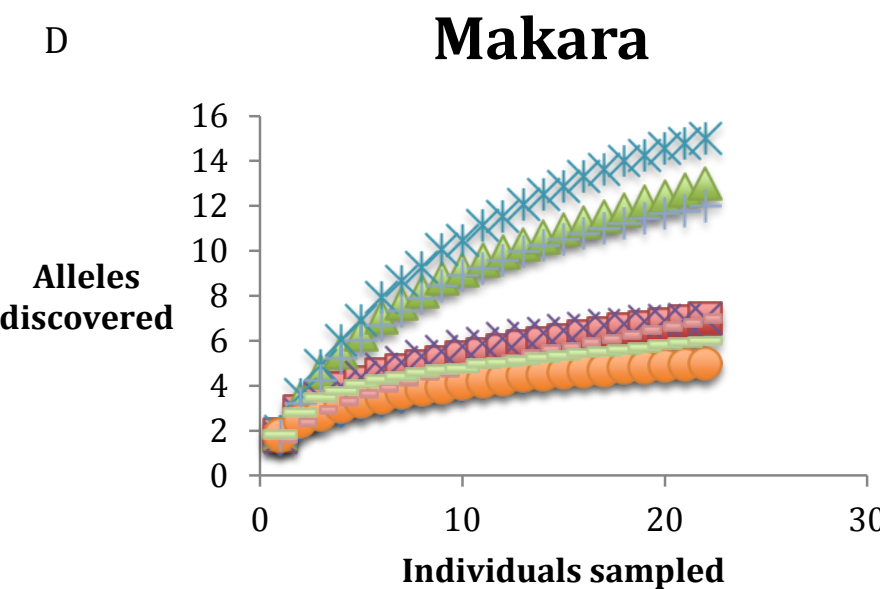

$\triangle$ GG0Q6A
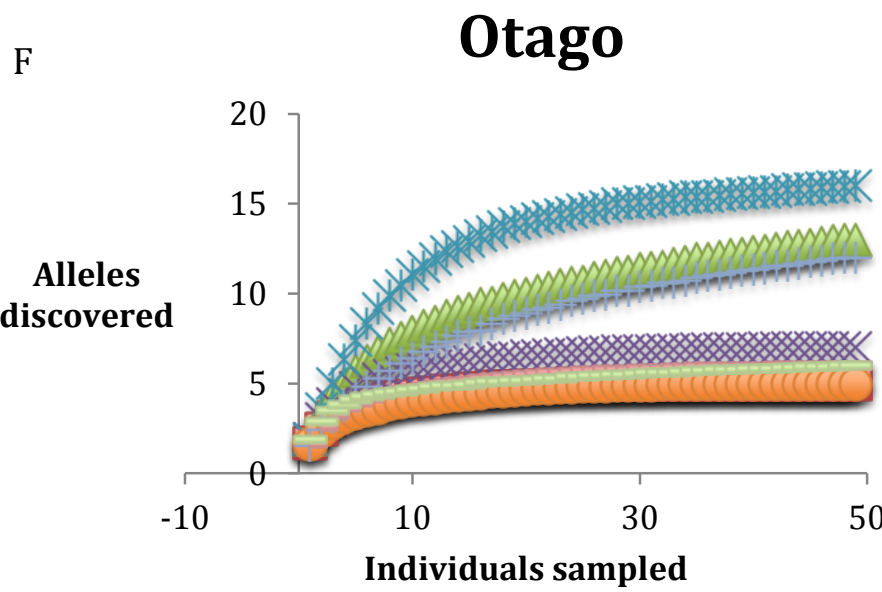

$\diamond$ GG0Q6A

$\square$ GHOOIK

$\triangle \mathrm{GJLKPX}$

$\times$ GJSLB2

* PAM010

- PAM017

+ PAM021

- PAM025

-PAM035 


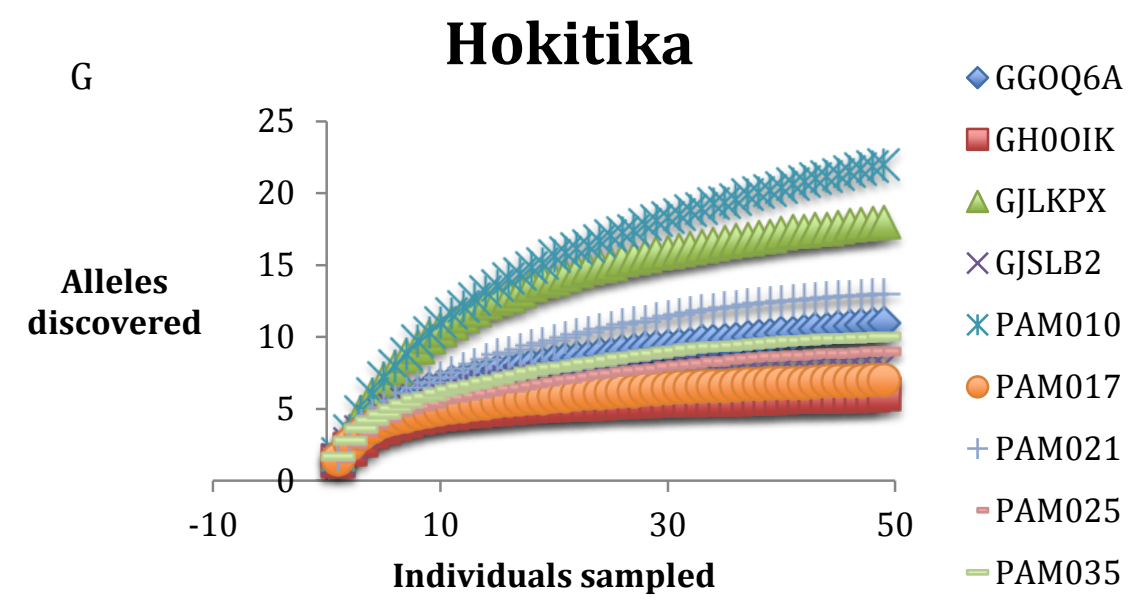

Figure 3.12 (A - G) Allele discovery curves for each sample site and loci, plotting the number of alleles discovered against the number of individuals sampled
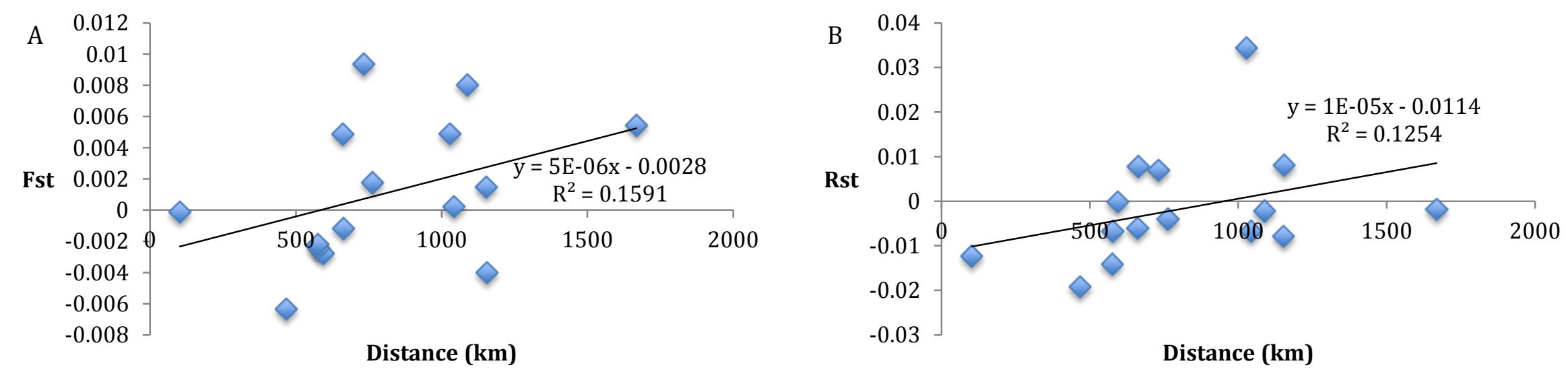

Figure 3.13 IBD plot of the regression of $F_{s t}(A)$ and $R_{s t}(B)$ against geographic distance between sampling sites excluding Hokitika 


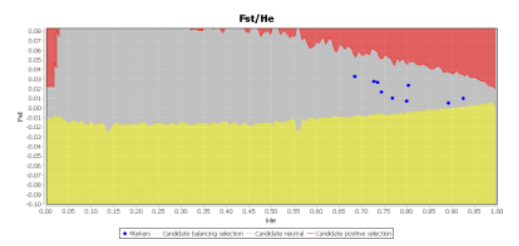

B

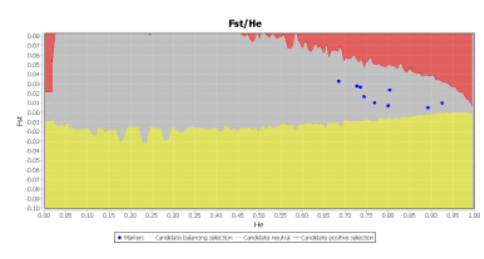

Figure 3.14 No outlier loci were discovered from our microsatellite markers. Each blue dot represents one loci, the red shade represents positive selection, the grey shade represents neutral selection and the yellow shade represents balancing selection. Both the IAM (A) and SMM (B) mutation models were used 
Table 3.11 AMOVA results between two groups (Hokitika and all other sites); DF, degrees of freedom; SS, sum of squares. Bold values, sig $P<0.05$. Both the $F_{\text {st }}$ (top) and $R_{\text {st }}$ (bottom) fixation indices were used

\begin{tabular}{|c|c|c|c|c|c|}
\hline Source of variation (Fst) & DF & SS & Variance Components & Variation \% & $\mathbf{P}$ \\
\hline Among Groups & 1 & 35.856 & 0.20054 & 5.45 & 0.143 \\
\hline Among Populations within groups & 5 & 19.221 & 0.00544 & 0.15 & 0.122 \\
\hline Within Populations & 511 & 1774.827 & 3.47324 & 94.40 & $<0.001$ \\
\hline Source of variation (Rst) & DF & SS & Variance Components & Variation \% & $\mathbf{P}$ \\
\hline Among Groups & 1 & 11776.115 & 69.25113 & 8.82 & 0.143 \\
\hline Among Populations within groups & 5 & 3776.500 & 0.59110 & 0.08 & 0.319 \\
\hline Within Populations & 511 & 365361.292 & 714.99274 & 91.10 & $<0.001$ \\
\hline
\end{tabular}

Table 3.12 A test for a genetic bottleneck was implemented for each sampling site under each of three mutation models. $P$ values (sig < 0.05 ) are shown

\begin{tabular}{cccc}
\hline Population & IAM & SMM & TPM \\
\hline Leigh & 0.285 & 0.993 & 0.993 \\
Hawkes Bay & 0.787 & 0.990 & 0.990 \\
Cook Strait & 0.326 & 0.787 & 0.751 \\
Makara & 0.674 & 0.898 & 0.875 \\
Otago & 0.065 & 0.455 & 0.455 \\
Hokitika & 1.000 & 1.000 & 1.000 \\
Chatham Islands & 0.990 & 1.000 & 1.000 \\
\hline
\end{tabular}




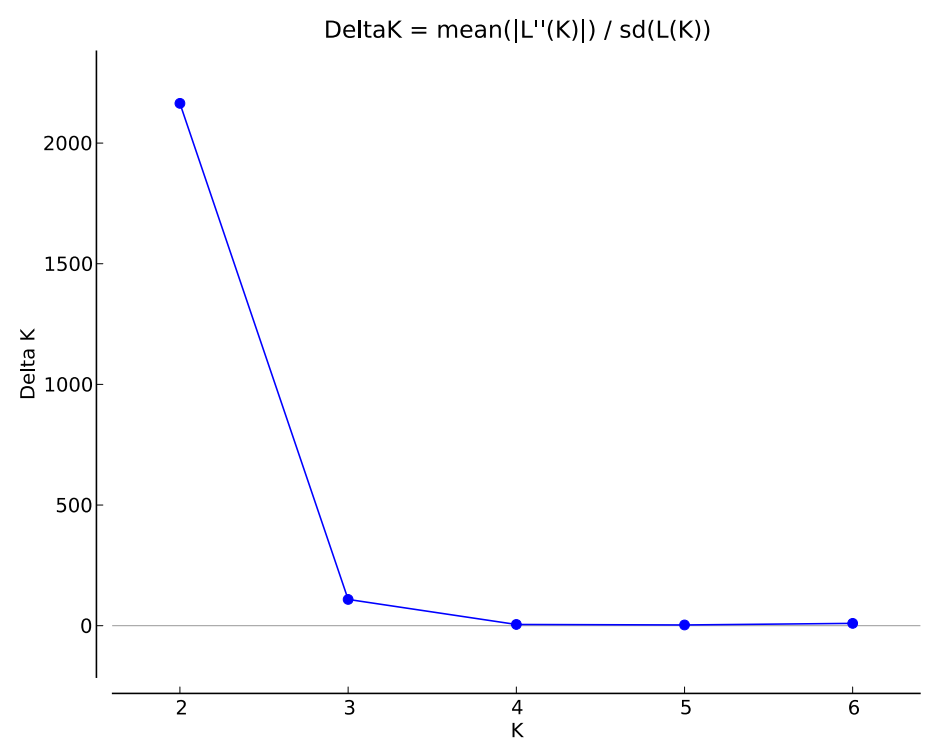

Figure 3.15 The number of genetic clusters within the microsatellite DNA data set as inferred by the Delta K estimator

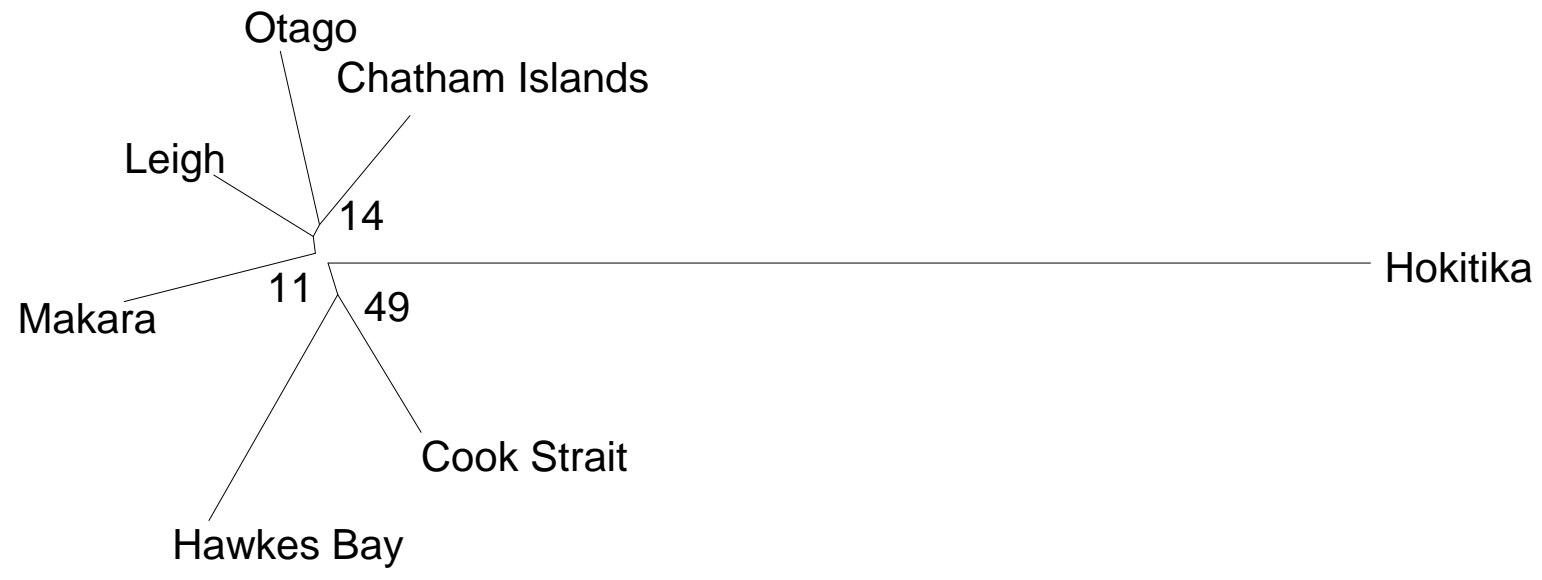

0.1

Figure 3.16 Neighbour-joining tree built on Nei's minimum distance with 1,000 bootstrap replications 
GG006A
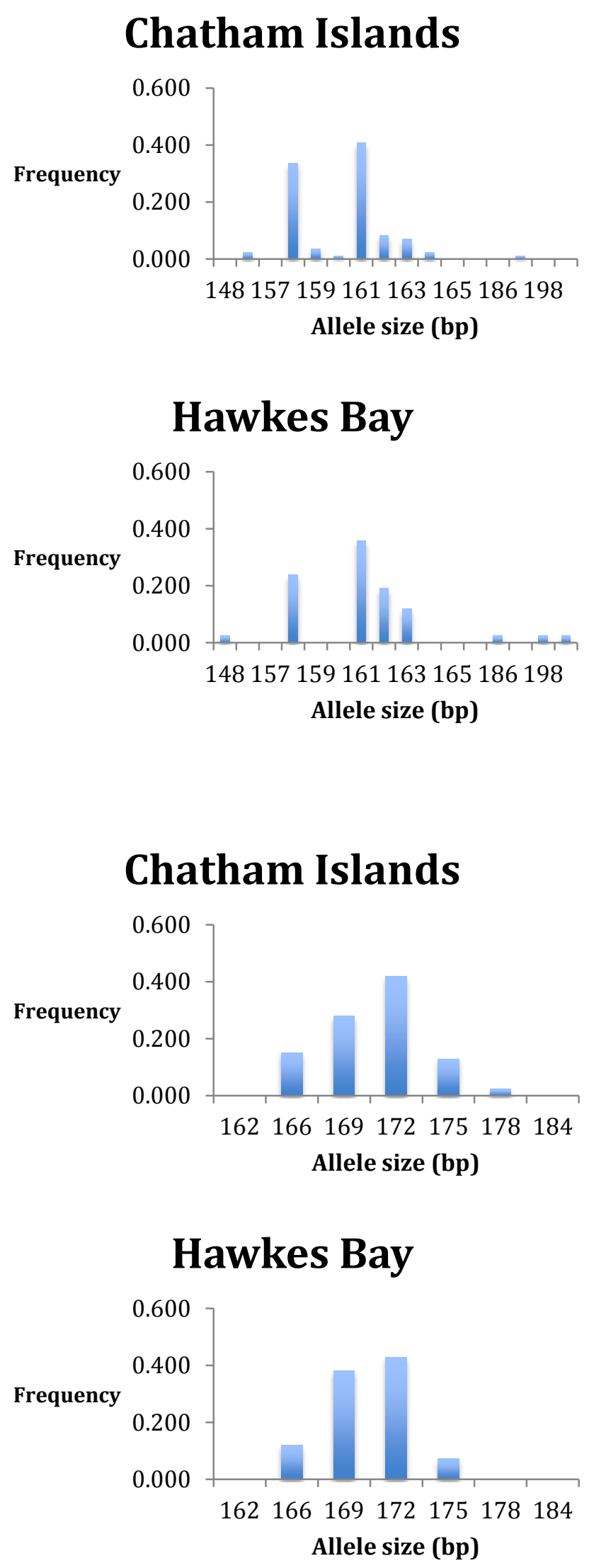
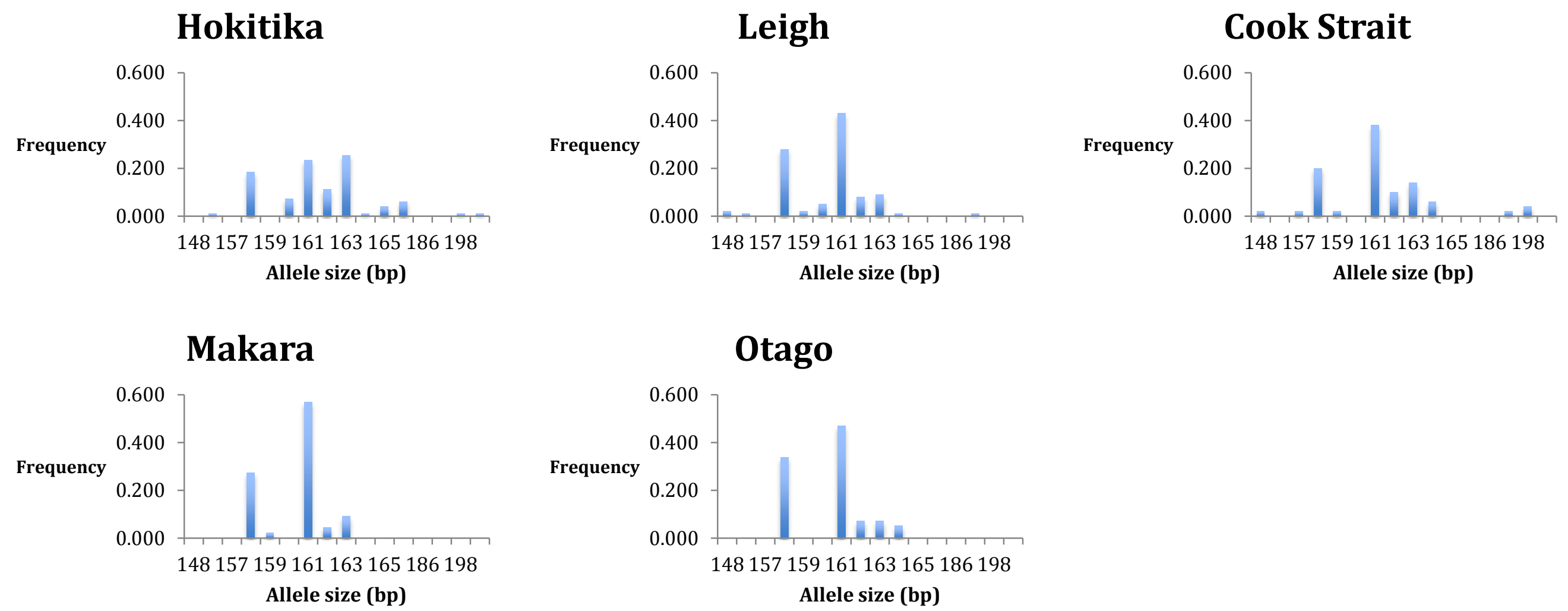

\section{GH0OIK}
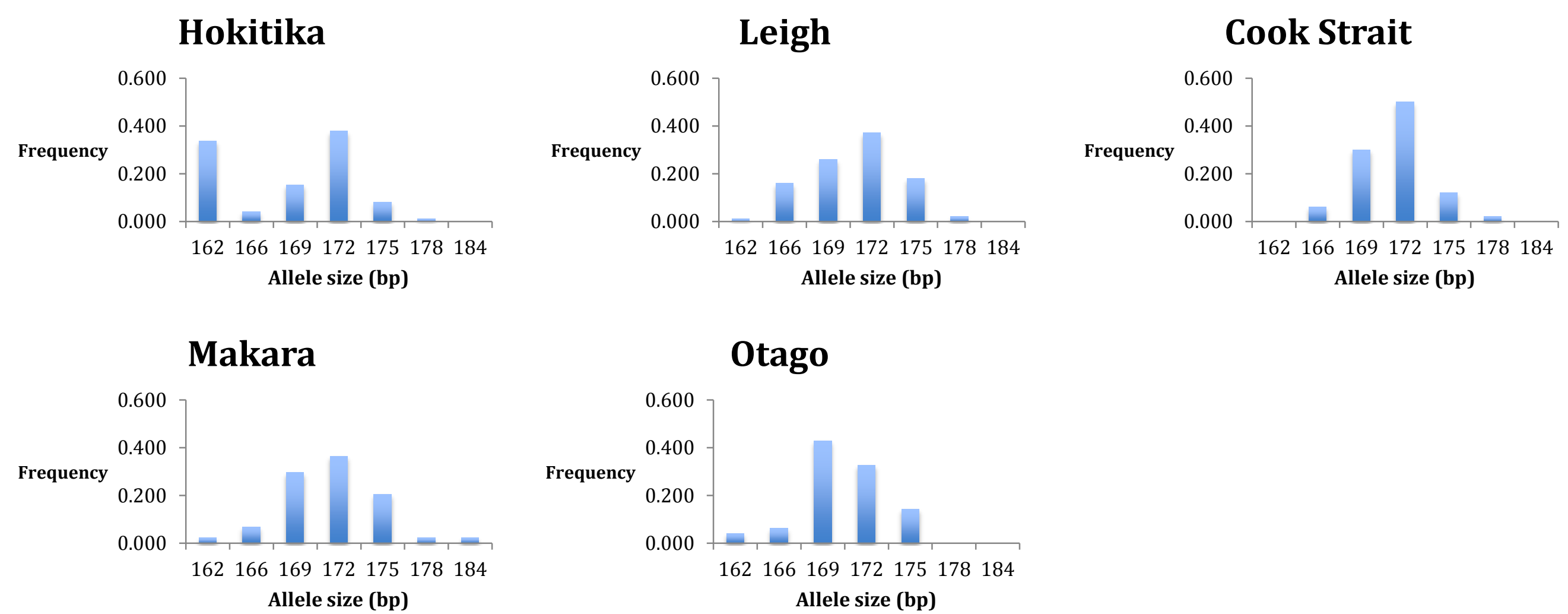

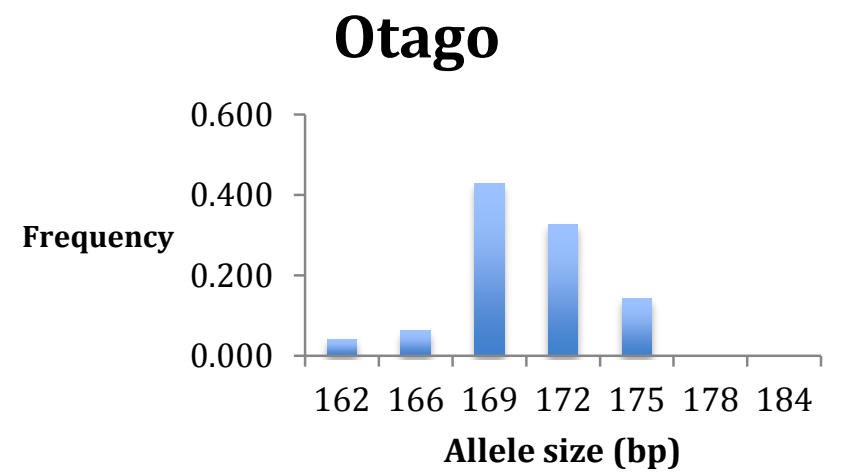


GILKPX

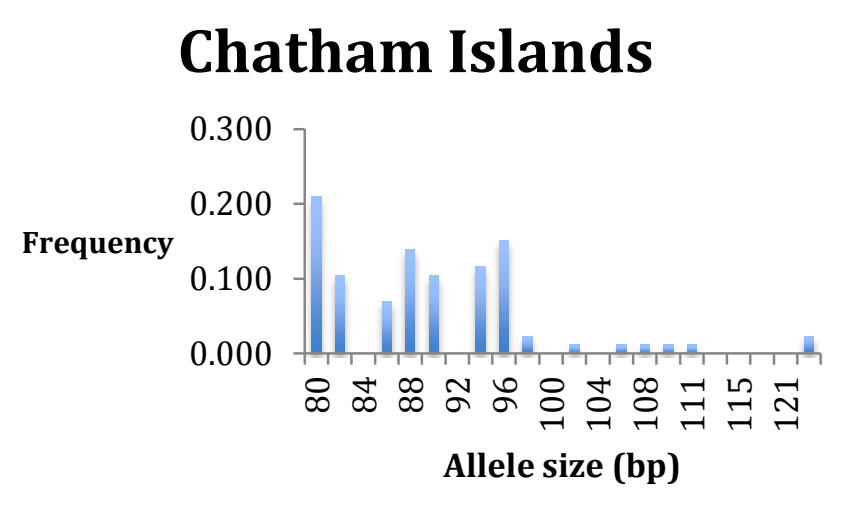

Hawkes Bay

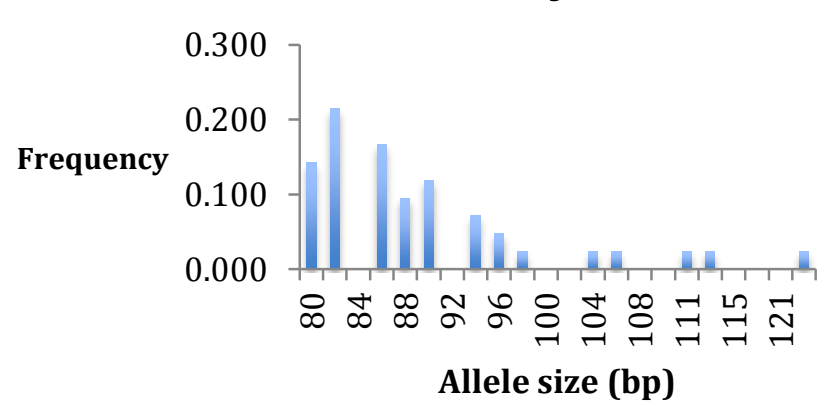

\section{Chatham Islands}

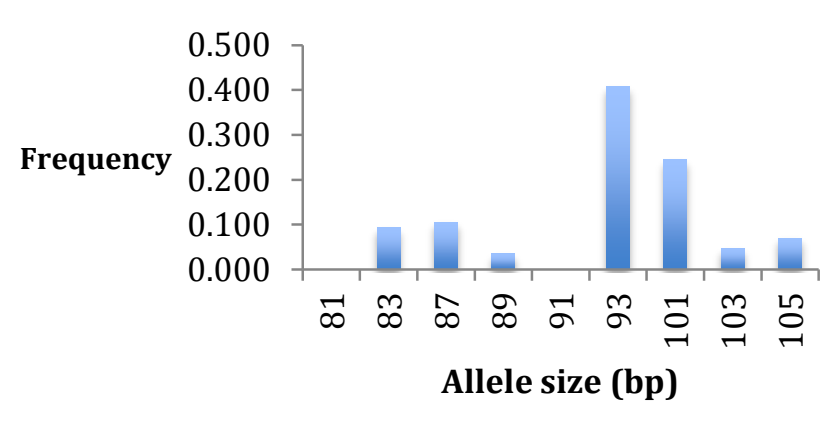

\section{Hawkes Bay}

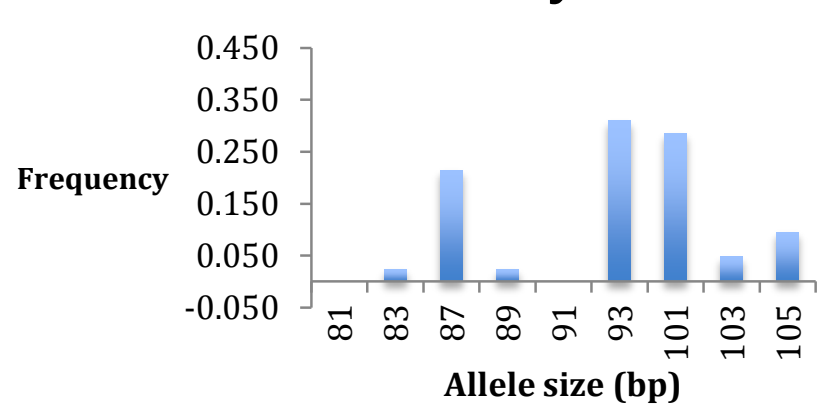

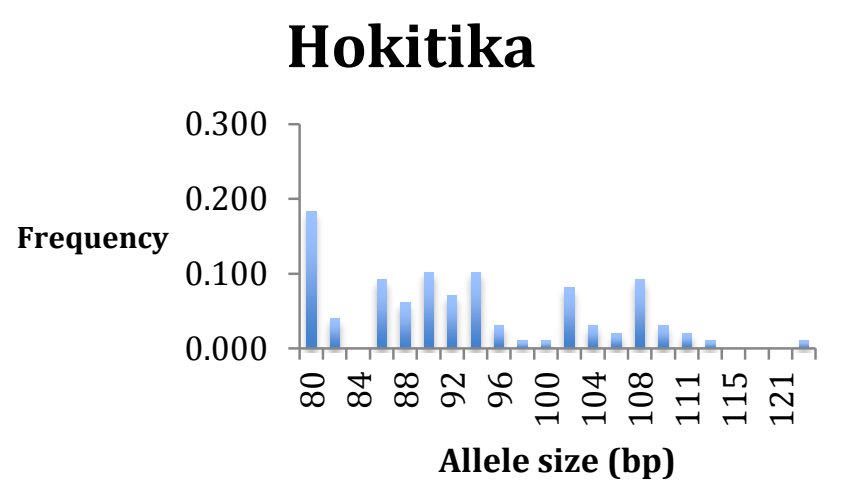

\section{Makara}

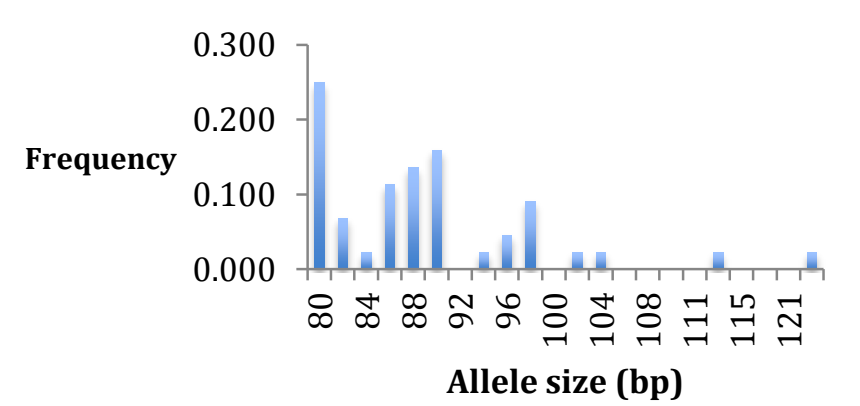

GJLBS2
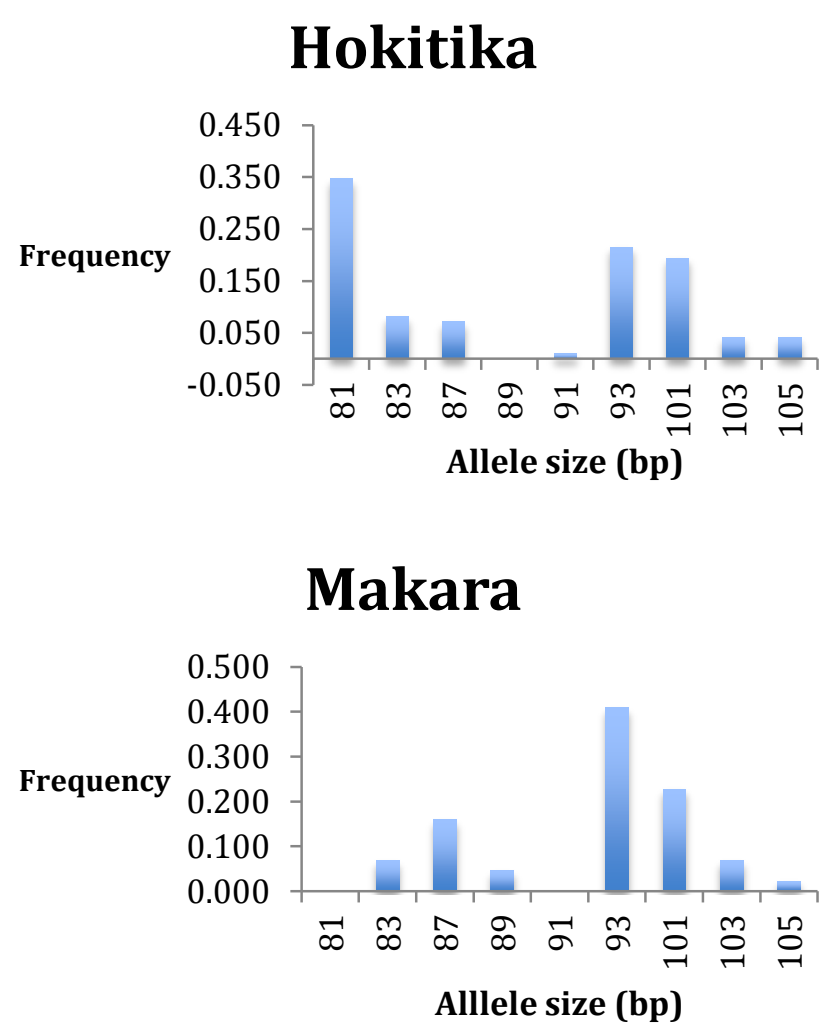
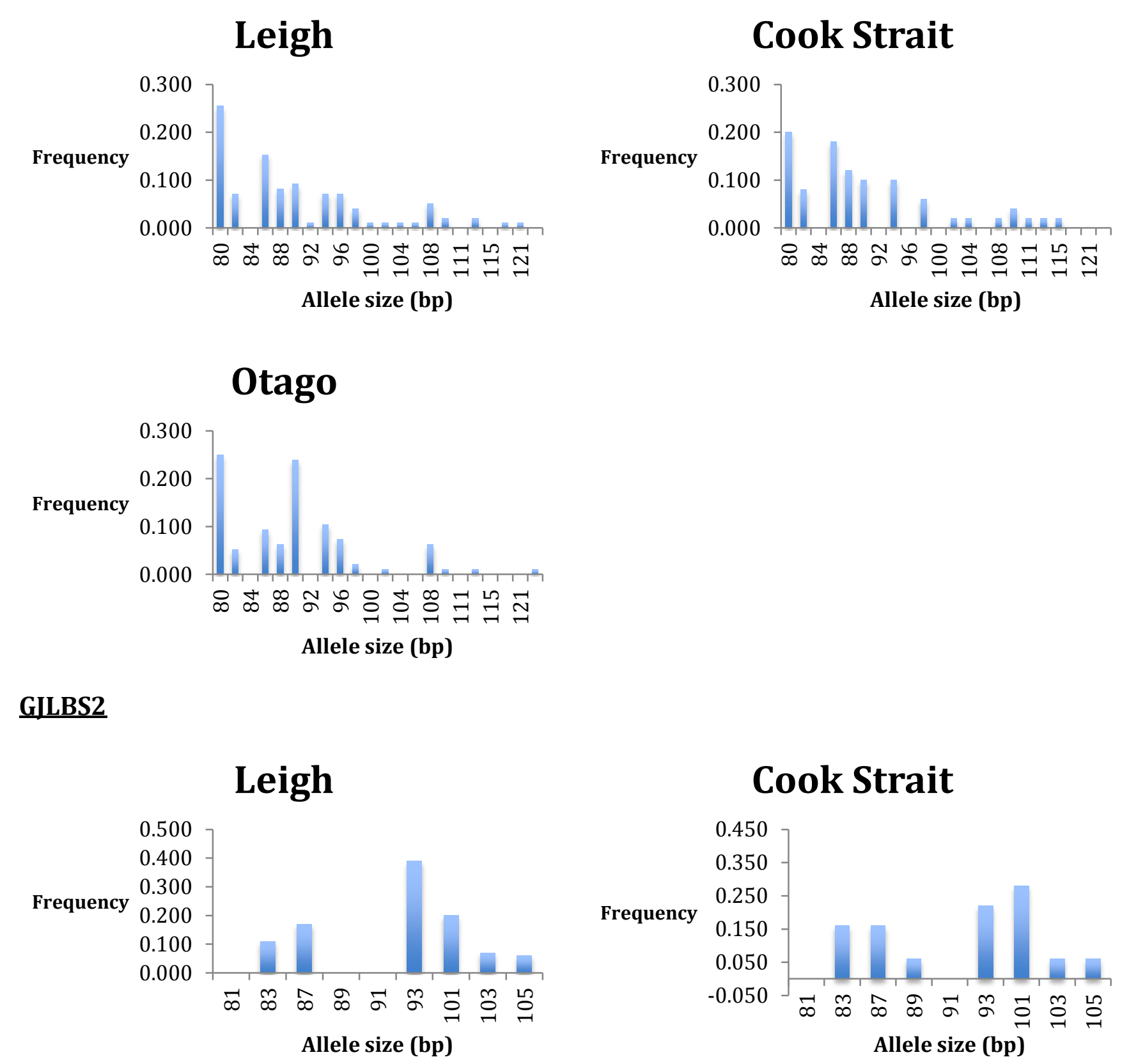


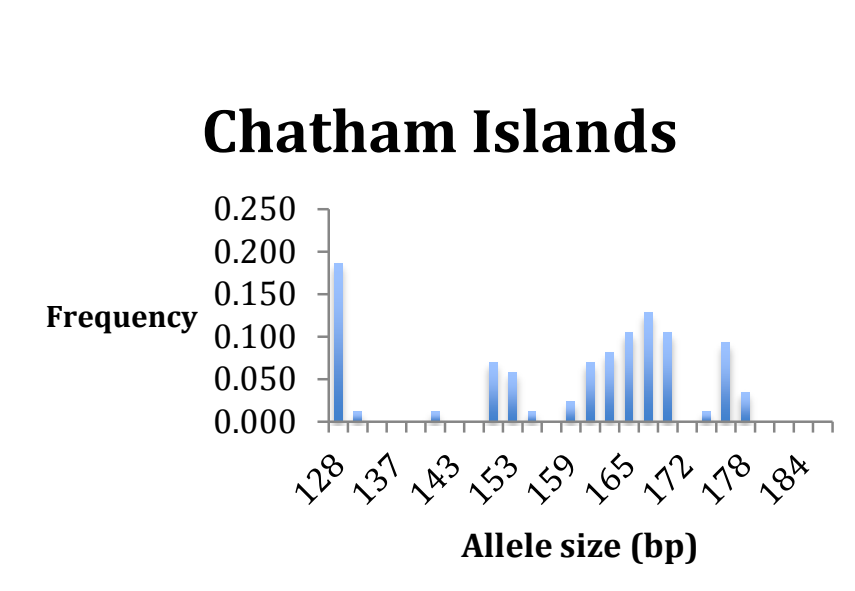

\section{Hawkes Bay}

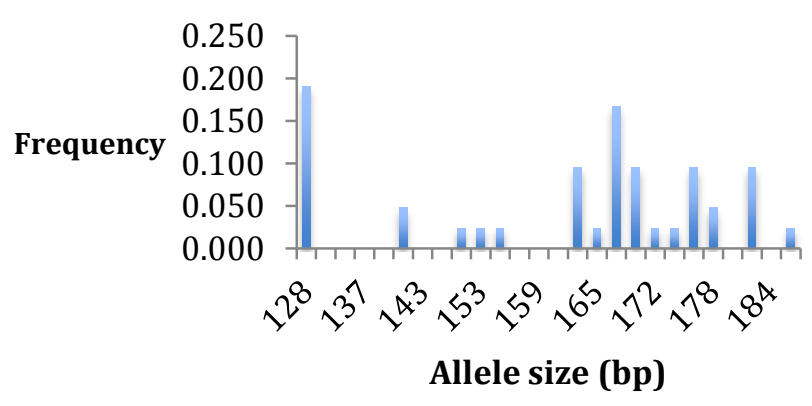

\section{Chatham Islands}
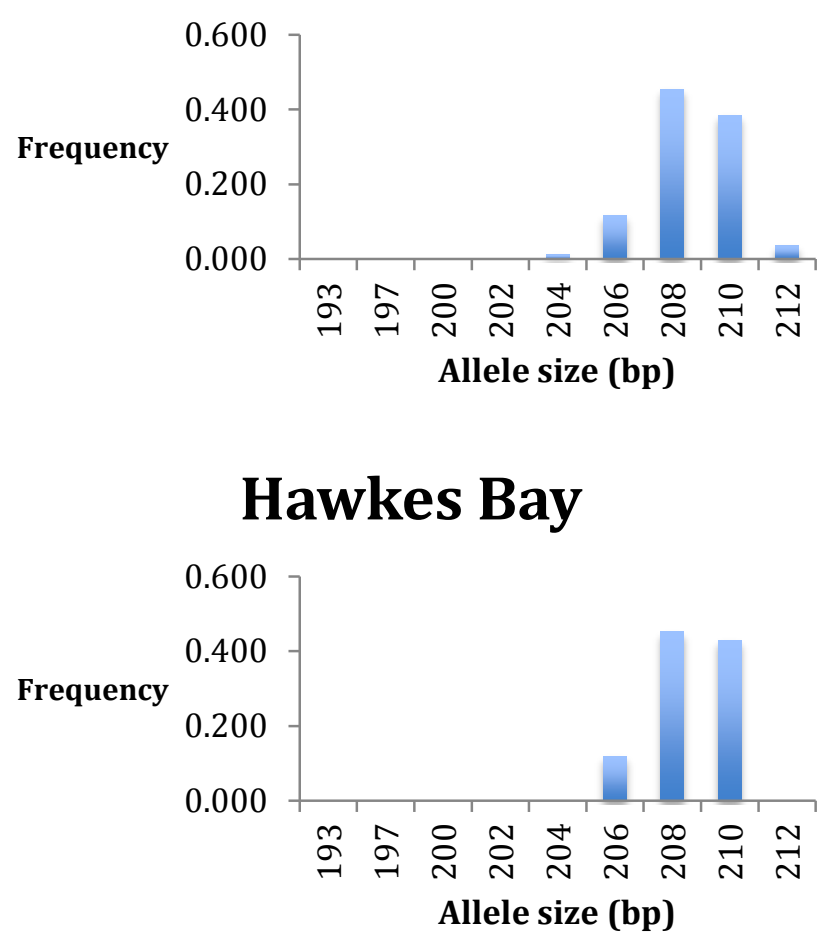

\section{$\underline{\text { Pam010 }}$}
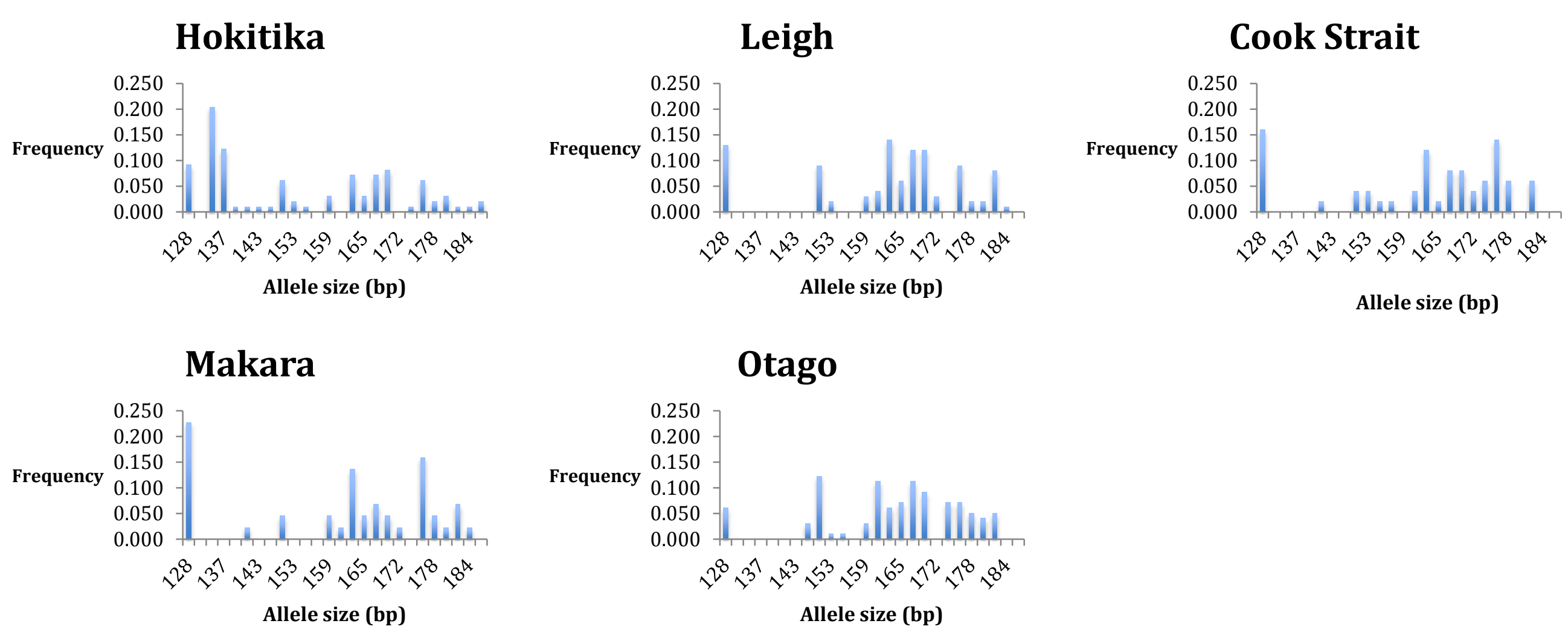

Pam017
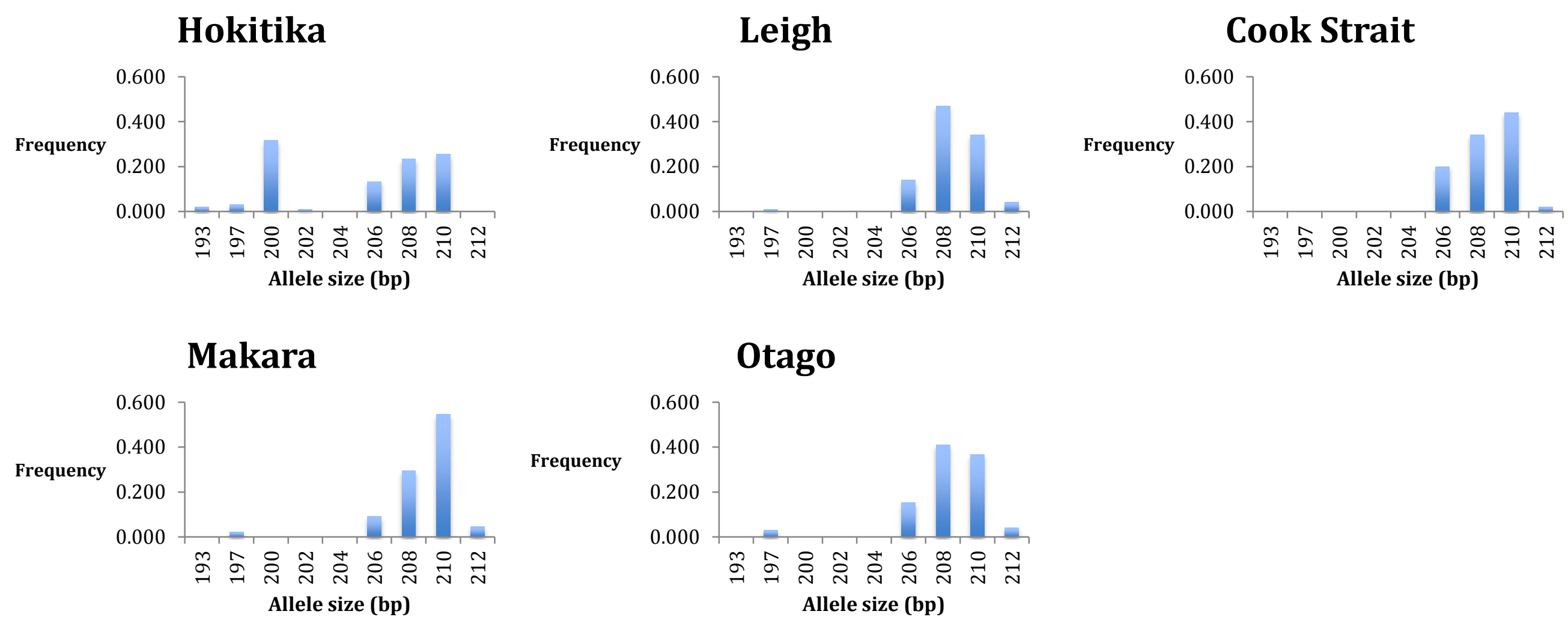

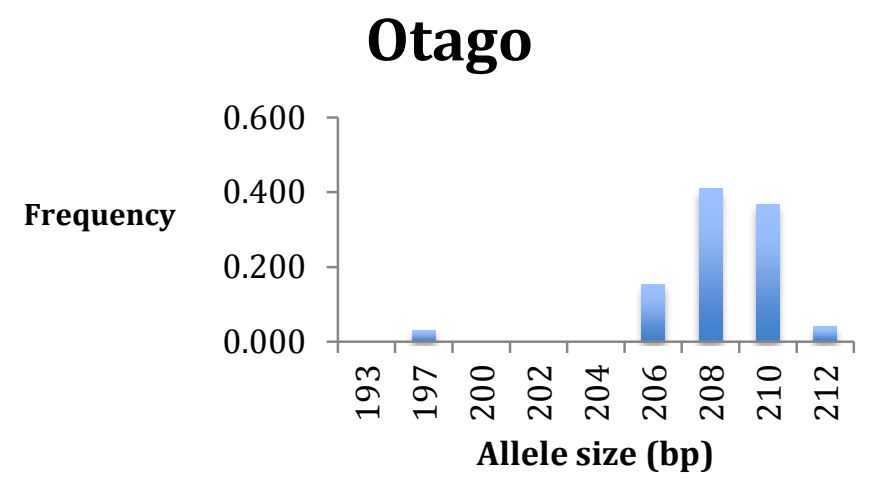




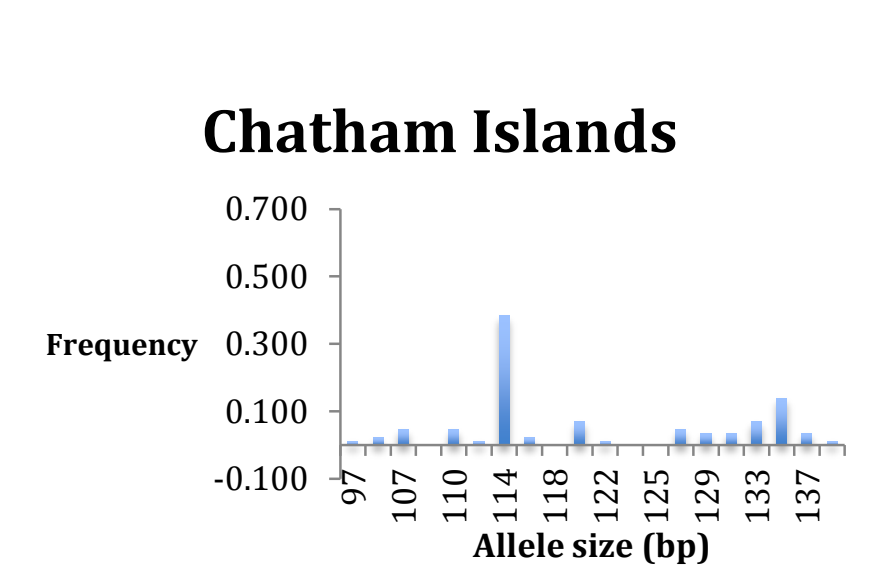

\section{Hawkes Bay}

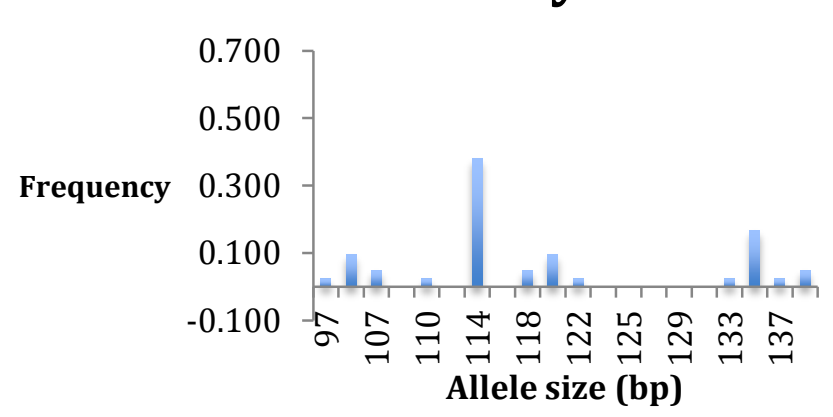

\section{Chatham Islands}

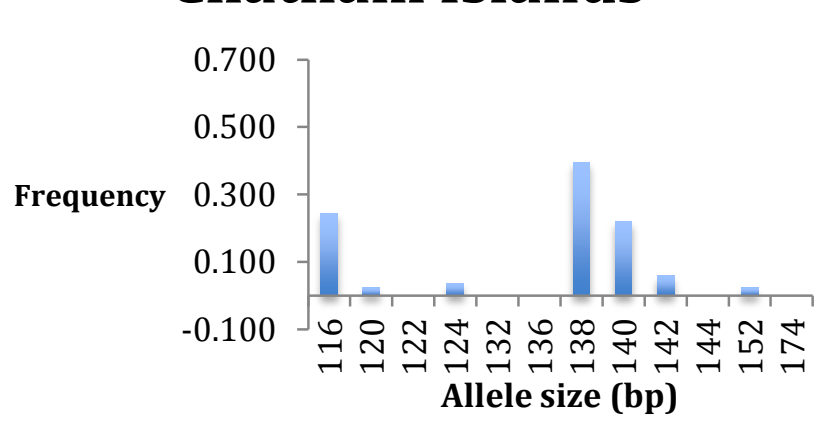

\section{Hawkes Bay}

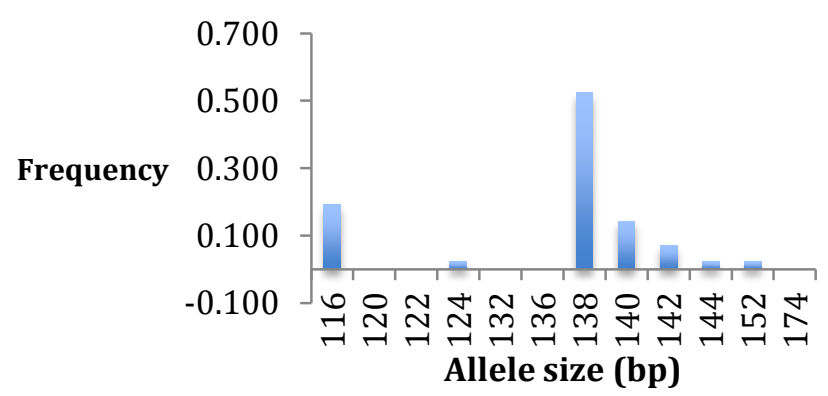

Pam021
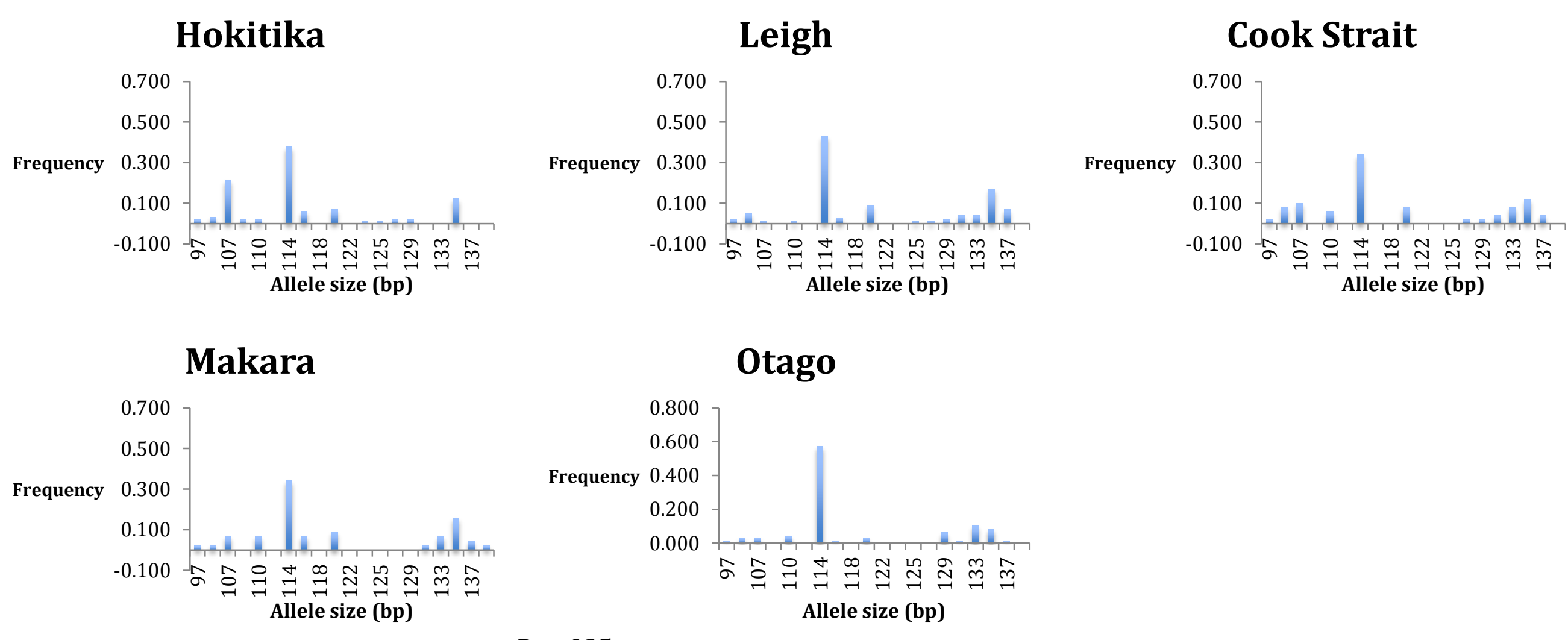

$\underline{\text { Pam025 }}$
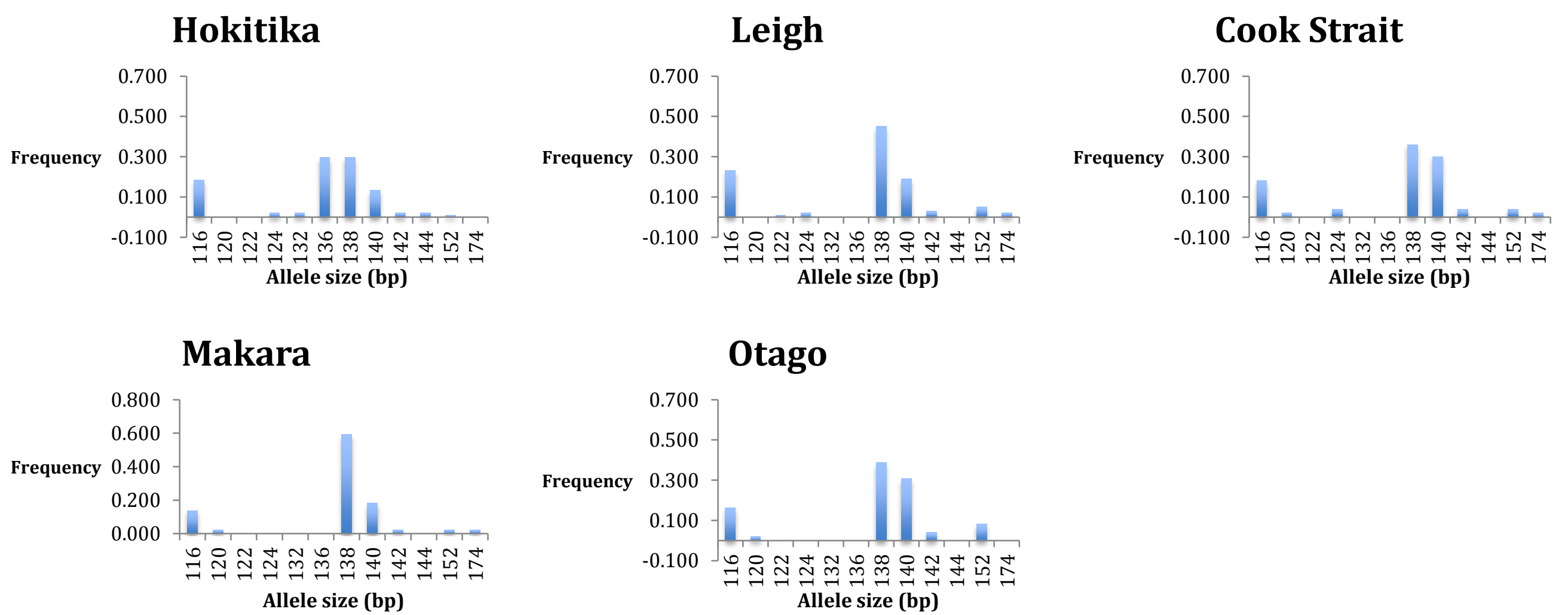


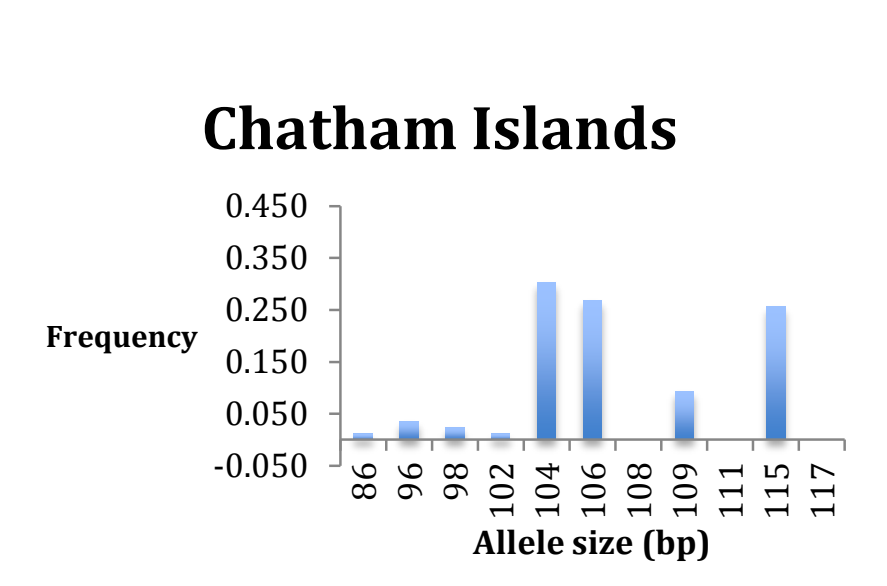

\section{Hawkes Bay}

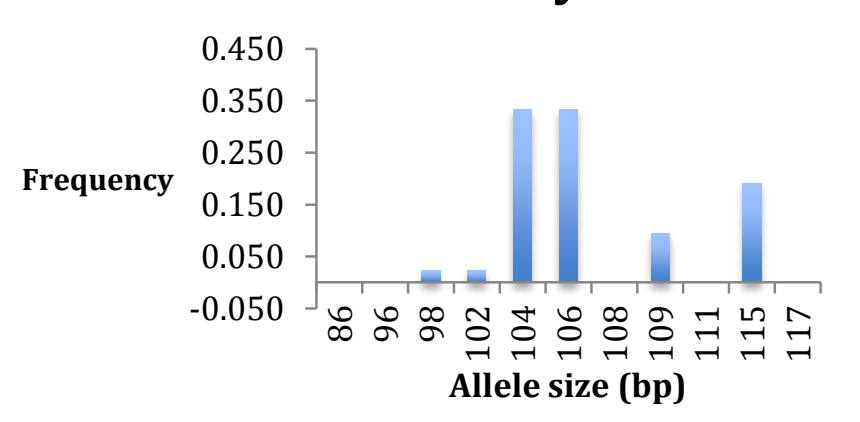

\section{Chatham Islands}

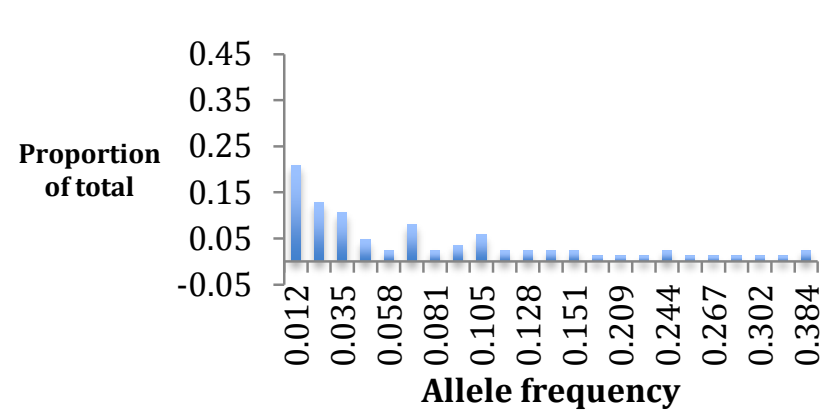

Hawkes Bay

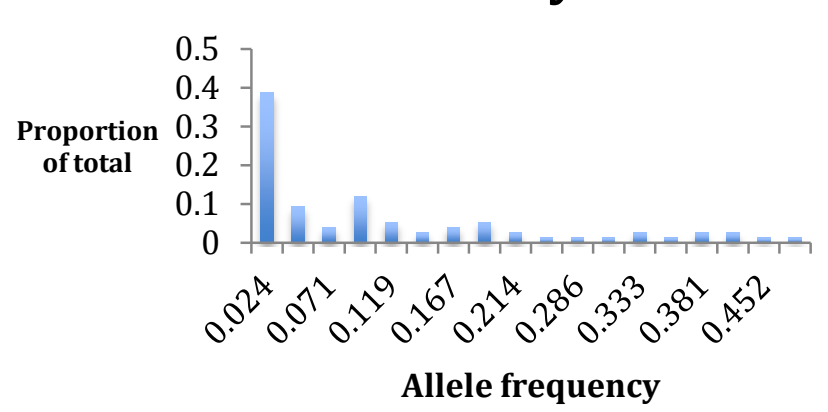

$\underline{\text { Pam035 }}$
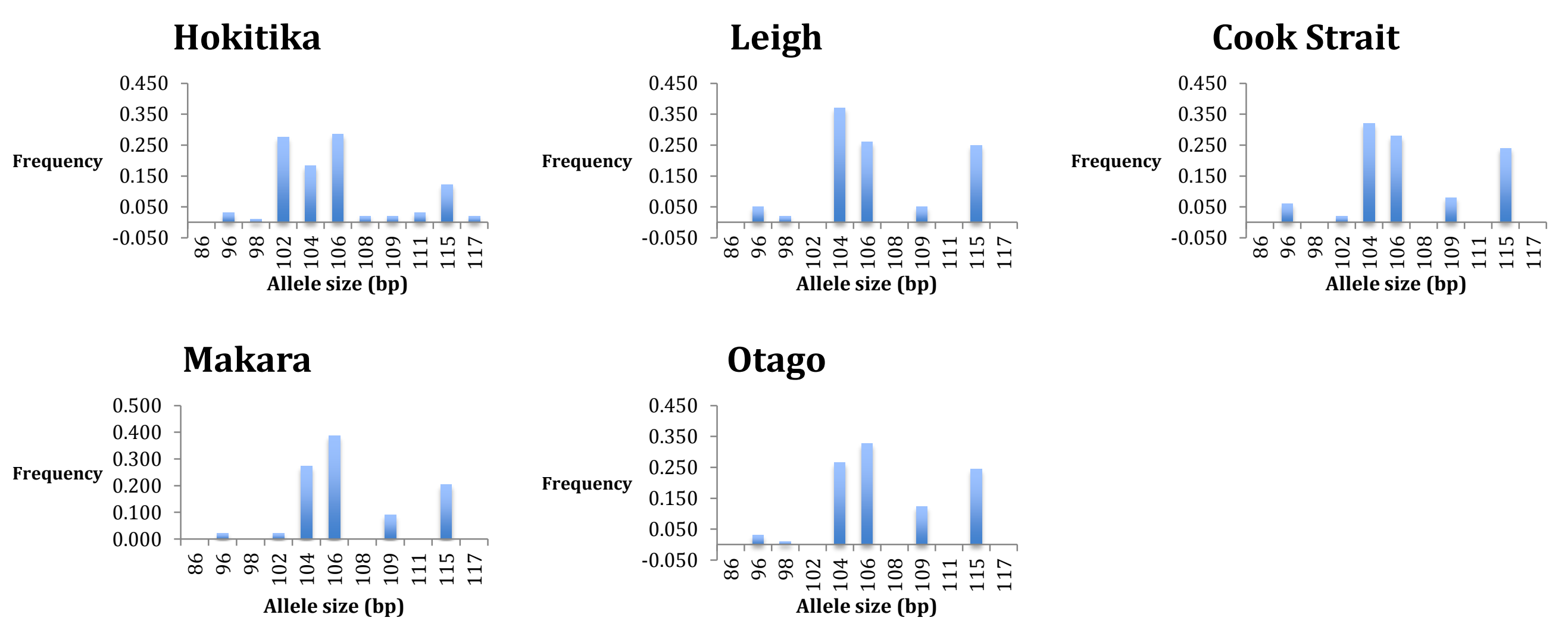

Figure 3.17 Allele frequency distribution of each locus for each sampled site
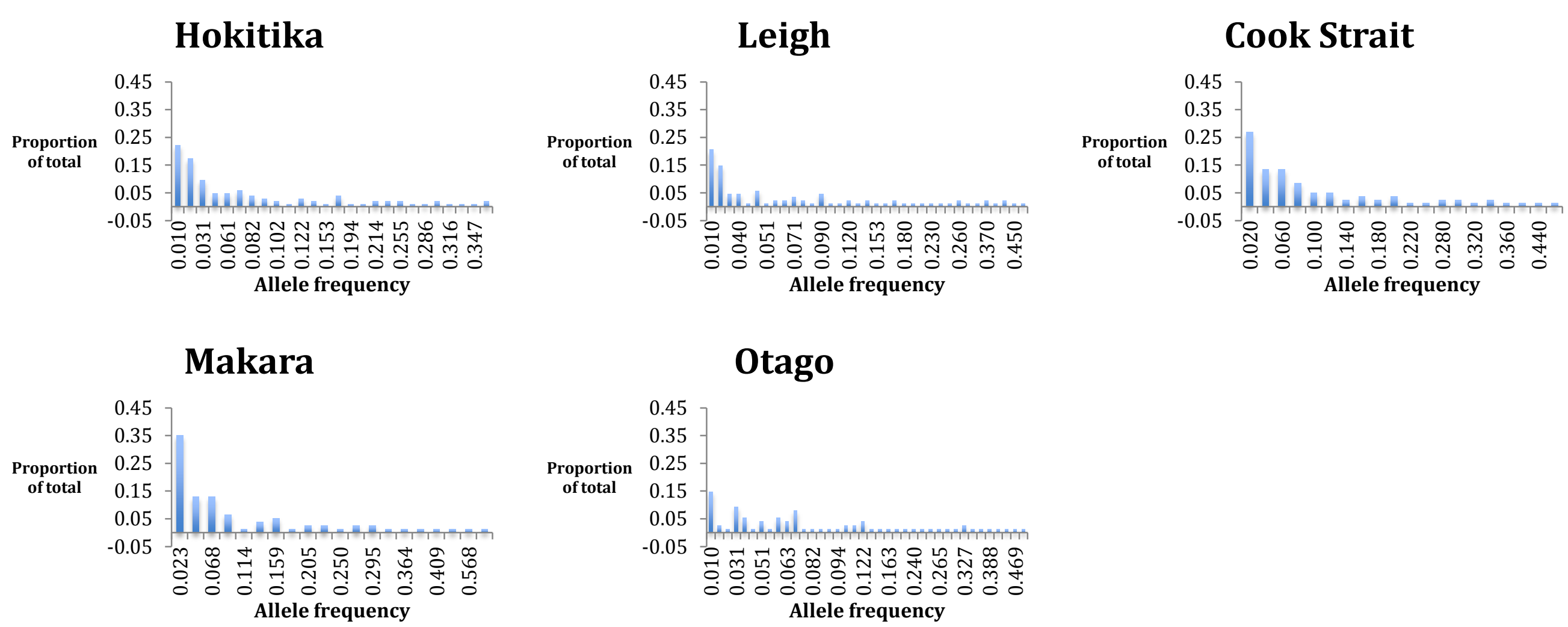


\section{Chapter Four}

\section{Genetic variability between hatchery and wild populations of Polyprion oxygeneios based on mitochondrial DNA control region sequences and microsatellite DNA genotyping}

\section{$\underline{4.1 \text { Introduction }}$}

There has been significant interest in the development of Polyprion oxygeneios (hapuku) as a high-value finfish for New Zealand aquaculture because of its excellent meat quality and premium market position (Symonds et al., 2012). The farming of P. oxygeneios has been developed at the hatchery scale, with commercial production systems anticipated in the near future (Zeldis et al., 2011). To date, only 10 - 15 ha of space has been developed for commercialscale marine finfish (Oncorhynchus tshawystscha) farming in New Zealand (Forrest et al., 2011). However, recent interest in the development of finfish aquaculture in New Zealand has led to an allocation of 390 ha of water space within the Firth of Thames (north east of the North Island), exclusively for the farming of finfish; primarily targeting P. oxygeneios and Seriola lalandi (kingfish)(Forest et al., 2011).

Information on genetic diversity of the broodstock and wild populations is required to ensure an appropriate level of genetic diversity is captured in the founding broodstock and is maintained through successive generations (Liu and Cordes 2004; Ha et al., 2009). A broodstock of an aquaculture species is established from individuals taken from wild populations, and like any farming, it relies on an "elite" breeding population that has the potential to perform well in captivity. It is desirable to have a high level of genetic diversity represented in the founding broodstock because it will largely determine the fitness of the offspring and the response to selective breeding. A number of failed attempts in finfish aquaculture have been attributed to low levels of genetic diversity in the founding broodstock (Teichert-Coddington and Smitherman 1988; Huang and Liao 1990). 
Population founding events experienced during broodstock collection can limit the level of diversity in the hatchery population (Pompoulie et al, 2006). Moreover, genetic diversity can be further reduced by certain hatchery practices in the absence of appropriate pedigree records (Frost et al., 2006). Due to the complex, and often random, natural mating system of fish, it can be logistically difficult to ensure a relatively equal parental contribution during spawning (Symonds et al., 2012). A disproportionate contribution of eggs and sperm by a few individuals will decrease the effective population size of the broodstock. A reduction in the effective population size can lead to lower levels of genetic diversity in subsequent generations and can often result in highly inbred offspring (Su et al., 1996). A reduction in the hatchery population's fitness as a consequence of inbreeding can be a problem for any farming activity, and is a major issue in finfish hatcheries (Gjerde et al., 1983). Wild populations of fish typically have large population sizes that enable them to maintain high levels of genetic diversity. While high levels of genetic diversity are beneficial for greater gains from selective breeding, deleterious gene variants can be concealed as heterozygote genotypes and subsequently become exposed as homozygotes if genetically similar individuals breed (Brummett et al., 2004). Establishing a genetically diverse broodstock and maintaining these diversity levels through parentage analysis and controlled breeding (Symonds et al., 2012) is critical to the long-term productivity of the broodstock.

Molecular DNA markers have been successfully applied to determine the genetic variation within and differentiation among cultured and wild populations (Ha et al., 2009). Lower levels of genetic diversity in a broodstock compared with wild populations are common and have been documented in a number of species e.g. turbot (Scophthalmus maxmimus)(Coughlan et al., 1988) and Atlantic salmon (Salmo salar)(Skaala et al., 2004). Because the wild genetic constitution of $P$. oxygeneios has been previously described (see Chapter Three), a comparison can now be made between NIWA's research broodstock held at the Bream Bay Aquaculture Park, and wild populations using microsatellite and mitochondrial DNA markers. The aim of the research presented in this chapter was to describe and compare the levels of genetic diversity present within the cultured and wild populations of $P$. oxygeneios. 


\section{$\underline{4.2}$ Methods}

\subsubsection{Sampling}

The mitochondrial DNA sequencing and microsatellite genotyping was completed for the research broodstock of wild P. oxygeneios held at NIWA's Bream Bay Aquaculture Park (figure 4.1). The F1 research broodstock were genotyped only. All assays in this research were done using the same molecular markers as described in Chapter Three. The wild broodstock were caught off the east coast of northern New Zealand and within the Cook Strait between 2002 and 2009. The F1 constitutes individuals produced from two spawning seasons: 2008 and 2010. Communal spawning wild broodstock produced all F1. In the 2008 season, the F1 were produced from two spawning tanks from a total of 21 females and 18 males. In the 2010 season, the F1 were produced from a total of 26 females and 15 males from two spawning tanks.

Fin clips were taken during scientific operations by researchers at NIWA's Bream Bay Aquaculture Park. A total of 74 wild broodstock individuals were sequenced, 98 wild broodstock individuals were genotyped and 4712 F1 individuals were genotyped. Initially 113 and 5005 individuals from the wild broodstock and F1, respectively, were genotyped; however, individuals with missing data were excluded from the analyses. For PCR protocols and primer information please refer to Chapter Three sections 3.2.2 \& 3.2.3. 


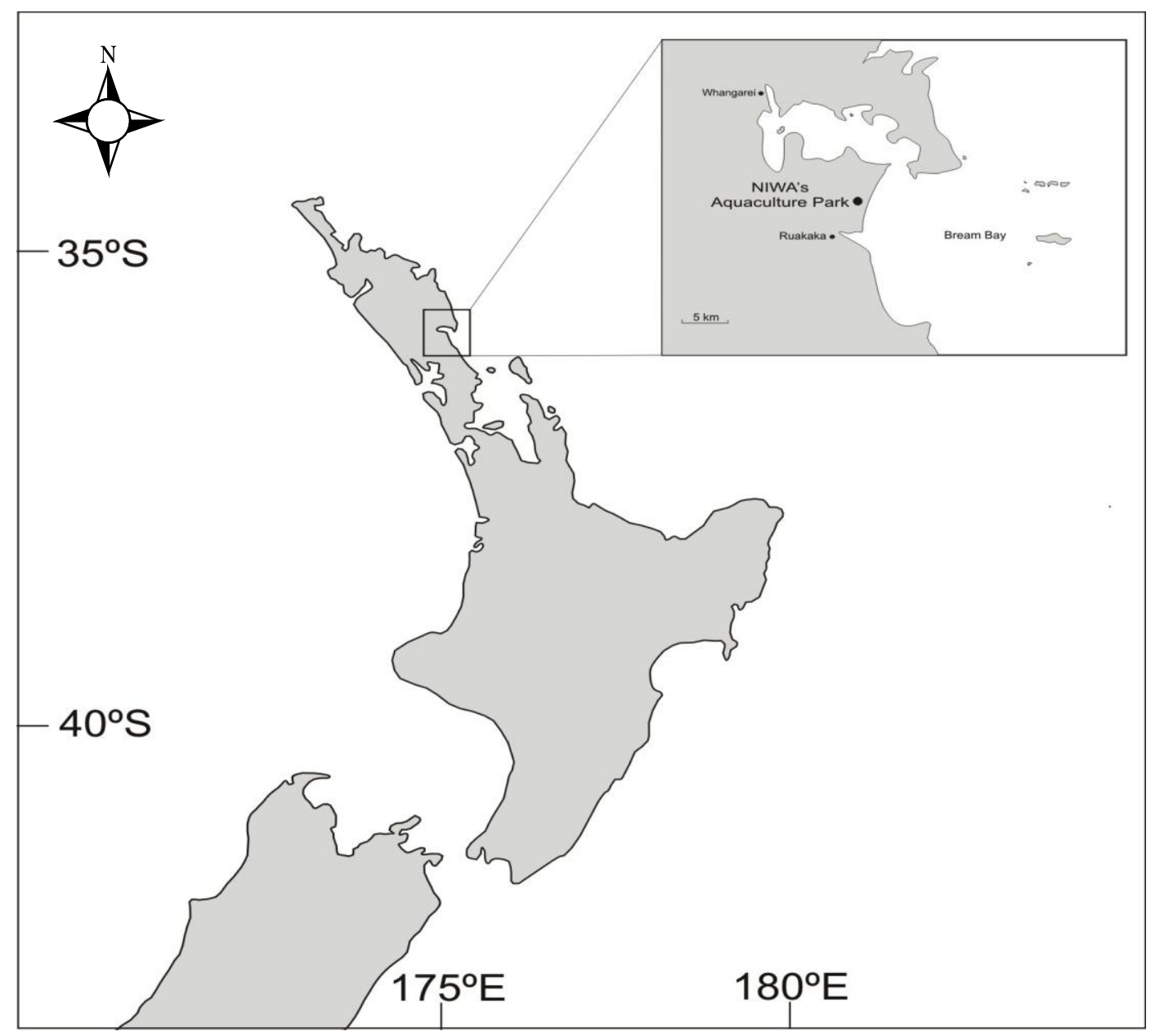

Figure 4.1 Location of NIWA's Bream Bay Aquaculture Park

\subsubsection{Genetic diversity}

\section{Mitochondrial}

The summary statistics for the level of genetic diversity in each population included: the number of polymorphic (segregating) sites $(S)$, the number of haplotypes $\left(N_{h}\right)$, haplotype diversity $(h)$, nucleotide diversity $(\pi)$ and private haplotypes $\left(\mathrm{P}_{h}\right)$. They were calculated in DnaSP 5.10.01 (Librado and Rozas 2009). Haplotype frequencies of the wild broodstock were calculated in DnaSP 5.10.01, graphed in Microsoft Excel, edited and visually represented in CorelDRAW. 


\section{Microsatellite}

Micro-checker 2.2.3 (Oosterhout et al., 2004) was used to identify any deviation from the Hardy-Weinberg equilibrium (HWE) by either large allele drop-out, scoring errors due to stuttering, or the presence of null alleles. The average number of alleles per locus and the values of observed and expected heterozygosity were calculated in Arlequin 3.11 (Excoffier et al., 2005). The total number of alleles, private alleles and allele frequency distribution graphs were generated in Genalex 6.5b3 (Peakall and Smouse 2006). The allelic and private allelic richness was determined in HP-RARE 1.1 (Kalinowski 2005), and the inbreeding coefficients were calculated in FSTAT 2.9.3 (Goudet 1995). As Hokitika is genetically differentiated from other wild locations (Chapter Three), it has been removed from all analyses unless other wise stated.

A Principle Component Analysis (PCA) was used to examine the genetic relationship between the wild broodstock and all wild sites (the F1 were not included in this analysis). The PCA was conducted on all populations with Genalex 6.5b3 using the standardised covariance method. A Bayesian approach was used to test for any genetic clusters within the program STRUCTURE 2.3.2 (Pritchard et al., 2000). The assignment of every individual to a 'population' (K) was achieved under the admixture model, with a Markov Chain Monte Carlo (MCMC) simulation run for $10^{6}$ steps and burn-in period of $10^{4}$ steps. The K value ranged from 1 - 8 and STRUCTURE Harvester 0.6.92 (Earl and von Holdt 2012) was used to estimate the optimum number of K using the Delta K estimator.

The program BOTTLENECK 1.2.02 (Piry et al., 1999) was used to test whether there was any genetic evidence of a population bottleneck in the wild broodstock and F1. A test for an excess of heterozygotes was implemented; with expected levels of heterozygosity being estimated from the observed alleles at each locus and a distribution of heterozygosity was generated based on 1,000 replications under the stepwise mutation model (SMM), infinite allele model (IAM) and the two-phase model (TPM). The interpretation of results focused on the TPM as it is recommended as a better fit than SMM and IAM (Piry et al., 1999). The TPM was set incorporating 95\% SMM and 5\% IAM. 


\subsubsection{Representation of wild genetic diversity in culture}

The percentage of alleles that were present at the wild sites but absent in the broodstock was determined in a broodstock selection program (Ashton unpublished data) written in Python 2.6. This script uses the Python module xlwt to produce a Microsoft Excel output file. This program was designed to use microsatellite DNA data to compare broodstock and wild populations, to simulate the addition of new individuals into the current broodstock, and to compare simulations of selecting a new broodstock. Currently, the script supports the use of one broodstock population and up to ten wild populations.

The focus of these analyses was a genetic comparison between wild sites and the wild broodstock, hence the F1 were not used in these analyses. Two different approaches were used to explore the level of wild genetic variation represented within the wild broodstock. Firstly, the script was used to plot the percentage of alleles frequencies found at each wild site against those alleles not represented in the broodstock. Hokitika was incorporated into only this simulation to highlight the significant genetic differentiation. In addition, the mean frequency of alleles across all wild sites was compared to their respective frequencies found in the broodstock. All simulations were run at 1,000 permutations.

Secondly, a simulation was run to test whether increasing the wild broodstock with individuals caught off Leigh could result in any genetic gains. Leigh was chosen for this analysis because any additions to the broodstock will likely be collected close to this area. Each simulation was run going up in increments of five individuals, up to a total of 50 new individuals. Similarly, the effect of increasing the broodstock with individuals caught from each wild site was tested. Eight simulations were run going up in increments of six (one from each site), totaling 48 new individuals added to the broodstock. All tests were run at 1,000 permutations.

A simulation was run at 1,000 permutations to test the level of sampling required to establish a new broodstock that would be representative of the wild genetic variation from Coromandel in the northeast of the North Island, and the 
Marlborough Sounds at the top of the South Island (two identified areas for $P$. oxygeneios farming). Wild sample locations of Leigh, Cook Strait and Makara were chosen for this test. Both Cook Strait and Makara were chosen to simulate collection for a Marlborough Sounds' broodstock, and Leigh to simulate Coromandel's broodstock. Simulations were run up to a total of 50 individuals in increments of five. A further simulation was run to test the establishment of new broodstock comprised of individuals from all wild sites. The simulation was run at 1,000 permutations going up in increments of six (one individual per population) up to a total of 54 individuals.

\section{$\underline{4.3 \text { Results }}$}

\section{$\underline{4.3 .1 \text { Genetic diversity }}$}

The DNA sequence of the mitochondrial DNA control region was determined for 74 wild NIWA individuals. The aligned DNA sequences had 30 polymorphic sites, and $\pi=0.01129$. A total of 22 haplotypes were recorded and haplotype diversity was 0.820 . There were 4 private haplotypes observed. The diversity indices of the wild broodstock were similar to the sample sites reported in Chapter Three (table 4.1). Referring to figure 4.2, the wild broodstock is represented by all high frequency haplotypes observed within all other wild sample sites. Moreover, they are roughly at the same frequency in the broodstock as they are found in the wild.

Table 4.1 Sampled sites, number of individuals sampled $(N)$, the average number of nucleotide differences $(S)$, the number of haplotypes $\left(N_{h}\right)$, haplotype diversity $(h)$, nucleotide diversity $(\pi)$, and number of private haplotypes $\left(\mathrm{Ph}_{\mathrm{h}}\right)$

\begin{tabular}{ccccccc}
\hline Location & $\boldsymbol{N}$ & $\boldsymbol{S}$ & $\boldsymbol{N}_{\boldsymbol{h}}$ & $\boldsymbol{h}$ & $\boldsymbol{\pi}$ & $\boldsymbol{P}_{\boldsymbol{h}}$ \\
\hline Leigh & 49 & 30 & 19 & 0.894 & 0.01153 & 2 \\
Hawkes Bay & 22 & 27 & 15 & 0.957 & 0.01370 & 4 \\
Cook Strait & 25 & 28 & 13 & 0.880 & 0.01170 & 4 \\
Makara & 21 & 19 & 8 & 0.805 & 0.01131 & 1 \\
Kaikoura & 39 & 29 & 16 & 0.853 & 0.01258 & 1 \\
Otago & 49 & 32 & 18 & 0.808 & 0.01216 & 3 \\
Hokitika & 45 & 23 & 17 & 0.822 & 0.00928 & 4 \\
Chatham Island & 44 & 28 & 17 & 0.878 & 0.00934 & 2 \\
Wild Broodstock & $\mathbf{7 4}$ & $\mathbf{3 0}$ & $\mathbf{2 2}$ & $\mathbf{0 . 8 2 0}$ & $\mathbf{0 . 0 1 1 2 9}$ & $\mathbf{4}$ \\
\hline
\end{tabular}




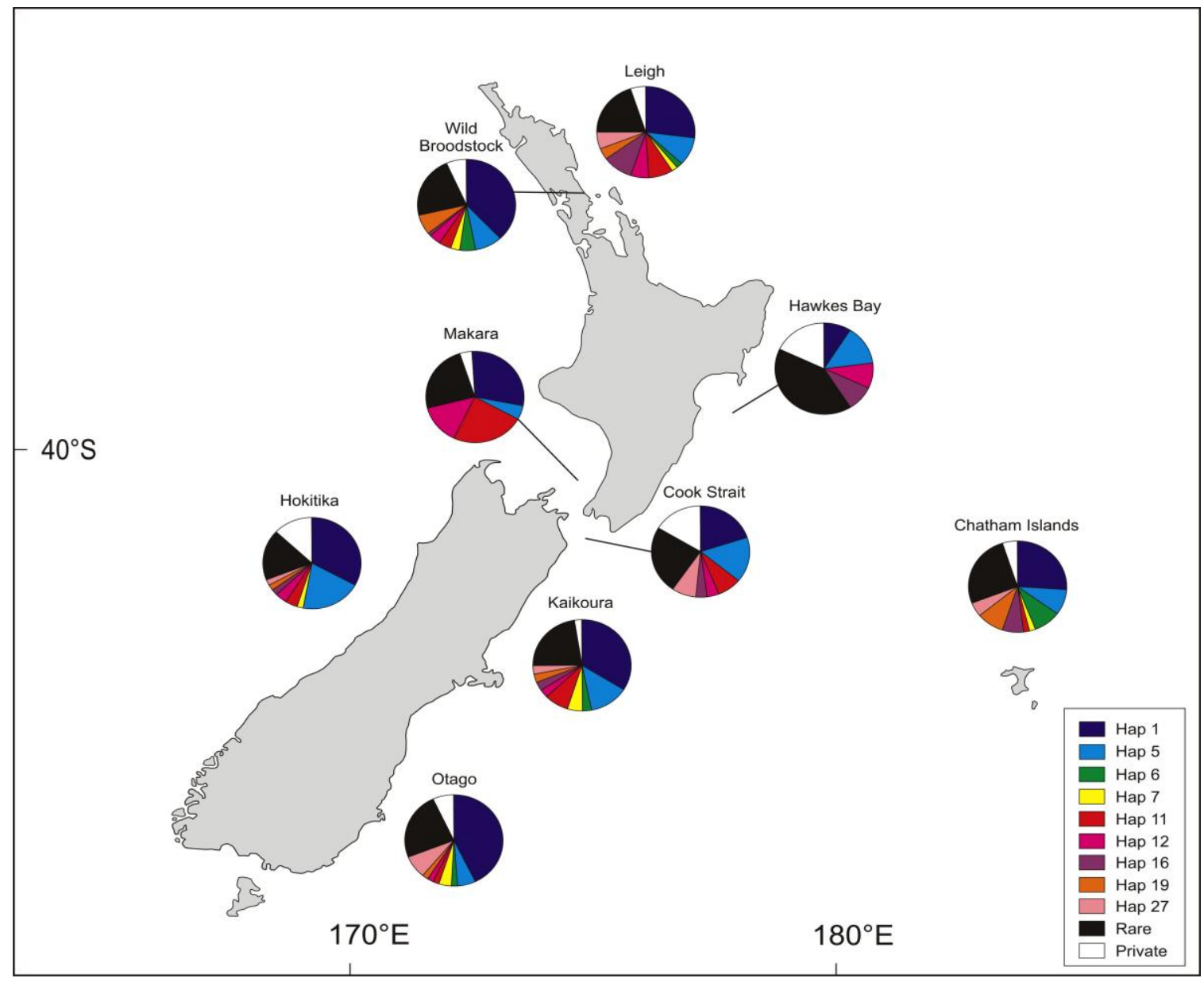

Figure 4.2 The frequency of haplotypes found within the wild broodstock in comparison to the other wild populations. Rare haplotypes (not in the 11 most common) and private haplotypes are shown

Micro-checker did not find any evidence of linkage disequilibrium, scoring errors or null alleles in the microsatellite DNA data (NIWA wild and F1). There was a high amount of polymorphism found across the microsatellites used. The number of alleles per locus per site ranged from five (Pam017) in the F1 to 19 (GJLKPX, Pam010) in the wild NIWA broodstock. The wild broodstock had more observed alleles (106) than the F1 (90). Subsequently, the wild broodstock also had a higher average number of alleles per locus (11.7) and allelic richness (10.07) than the F1. Moreover, there was also a higher observation of private alleles recorded in the wild broodstock (25) compared to the F1 (6)(table 4.2). Significant deviations from the HWE were observed across all loci in the F1, while all loci in the wild broodstock were in HWE (table 4.3). 
Table 4.2 Sampled sites, number of individuals sampled $(N)$, total number of alleles (a), average number of alleles per locus $(\mathrm{Na})$, allelic richness $\left(A_{\mathrm{r}}\right)$, private alleles $(\mathrm{P})$, private allelic richness

$\left(P A_{r}\right)$, inbreeding coefficient $\left(F_{\text {is }}\right)$

\begin{tabular}{cccccccc}
\hline Location & $\boldsymbol{N}$ & $\mathbf{a}$ & $\mathbf{N a}$ & $\mathbf{A}_{\mathbf{r}}$ & $\mathbf{P}$ & $\mathbf{P A}_{\mathbf{r}}$ & $\mathbf{F}_{\text {is }}$ \\
\hline Leigh & 49 & 88 & 9.7 & 6.38 & 3 & 0.25 & -0.011 \\
Hawkes Bay & 21 & 75 & 8.3 & 6.43 & 2 & 0.48 & -0.022 \\
Cook Strait & 25 & 82 & 9.1 & 6.93 & 3 & 0.35 & -0.026 \\
Makara & 22 & 77 & 8.5 & 6.49 & 2 & 0.27 & -0.057 \\
Otago & 48 & 75 & 8.3 & 6.06 & 0 & 0.12 & -0.017 \\
Hokitika & 49 & 104 & 11.5 & 7.18 & 18 & 1.45 & 0.237 \\
Chatham Island & 43 & 86 & 9.5 & 6.46 & 4 & 0.28 & 0.056 \\
Wild Broodstock & $\mathbf{9 8}$ & $\mathbf{1 0 6}$ & $\mathbf{1 1 . 7}$ & $\mathbf{1 0 . 0 7}$ & $\mathbf{2 5}$ & $\mathbf{2 . 9 0}$ & $\mathbf{- 0 . 0 3 3}$ \\
$\mathbf{F 1}$ & $\mathbf{4 7 1 2}$ & $\mathbf{9 0}$ & $\mathbf{1 0}$ & $\mathbf{8 . 1 6}$ & $\mathbf{6}$ & $\mathbf{0 . 9 9}$ & $\mathbf{- 0 . 0 4 0}$ \\
\hline
\end{tabular}

The Bayesian cluster analysis identified two distinct genetic clusters $(\mathrm{K}=2)$, with both clusters being equally distributed throughout all eight sites analysed (figure 4.4). The PCA revealed that the first two axes explained $53.96 \%$ and $30.72 \%$ of the total genetic variation respectively. The wild broodstock was located near the main cluster of sampled sites, with most of the genetic variation being explained through Otago (figure 4.3).

There was no evidence of a genetic bottleneck during the founding of the wild broodstock or during captive spawning as inferred by BOTTLENECK 1.2.02. All sites were in equilibrium under the three mutational models, except the F1 were significant for an excess of heterozygotes under the IAM $(P<0.001)$.

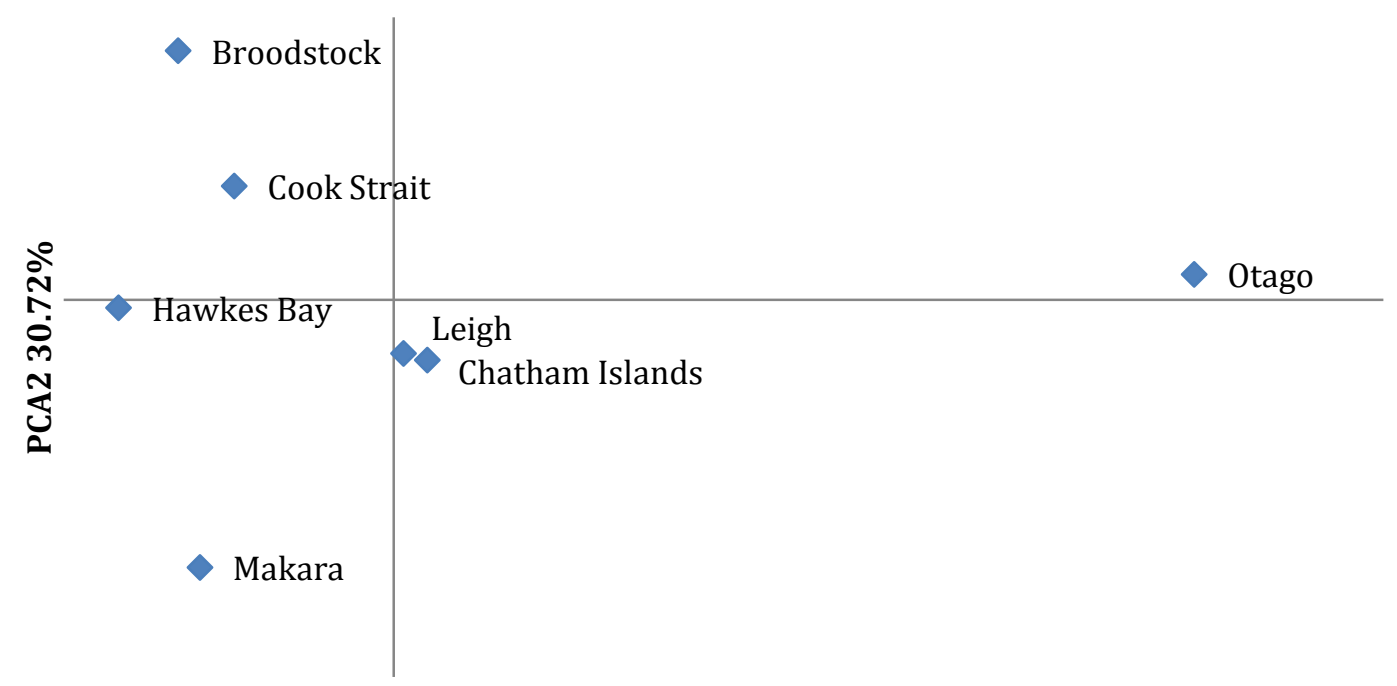

PCA $153.96 \%$ 
Table 4.3 Number of individuals genotyped $(N)$, number of alleles found (a), observed heterozygosity $\left(\mathrm{H}_{\mathrm{o}}\right)$, expected heterozygosity $\left(\mathrm{H}_{\mathrm{e}}\right)$; $P$, bold values sig < 0.05 across nine microsatellite loci for the wild broodstock and F1

\begin{tabular}{|c|c|c|c|c|c|c|c|c|c|}
\hline $\begin{array}{l}\text { Site, } \\
\text { Locus }\end{array}$ & GJLKPX & Pam010 & Pam021 & Pam035 & GG0Q6A & GH00IK & GJSLB2 & Pam017 & Pam025 \\
\hline \multicolumn{10}{|l|}{ Wild } \\
\hline$N$ & 98 & 98 & 98 & 98 & 98 & 98 & 98 & 98 & 98 \\
\hline $\mathbf{a}$ & 19 & 19 & 18 & 7 & 11 & 7 & 7 & 5 & 13 \\
\hline $\mathbf{H}_{\mathrm{o}}$ & 0.898 & 0.959 & 0.796 & 0.827 & 0.776 & 0.633 & 0.816 & 0.745 & 0.714 \\
\hline $\mathbf{H}_{\mathbf{e}}$ & 0.869 & 0.907 & 0.776 & 0.758 & 0.720 & 0.671 & 0.810 & 0.692 & 0.732 \\
\hline$P$ & 0.256 & 0.771 & 0.599 & 0.601 & 0.655 & 0.099 & 0.204 & 0.449 & 0.117 \\
\hline \multicolumn{10}{|l|}{ F1 } \\
\hline$N$ & 4712 & 4712 & 4712 & 4712 & 4712 & 4712 & 4712 & 4712 & 4712 \\
\hline $\mathbf{a}$ & 14 & 19 & 14 & 6 & 7 & 7 & 8 & 5 & 10 \\
\hline $\mathbf{H}_{\mathbf{o}}$ & 0.871 & 0.921 & 0.859 & 0.783 & 0.785 & 0.666 & 0.866 & 0.638 & 0.666 \\
\hline $\mathbf{H}_{\mathbf{e}}$ & 0.853 & 0.887 & 0.831 & 0.750 & 0.702 & 0.633 & 0.796 & 0.622 & 0.710 \\
\hline$P$ & $<0.001$ & $<0.001$ & $<0.001$ & $<0.001$ & $<0.001$ & $<0.001$ & $<0.001$ & $<0.001$ & $<0.001$ \\
\hline
\end{tabular}

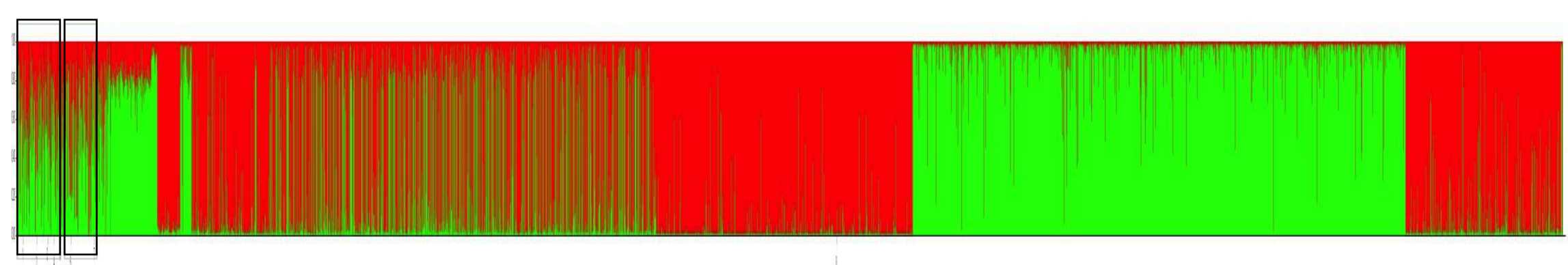

Figure 4.4 Structure analysis $(\mathrm{K}=2)$ of the wild and hatchery $P$. oxygeneios (six wild sites and two broodstock populations). A single vertical line represents each individual. All wild sites are represented in the left box, the wild broodstock is represented in the middle box and the F1 is the remainder. 


\subsubsection{Representation of wild genetic diversity in culture}

The comparison of alleles present in all wild sample sites (except for Hokitika) showed that there were similar alleles present in the broodstock. An allele that is '100\% represented in the broodstock' represents that all individuals within the broodstock have at least one copy of that respective allele. Hokitika was observed to have alleles at high frequencies (16\%,23\% and $25 \%)$ that were absent in the broodstock. For this reason, Hokitika was removed from all other analyses. Across all other sites alleles above 5\% in frequency are $100 \%$ represented in the broodstock apart from Otago. The broodstock is missing $50 \%$ of alleles at $8 \%$ in frequency in Otago (figure 4.5 ). The mean frequency of alleles across all wild sample sites indicated that all alleles over $10 \%$ in frequency within these sites are $100 \%$ represented in the broodstock. The average percentage of alleles not represented in the broodstock was under $15 \%$ for alleles between the frequency of $5 \%$ and $10 \%$ in the wild population. Rare alleles, below $5 \%$, are on average around $15-20 \%$ absent in the broodstock (figure 4.6).

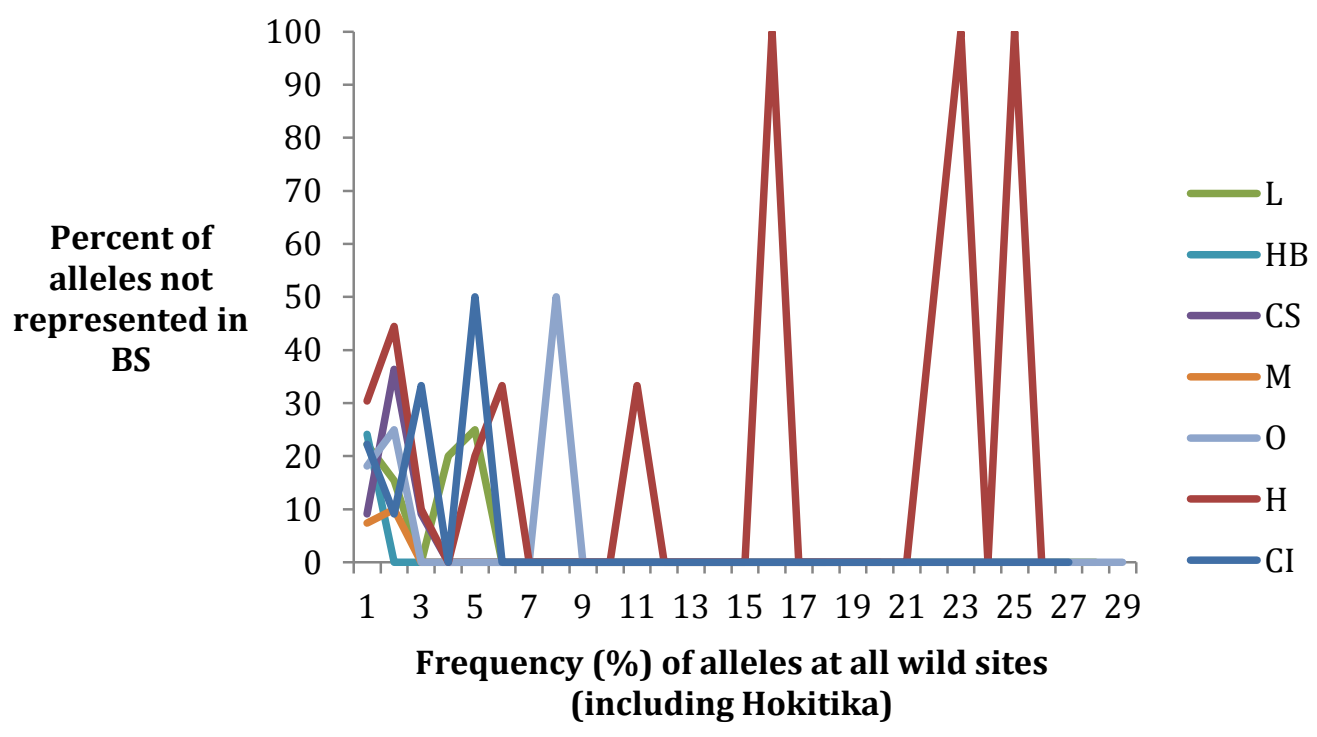

Figure 4.5 The percentage of alleles not represented in the wild broodstock in relation to their frequency at each respective wild site. L, Leigh; HB, Hawkes Bay; CS, Cook Strait; M, Makara; 0, Otago; H, Hokitika; CI, Chatham Islands. 


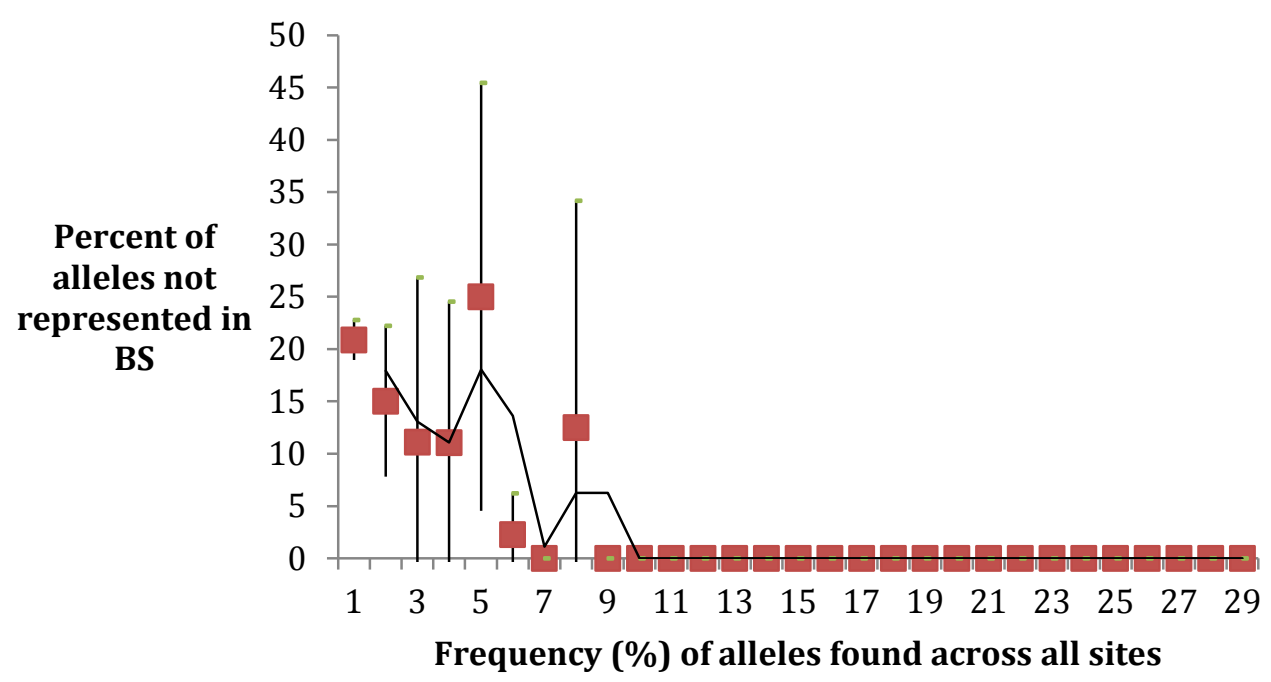

Figure 4.6 The average percentage of alleles not represented in the wild broodstock in relation to their frequency at each wild site. The vertical lines represent the max. and min. SD, with the line of moving average fitted

Any additional sampling of wild P. oxygeneios for aquaculture is likely to be sourced from Northland, assumed in this analysis to be similar to the Leigh sample site. Increasing the number of broodstock with individuals from this area is likely to have the largest genetic gains in the first 20 individuals sampled, as the absence of alleles at 5\% in frequency at the Leigh site was reduced from $25 \%$ to $5 \%$ (figure 4.7). An additional 30 individuals sampled from this area reduces the absence of this allele in the broodstock from $5 \%-\sim 1 \%$. However, when this sampling is compared to the genetic variation across all wild sites (figure 4.8), it is apparent that there are low frequency alleles in Leigh that are at a much higher frequency in Otago (refer to figure 4.5 - 8\% frequency alleles). A sample of 50 individuals from Leigh will increase this allele's frequency in the broodstock. However, due to the higher frequency in which these alleles are found at Otago means only 15 individuals need to be sampled for these alleles to be $99 \%$ present in the broodstock (figure 4.9). If sampling was to be conducted across all six sites then the genetic gains would be similar except this method of sampling will reduce the percentage of lower frequency alleles in the broodstock (figure 4.10). 


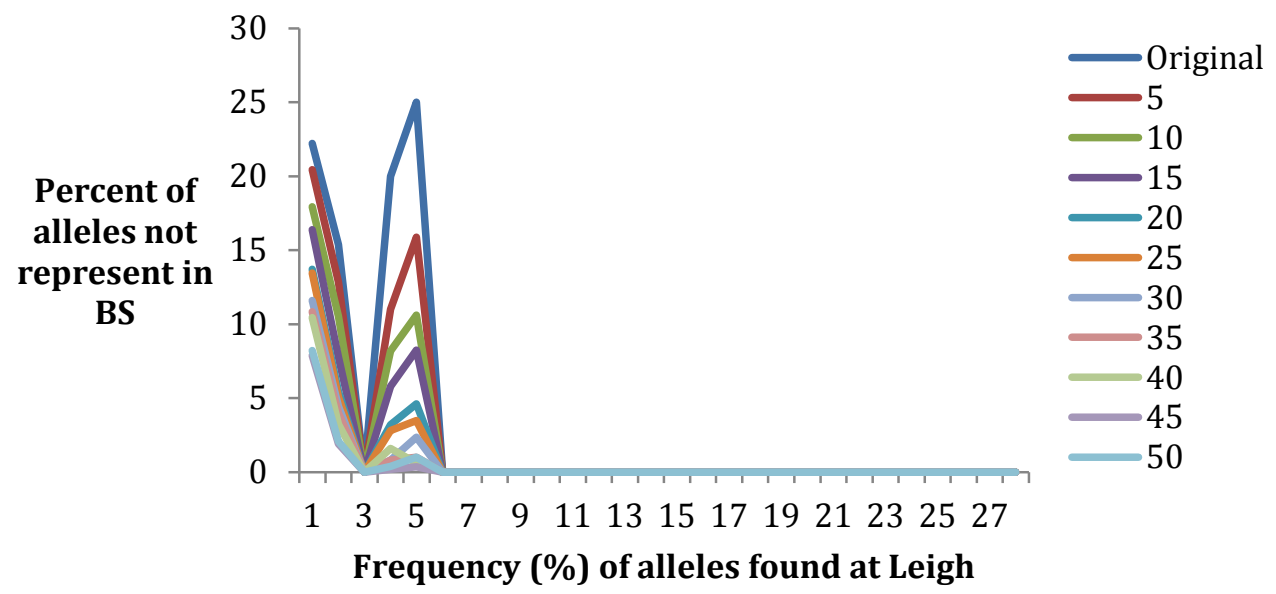

Figure 4.7 Increasing the number of individuals in the wild broodstock with fish taken from Leigh compared to alleles found at Leigh. Each line is representative of an additional five individuals added to the broodstock.

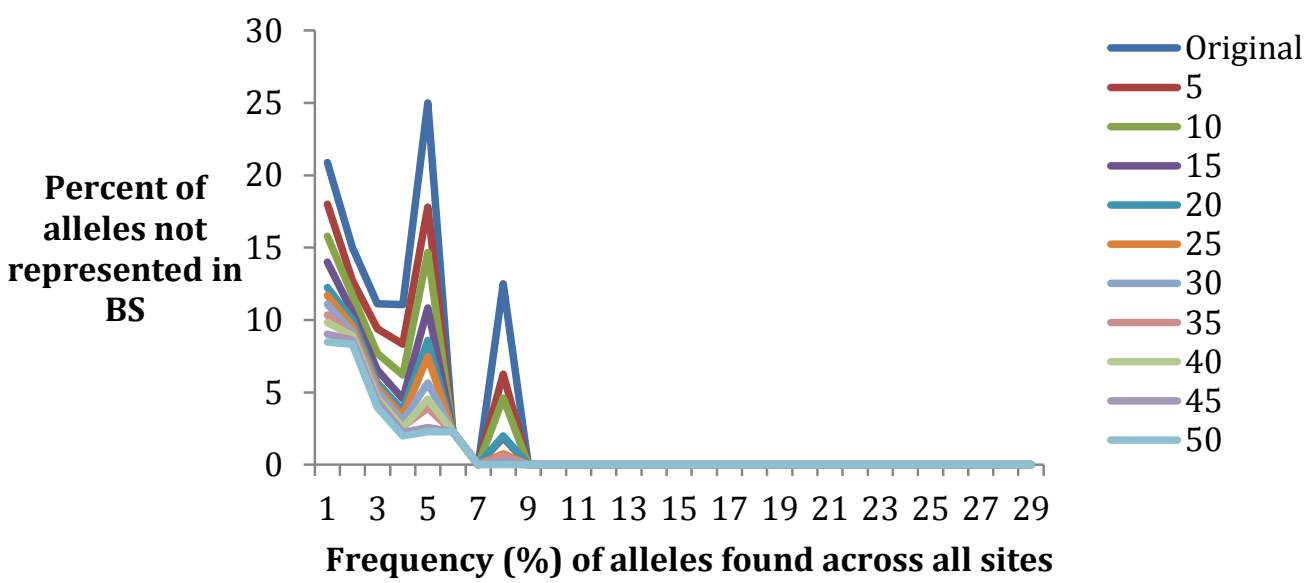

Figure 4.8 Increasing the number of individuals in the wild broodstock with fish taken from Leigh compared to alleles across all wild sites.

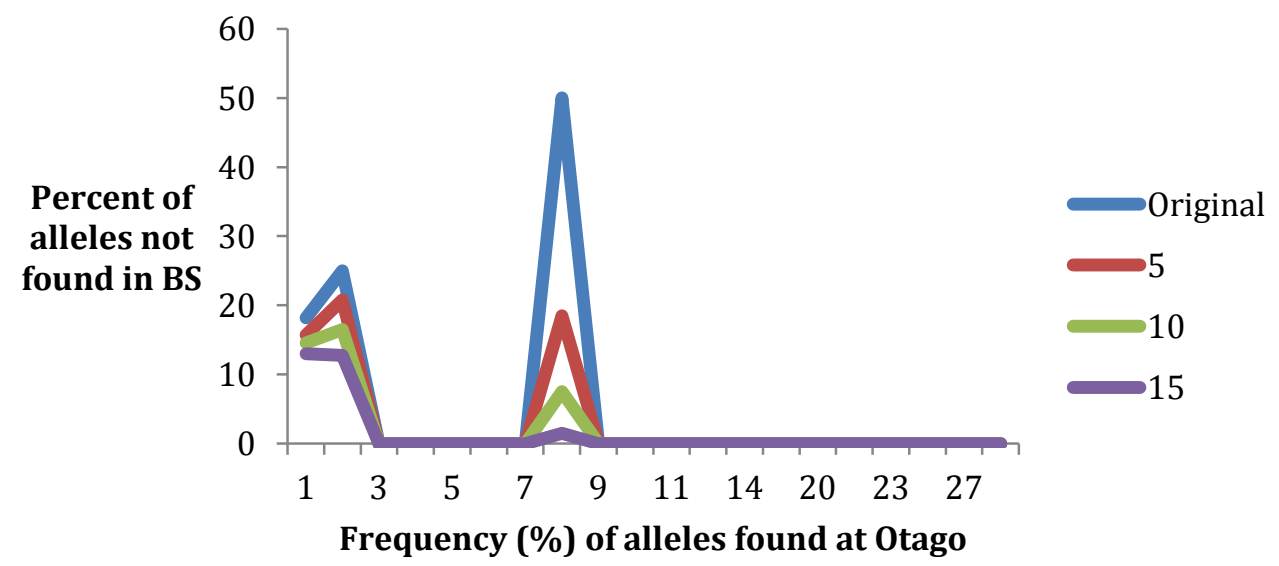

Figure 4.9 Increasing the number of individuals in the wild broodstock with fish taken from Otago compared to alleles found in the wild Otago population 


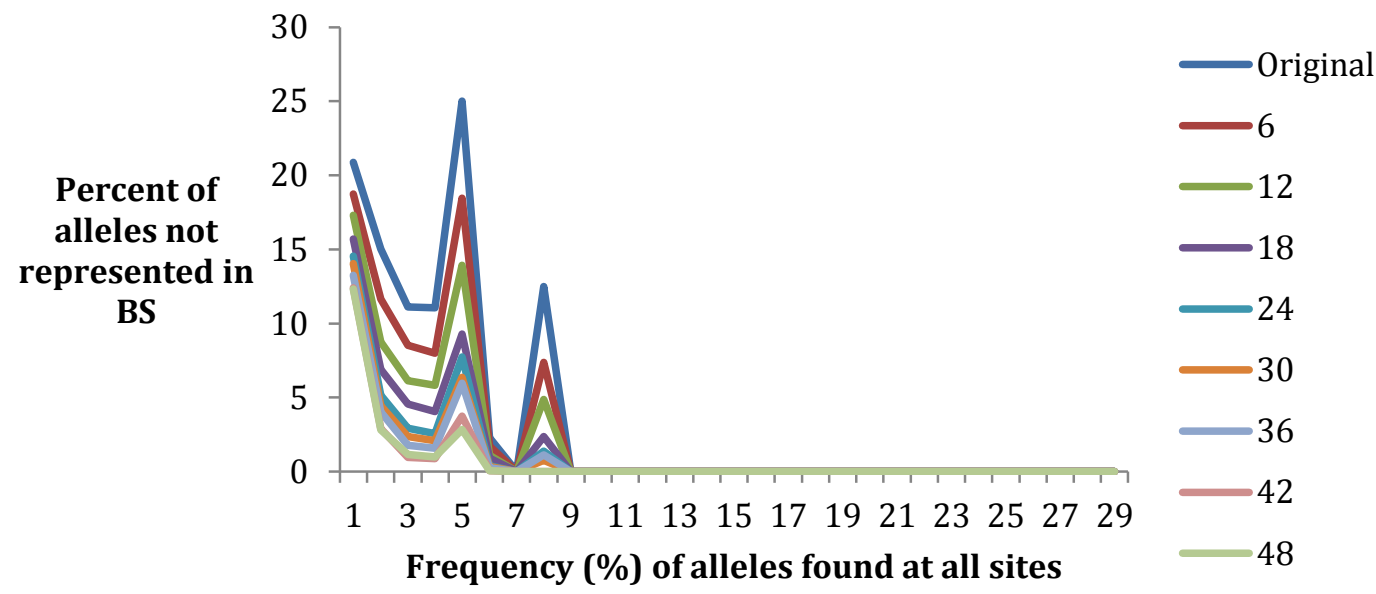

Figure 4.10 Increasing the number of individuals in the wild broodstock with fish taken from all wild sites compared to alleles found across all wild sites. Each line is representative of an additional six individuals (one from each wild site) added to the broodstock

A general 'rule-of-thumb' is that $\sim 50$ individuals with an equal sex ratio are required to capture $99 \%$ of the wild genetic variation when establishing a broodstock (Smith 2008). This holds true for establishing two new broodstocks from the Leigh and the Cook Strait areas. Most of the major genetic improvements are achieved within the first 25 individuals sampled (figures 4.11 \& 4.12). Sampling 50 individuals allows for a greater representation of rare alleles in the broodstock. A similar trend was also found when sampling was conducted with one individual from each site, although there were less rare alleles captured by this sampling method (figure 4.13).

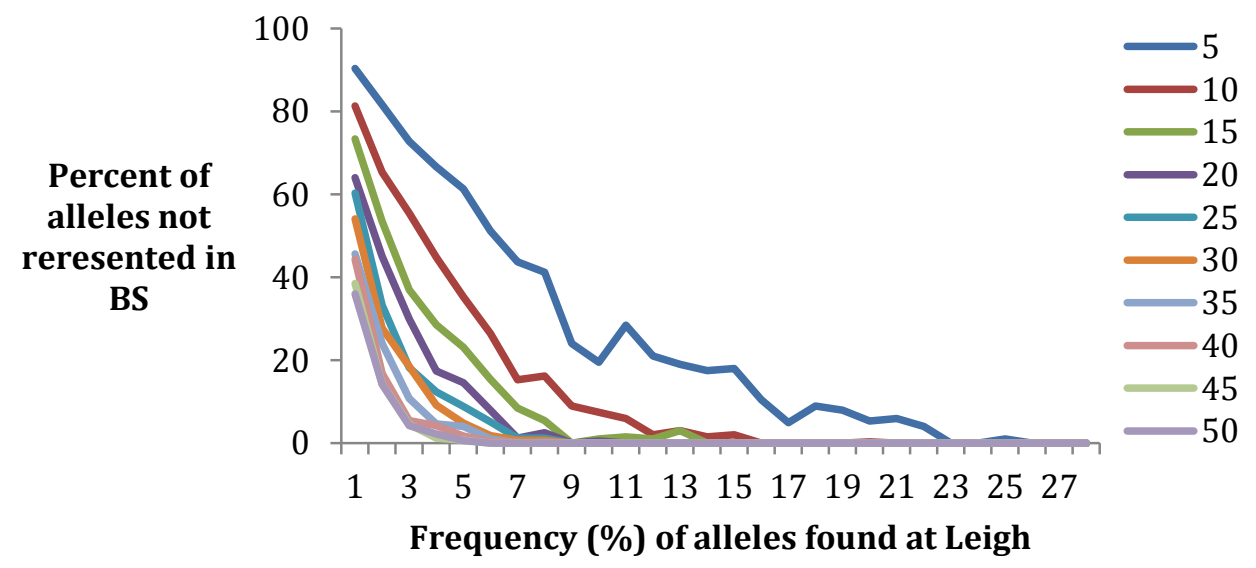

Figure 4.11 Establishing a new broodstock with individuals taken from Leigh compared with the alleles found at Leigh. Each line is representative of an additional five individuals added to the broodstock 


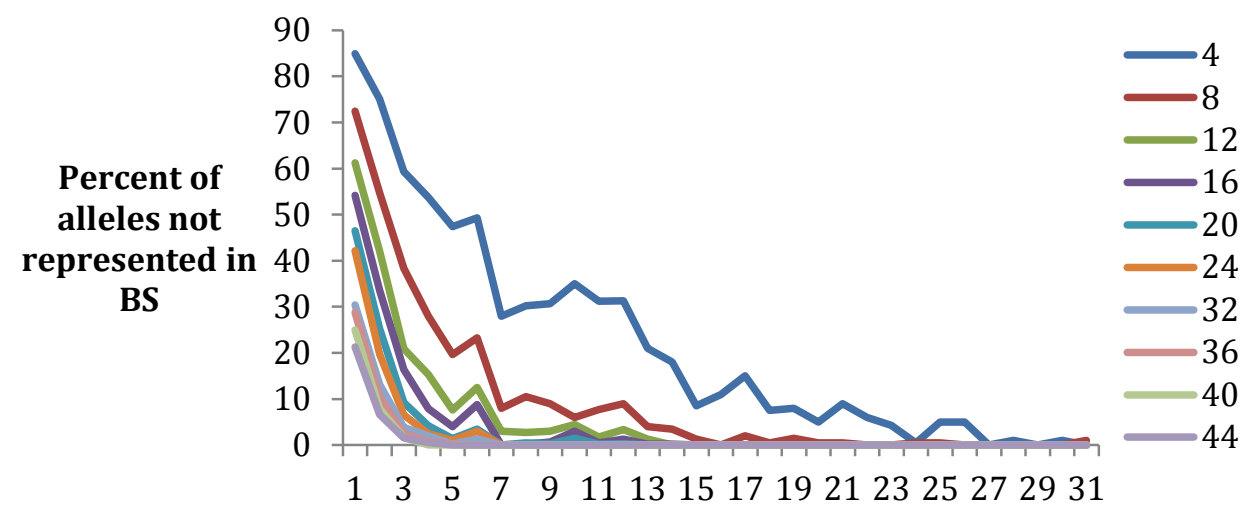

Frequency (\%) of alleles found at Cook Strait and Makara

Figure 4.12 Establishing a new broodstock with individuals taken from the Cook Strait and Makara compared with alleles found at these two sites. Each line is representative of an additional four individuals (two from each site) added to the broodstock.

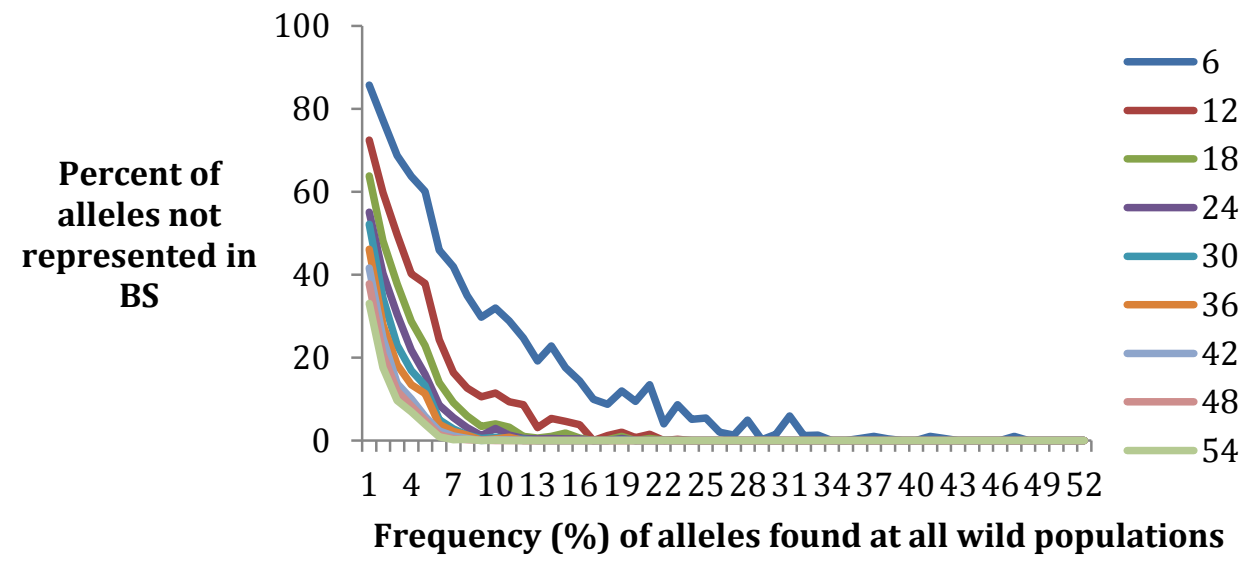

Figure 4.13 Establishing a new broodstock with individuals taken from all wild sites compared to alleles found across these sites. Each line is representative of an additional six individuals (one from each site) added to the broodstock

\subsection{Discussion}

The amount of genetic diversity in an aquaculture broodstock is a major factor that can determine the fitness of progeny and the response to selective breeding programs (Ha et al., 2009). The research broodstock at NIWA's Bream Bay Aquaculture Park contains individuals that have all major mitochondrial haplotypes and it is representative of all high frequency microsatellite alleles found within the sampled wild sites (excluding Hokitika). The similarity between 
the current broodstock and the wild populations suggests that the P. oxygeneios in culture will in many cases hold the major wild gene variants.

Sequencing and genotyping data from 74 and 98 wild broodstock individuals, respectively, and genotyping from 4712 F1 individuals showed similar levels of genetic diversity that were found in the study on wild P. oxygeneios (tables 4.1 and 4.2). A similar overall trend was observed between allele frequencies of each site compared to the percent represented in the wild broodstock (figure 4.5). This is most likely attributed to no significant levels of genetic differentiation observed between these wild sites (Chapter Three). Hokitika is representative of a discrete population and subsequently $100 \%$ of high frequency alleles in this population were not present in the broodstock (figure 4.5).

Although other studies have reported similar findings of genetic similarity between captive broodstock and wild populations (Palm et al., 2003; Ha et al., 2009), generally a reduction in genetic diversity at neutral markers is observed in cultured populations relative to wild populations (Sekino et al., 2002; Porta et al., 2007; Song et al., 2011). This is often because of a founder effect and/or inbreeding from a reduction in the effective population size $\left(N_{e}\right)$ (Ha et al., 2009). Population genetic theory suggests that a minimum $N_{e}$ of 50 , with an equal sex ratio is required to retain $99 \%$ of genetic variation in the founding population (Smith 2008). Significant genetic differentiation was observed between cultured and wild populations of Japanese flounder (Paralichthys olivaceus) across microsatellite DNA markers and mitochondrial DNA control region sequences. The decline in genetic diversity in the cultured population is attributed to a small $N_{e}$ (Sekino et al., 2002), and it is acknowledged that the development of parentage analyses from the employed markers is the best approach for managing the $N_{e}$ and maintaining the genetic diversity in culture. The development of microsatellite DNA markers for parentage analysis in $P$. oxygeneios has proved effective for managing the parental contribution during spawning (Symonds et al., 2012). P. oxygeneios are serial batch spawners and the continual management of the wild broodstock in culture is crucial for the maintenance of a genetically diverse F1 population, which is an important 
foundation for the future aquaculture industry in New Zealand (Symonds et al., 2012).

There is no evidence of a founder effect in either the wild broodstock or F1 (table 4.4). This suggests that the wild broodstock was founded from an appropriate number of parents, which was described earlier to be 21 females and 18 males from one spawning season and 26 females and 15 males from another (J. Symonds Pers. Coms.; Symonds et al., 2012). Similar results were found in a genetic comparison between cultured and wild populations of the striped catfish (Pangasianodon hypophthalmus). A lack of genetic differentiation between the two populations was attributed to a sufficient number of parents within the founding broodstock (Ha et al., 2009). However, it is recognised within the cultured populations of $P$. hypophthamus, like P. oxygeneios, that the domestication process is still in the early stages and that reductions in genetic diversity can often go unnoticed for many generations (Frost et al., 2006). Therefore, having accurate broodstock management plans, including the continual surveillance of genetic diversity through molecular markers, is important to the future productivity of finfish species in culture (Ha et al., 2009).

A proper description of the levels of wild genetic diversity can be used to define sampling efforts (numbers and locations) that are required to capture an appropriate amount of genetic diversity when establishing a broodstock. Any new additions to the wild broodstock at Bream Bay Aquaculture Park will most likely be caught off Northland due to the proximity to the facility and higher survival of the captured individuals (J. Symonds Pers. Coms.). Although there is no significant level of genetic differentiation between the wild populations analysed, the PCA and observed differences in allele frequencies present at each site suggests that they are weakly subdivided (figures 4.3 and 4.5). Alleles at lower frequency at Leigh are observed at higher frequencies at Otago. As these alleles are also present at Leigh, this will not affect the overall measurement of allelic diversity within the broodstock. However, a simulation suggested that because of their higher frequency at Otago, only 15 individuals were needed to get this alleles $\sim 99 \%$ present within the wild broodstock (figure 4.9) compared 
to 50 individuals needed from Leigh (figure 4.7). Simulations suggest that increasing the broodstock with individuals from either one site, or from many sites will result in similar levels of genetic diversity within the broodstock. In utilising the wild genetic data set, the most efficient form of sampling should be considered because collections logistics and survival, stocking densities and finite space of an aquaculture farm are important biological and financial considerations.

Suitable locations for the farming of $P$. oxygeneios have been identified around the Firth of Thames and the Marlborough Sounds (Zeldis et al., 2011; J. Symonds Pers. Coms.). The simulations showed that $\sim 35$ individuals would be required from these two areas for the new broodstock to be appropriately representative of the genetic diversity in the wild populations. When sampling for a new broodstock only alleles above $5 \%$ would be needed, because rare alleles would be more difficult to obtain and would most likely provide little genetic gains for the broodstock (FAO 2008). In the establishment of a new broodstock, sampling a large number of individuals from one population compared with a fewer individuals from many populations, appears to better represent the wild genetic diversity (figures 4.11, 4.12 and 4.13). This may simply be because when sampling many individuals from one population there is a better chance of capturing lower frequency alleles compared with sampling only a few individuals from one population at a time.

The genetic similarity revealed by the results of this chapter suggests that NIWA's research broodstock held at the Bream Bay Aquaculture Park are appropriately representative of the levels of genetic diversity found in wild populations of $P$. oxygeneios. The long-term productivity of the cultured populations is reliant on genetic diversity to be maintained through accurate broodstock management. Furthermore, the level of sampling required to capture the appropriate amount of genetic diversity when either establishing new broodstock or supplementing existing ones has been described, and may be useful in the future expansion of P. oxygeneios in New Zealand aquaculture. 


\section{Supplementary Information}

Table 4.4 A test for a genetic bottleneck was implemented for the wild broodstock and F1 under each of three mutation models. $P$ values are shown, with bold values sig. at $P<0.05$

\begin{tabular}{cccc}
\hline & IAM & SMM & TPM \\
\hline Wild broodstock & 0.125 & 0.936 & 0.875 \\
F1 & $<\mathbf{0 . 0 0 1}$ & 0.185 & 0.150 \\
\hline
\end{tabular}

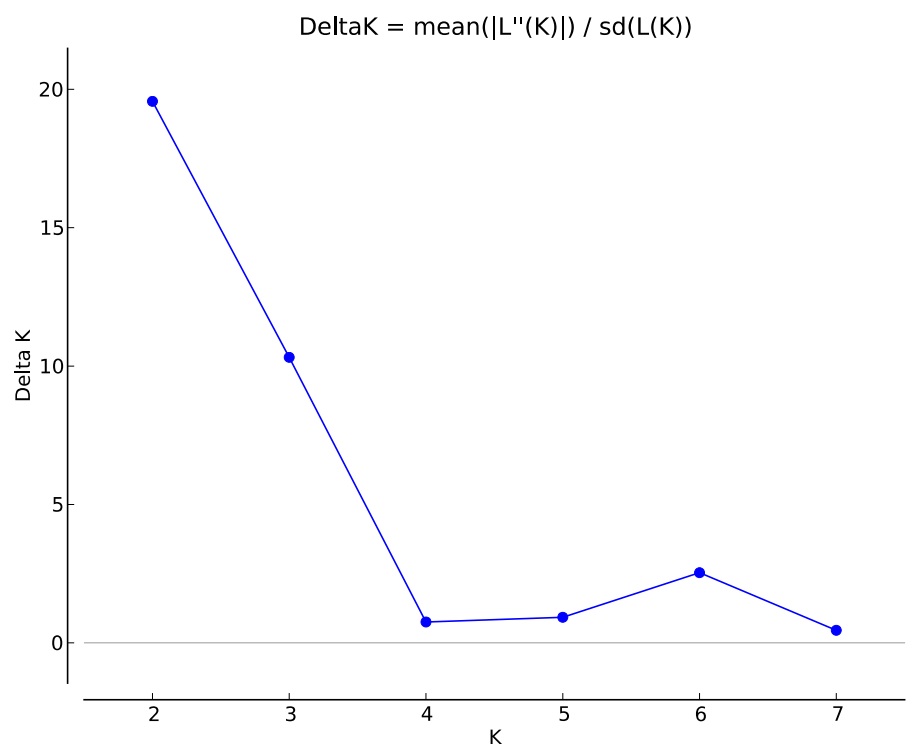

Figure 4.14 The number of genetic clusters within the microsatellite DNA data of six wild sites and two broodstock populations as inferred by the Delta K estimator 

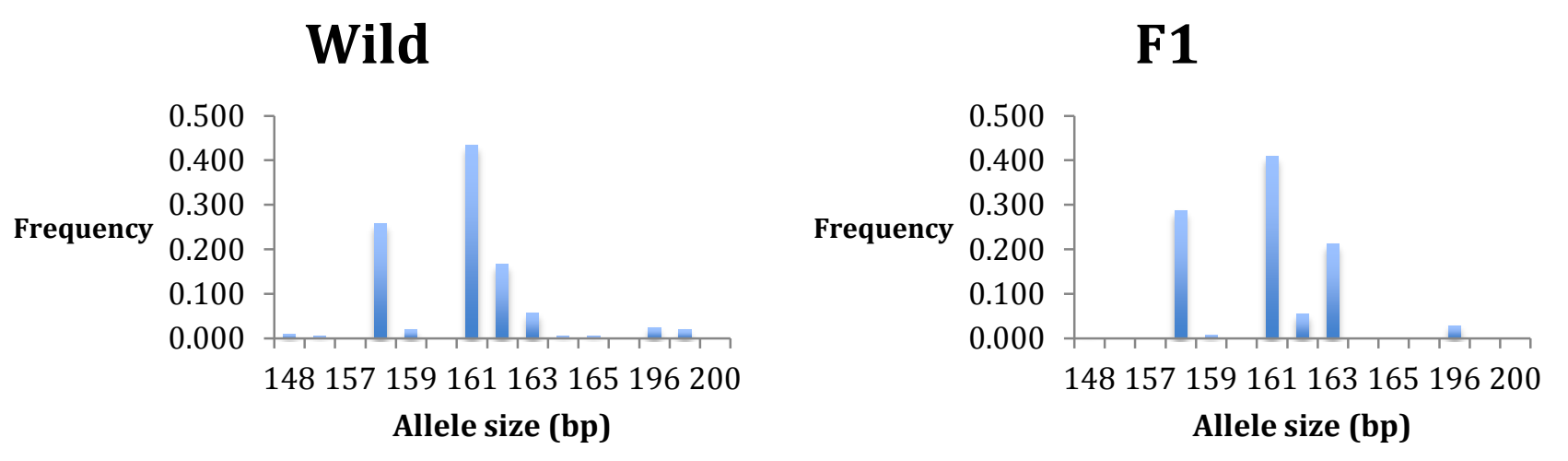

GILKPX
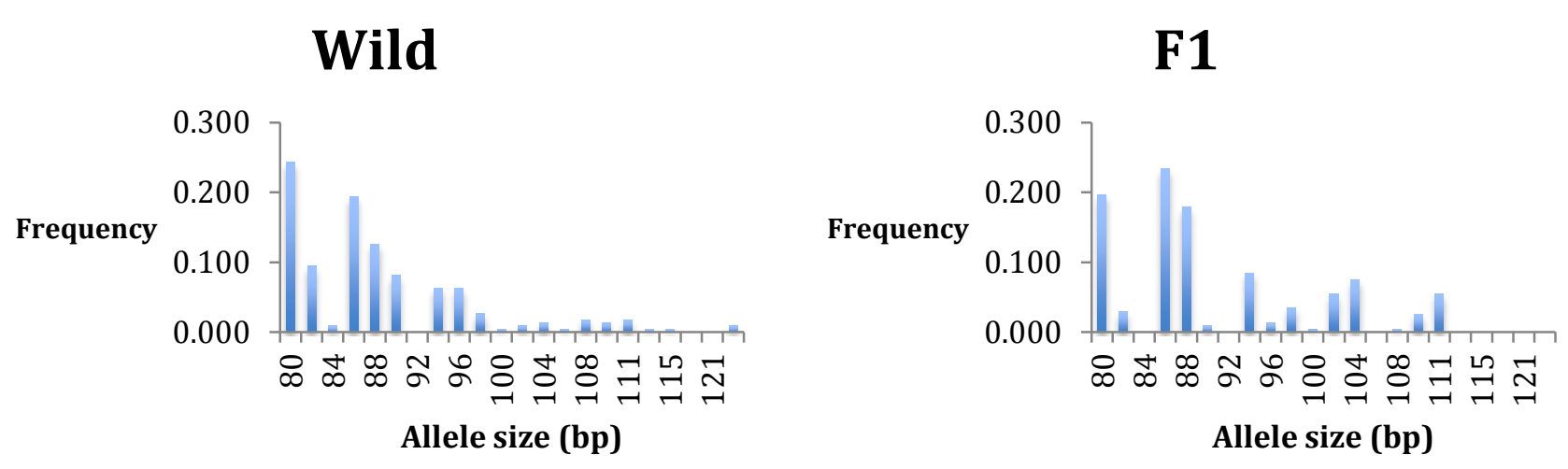

Pam010
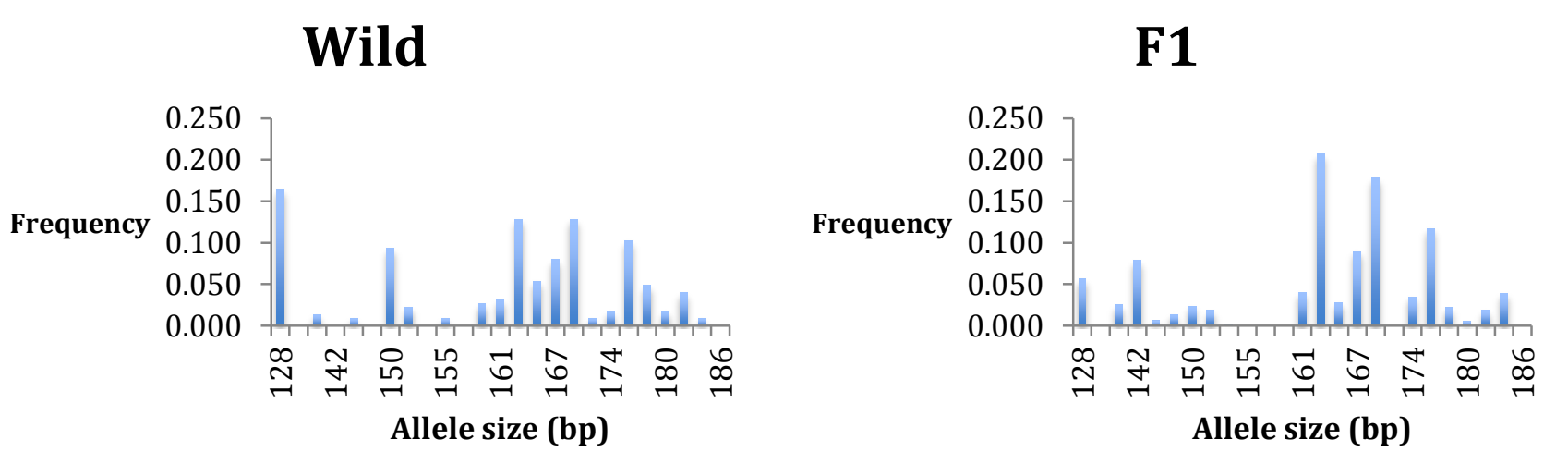

Pam021
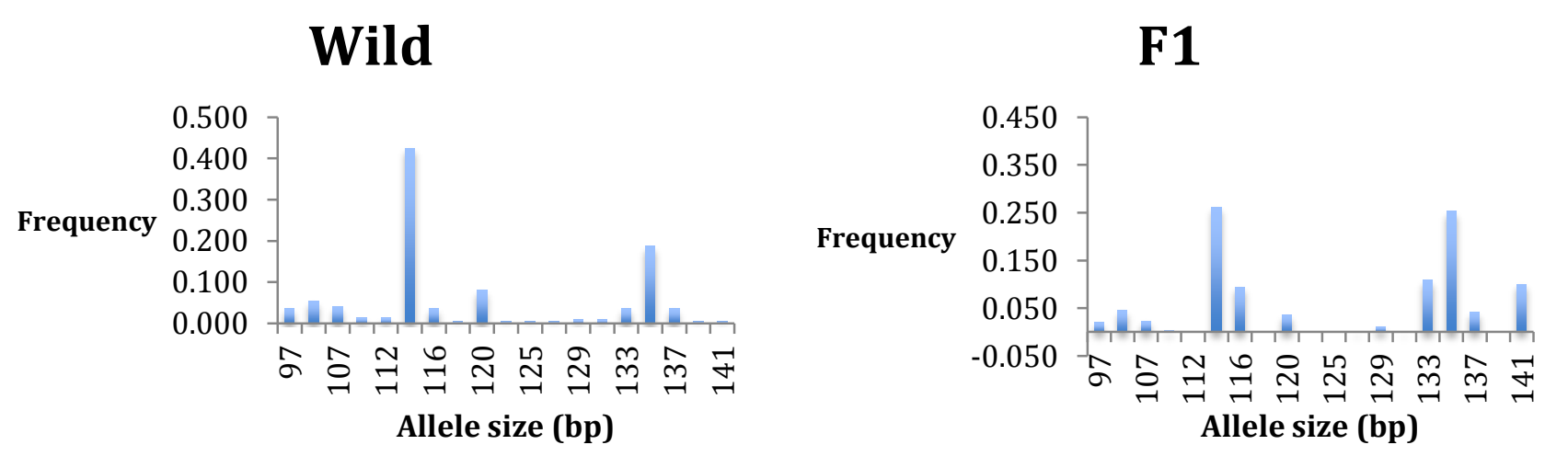

Wild
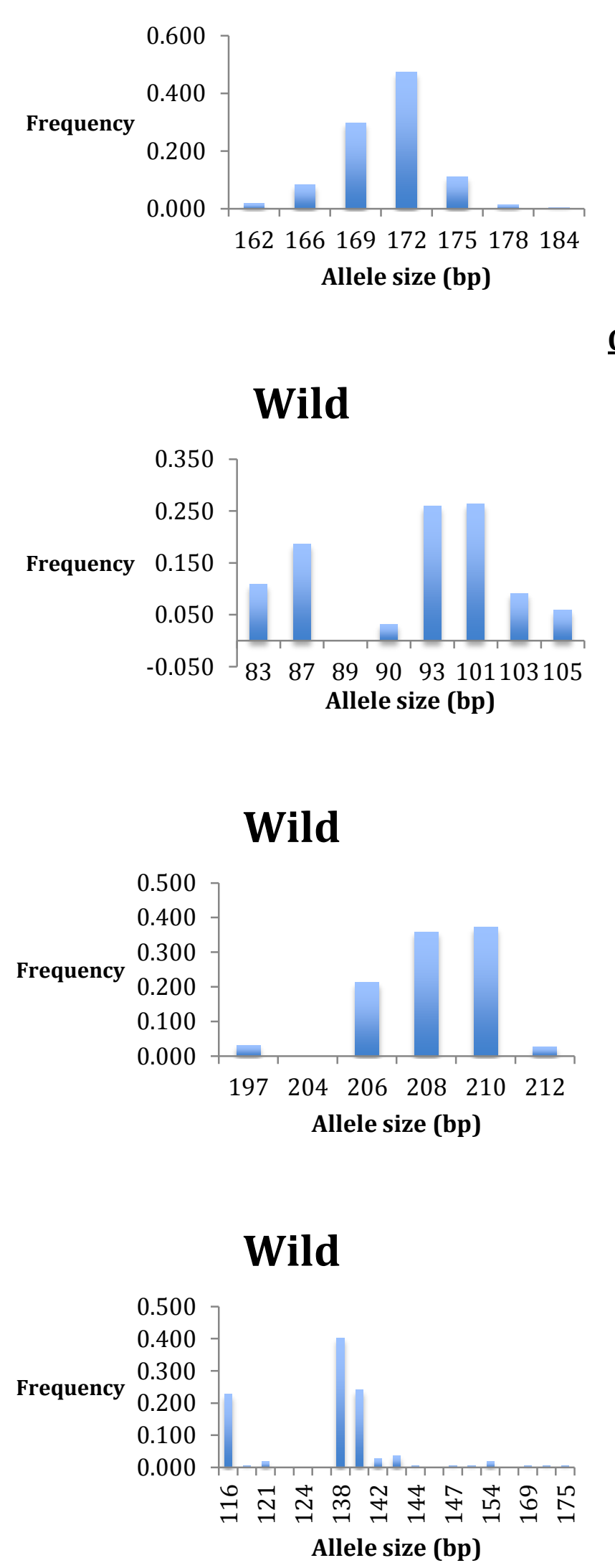

F1

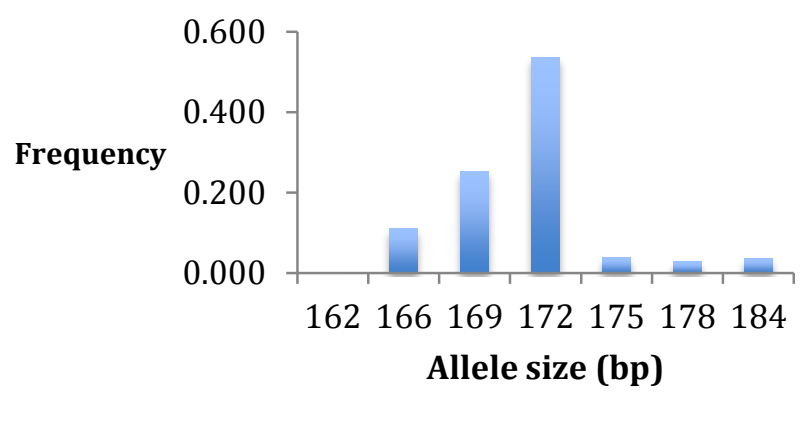

GILSB2

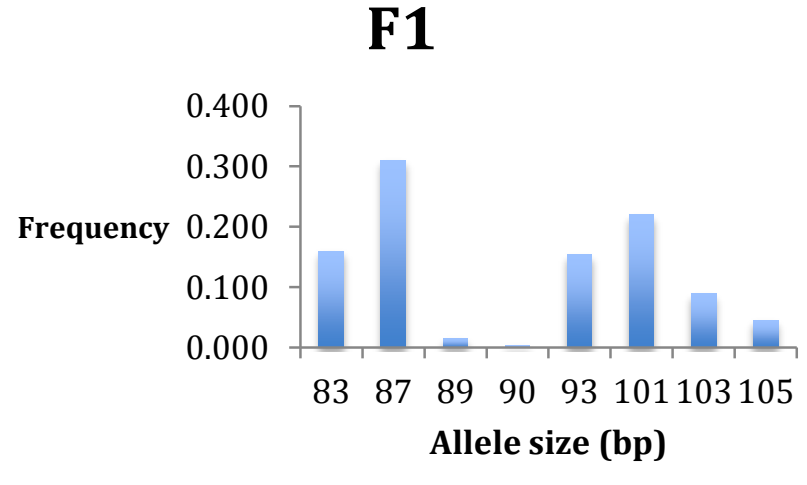

Pam017

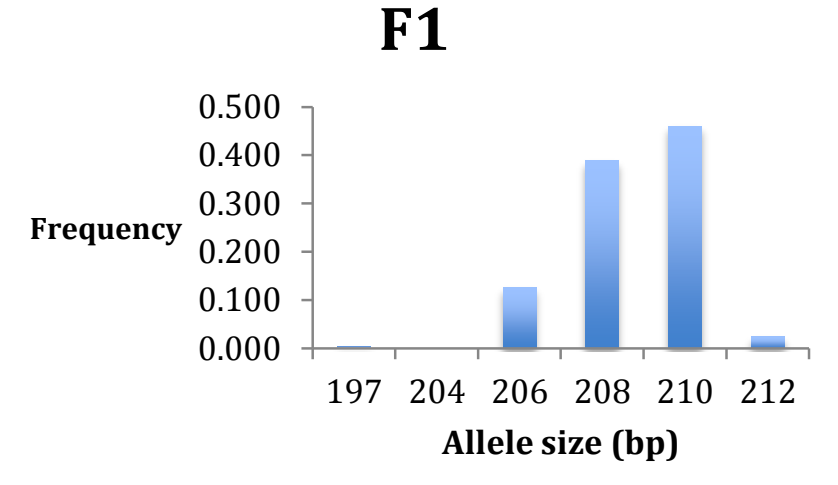

$\underline{\text { Pam025 }}$

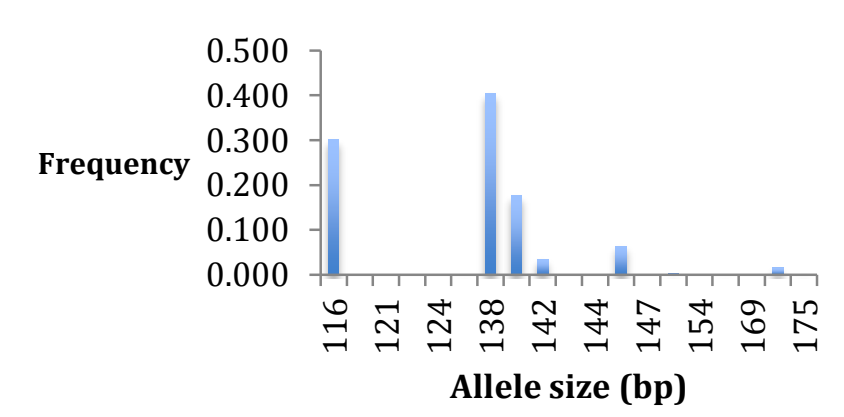




\section{Pam035}

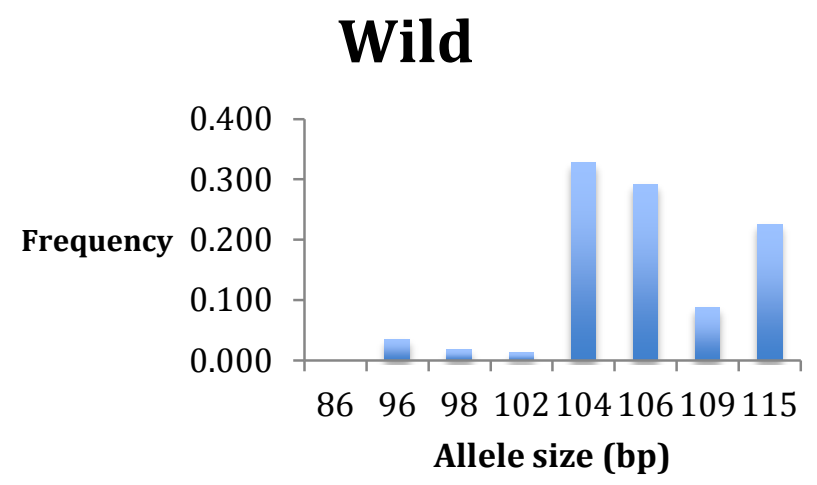

F1

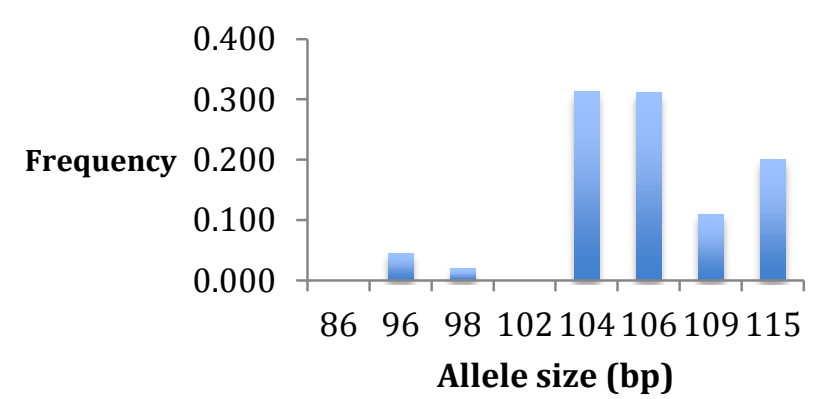

Figure 4.15 Allele frequency distributions for all loci across both the wild broodstock and F1

Wild

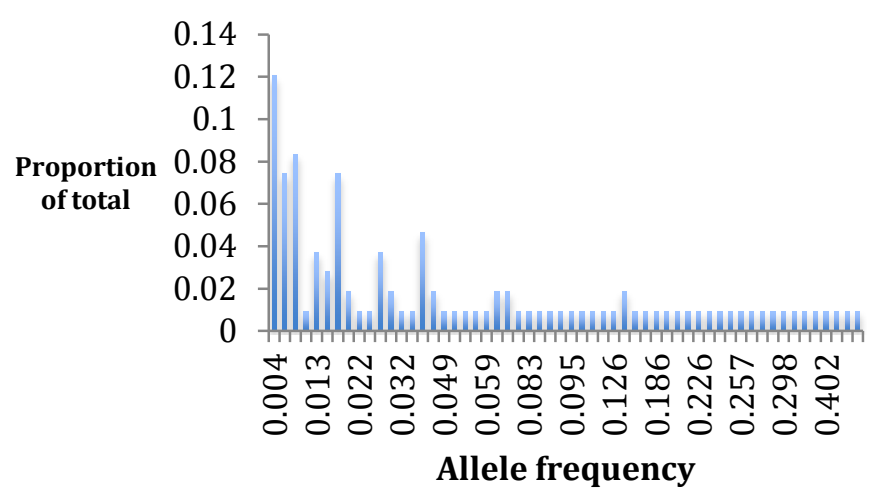

F1

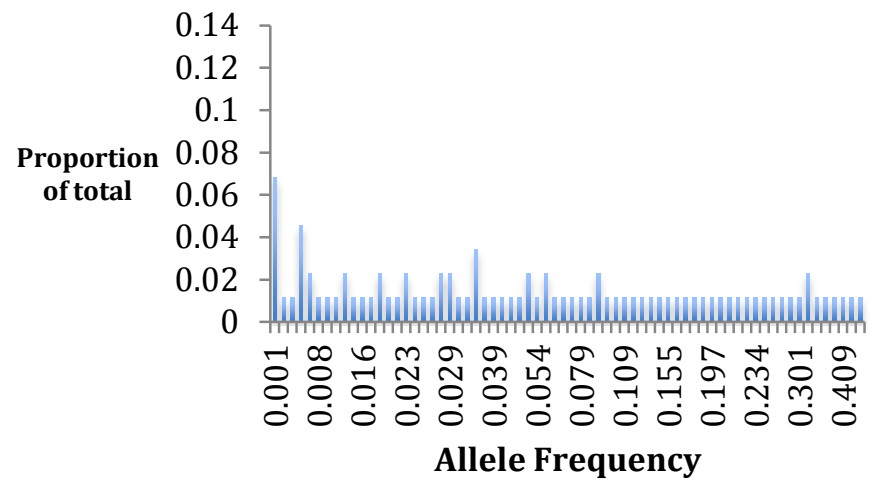

Figure 4.16 Rare allele distribution of the frequency of alleles in the wild broodstock and F1 against the portion each allele makes up of the total 


\section{Chapter Five}

\section{General Discussion}

This thesis has primarily investigated the population genetic structure of Polyprion oxygeneios (hapuku) from around New Zealand. In addition to the elucidation of the genetic structure of $P$. oxygeneios, mitochondrial DNA resources have been developed for P. oxygeneios and P. americanus (bass). Furthermore, the levels of genetic diversity within the broodstock of $P$. oxygeneios held at NIWA's Bream Bay Aquaculture Park were described and compared with the levels of genetic diversity observed within wild P. oxygeneios.

The whole mitochondrial genome for P. oxygeneios was, for the first time, sequenced and characterised (Chapter Two), which creates the potential for phylogenetic work across the Polyprion genus. This new genetic resource may help elucidate the current taxonomic uncertainties surrounding the species within the Polyprion genus. Moreover, the development of mitochondrial DNA primers for the control region of $P$. oxygeneios and $P$. americanus establishes a molecular test that could be applied by researchers to differentiation between Polyprion spp. in catch records and future population genetic studies. Both species are commercially important and the determination of the genetic stock structure of $P$. americanus may be particularly useful for a pair-species management scheme.

Mitochondrial DNA sequence data from the control region coupled with the genotyping data from nine microsatellite loci provided the first description of the population genetic structure of New Zealand P. oxygeneios. A putative discrete population along the west coast of the South Island was detected, while the remaining sample sites appear to belong to one panmictic population. Fisheries managers should take the possibility of two discrete stocks into consideration when conducting a stock assessment. Utilizing the same molecular markers used to describe the population genetic structure of P. oxygeneios, the wild and F1 
research broodstock of $P$. oxygeneios were assayed. The level of genetic diversity in the cultured P. oxygeneios was similar to the diversity in the wild populations. The sampling design for the founding broodstock was able to capture most of the genetic diversity present in the wild population, and on-going genetic management of these hatchery populations will be needed to ensure that the genetic diversity is maintained over the long-term.

\section{$\underline{5.1 \text { Fisheries }}$}

In spite of the decline of global marine capture fisheries, good progress has been made within New Zealand's marine fisheries as a result of the Quota Management System (QMS), which has resulted in 69\% of assessed stocks above management targets (FAO 2012). Critical to the effectiveness of fisheries management has been the scientific studies that have informed management decisions (Botsford et al., 1997). The sustainability of marine fisheries is important because the collapse of a fishery can have severe socioeconomic consequences (Mora et al., 2009).

The New Zealand hapuku fishery (HPB) is a mixed species quota of $P$. oxygeneios and P. americanus, and the fishery has never exceeded its Total Allowable Commercial Catch (TACC). A description of the population genetic structure of $P$. oxygeneios and P. americanus has been lacking, which means the stock boundaries might not reflect natural areas of productivity for the species (Laikre et al., 2005). Understanding the population genetic structure can be extremely useful for accurately applying stock assessment models and developing management strategies. This thesis research has provided the first description of the population genetic structure of $P$. oxygeneios from around New Zealand based on mitochondrial DNA and microsatellite DNA markers (Chapter Three).

Over the past six decades there has been an increase in the use of genetic markers to address fisheries management questions. Over the last decade the view of how fish populations are genetically structured has shifted (Hauser and Carvalho 2008). Traditionally the ocean has been thought of as an environment 
that is demographically open, characterised by high gene flow and large effective population sizes, but an increasing number of studies are now showing that some marine species with high dispersal capabilities have genetically differentiated populations (Palumbi 2003). These new insights have been brought about by the increased resolving power of new genetic marker types that can sample more independent points along the genome. Based on the findings of recent studies, it is not unusual to detect spatially structured populations in a species like $P$. oxygeneios, which potentially has a high power of dispersal (Beentjes and Francis 1999).

Despite the increasing number of cases where genetic structure has been reported for species previously considered to comprise genetically homogenous populations, the findings from this research and others (e.g. Dammannagoda et al., 2011) are still surprising because it only requires a small amount of gene flow between populations to prevent genetic differences from arising. For example, if one individual per generation moves to another breeding population, then theoretically this small genetic exchange is enough to homogenise allele frequencies (Mills and Allendorf 1996). However, genetic methods alone can often provide little information about the level of demographic connectivity among populations, which is a parameter of central importance to natural resource management (Lowe and Allendorf 2010). Unlike genetic connectivity, which is primarily a function of the absolute number of dispersers, demographic connectivity is a function of the proportion of migrants moving between populations (Lowe and Allendorf 2010). When two populations are genetically differentiated they are also likely to be demographically uncoupled (Lowe and Allendorf 2010). Therefore, drawing conclusions about the contemporary patterns of connectivity based on a typical genetic data set would be premature without the support of direct measures of dispersal (Begg and Waldman 1999). For example, genetic differentiation between populations could reflect historical events that once restricted gene flow, and although these populations are readily exchanging alleles not enough time has passed to equilibrate allele frequencies between populations. On the other hand, genetically homogenous populations may have only recently become isolated and insufficient time has passed for 
genetic differences to arise. To determine whether the findings of a genetic study also reflect the contemporary ecological processes, molecular data needs to be coupled with direct measures of dispersal (Begg and Waldman 1999). Examples of such measures would be to determine the distribution of spawning individuals or juveniles, otolith microchemistry analysis or oceanographic models (Paul 2002a). Future work should be undertaken to improve the biological information about $P$. oxygeneios, with a particular emphasis on movements associated with spawning (Paul 2002a). This may enable a clearer insight into the genetic differentiation observed between Hokitika and all other New Zealand sample sites. In a recent review of the molecular studies undertaken in New Zealand (Ross et al., 2009), only four studies observed distinct east and west coast populations and only included species with low dispersal capabilities (see Ross et al., 2009). Therefore, any east-west population differentiation in New Zealand of pelagic fishes is unique and needs to be investigated further with an interdisciplinary methodological approach, which is recognised as the most effective way to identify stock boundaries (Jennings and Beverton 1991).

\subsection{Management recommendations}

There are limitations on the conclusions that can be made about the results of this genetic study of $P$. oxygeneios, but some management suggestions can be made for the HPB fishery and for what research gaps are left to fill that best compliment this research. As mentioned earlier, the genetic data suggests that there are two distinct populations of $P$. oxygeneios, one in the Hokitika area and another occupying all other sample sites around New Zealand. However, the HPB fishery is managed as eight separate stock areas. It is widely accepted that the splitting of one genetically homogenous population into separate management units would be more or less harmless to the overall stock (Laikre et al., 2005). A fisheries manager should more reluctant to accept the suggestion that there is no differentiation among sites to prevent local depletions and minimise risk (Laikre et al., 2005). 
The presence of a discrete population along the west coast of the South Island, suggests that HPB7 should continue to be maintained as a separate management area. Allowing HPB7 to be incorporated into another stock may cause it to become overfished, resulting in a loss of genetic variation and disrupting the natural population structure that has evolved (Allendorf et al., 2008). The lack of any detectable differentiation between the eastern and the Cook Strait populations is consistent with the findings of the other studies on P. oxygeneios (Beentjes and Francis 1999). Currently, the Cook Strait region is divided into three separate stocks: HPB2, HPB7 and HPB8, none of which include the OtagoCanterbury fishery: HPB3. The mix of stock boundaries within the Cook Strait do have some unfortunate consequences; landings from the Cook Strait are amalgamated with landings from a far afield as New Plymouth, East Cape and Hokitika (Paul 2002a). The present stock boundaries within the Cook Strait are most likely inappropriate for the management of Cook Strait and east coast South Island P. oxygeneios, and tend to obscure any real trends in regional landings (Paul 2002a). Coincidentally, emphasis needs to be given to revising the stock boundaries within the Cook Strait region in the future. In a review of the HPB fishery, Paul (2002a) suggests that the boundaries that subdivide the Cook Strait should be removed and he proposed several options (figure 5.1). Taking into consideration the discrete population along the west coast of the South Island, the most suitable revision of the management boundaries is likely to be the option that removes the boundaries within the Cook Strait but still manages the Hokitika population as a separate fishery (option C).

The present study only sampled fish at one point in time. Therefore, there is the possibility that stocks are temporally differentiated and that if samples were taken from the same site at different times, genetic differences might change (Paul 2002a). Any conclusion on the division of the Cook Strait fishery into three stocks will require a longer-term sampling plan that takes into account temporal variation. It has been previously suggested that temporal genetic differentiation among stocks of P. oxygeneios may be present (Smith and Johnson 1985; Beentjes and Francis 1999). 

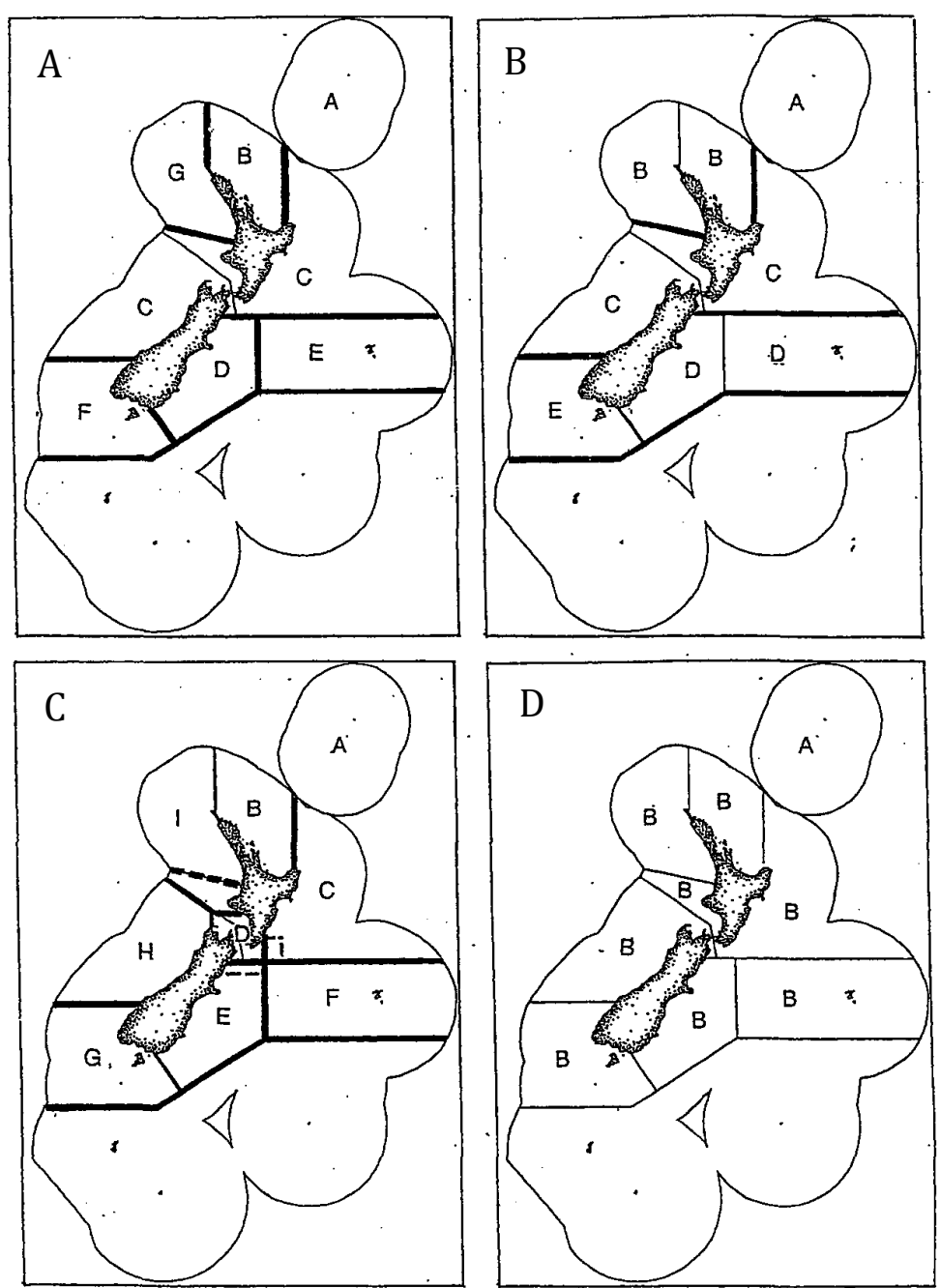

Figure 5.1 Some proposed options for the revised management areas for the HPB fishery

(Paul 2002a). Each letter represents an independent management area. Thin lines represent existing stock boundaries. Bold lines represent newly proposed stock boundaries. Dashed lines represent a possible stock boundary.

\section{$\underline{5.3 \text { Aquaculture }}$}

The management of genetic diversity in P. oxygeneios broodstock and captive reared populations is important for the long-term success of the industry. The establishment of new aquaculture broodstock requires individuals to be sampled from wild populations in a way that captures a broad genetic base in the founding broodstock, which is then maintained through careful genetic management (Ha et al., 2009). 
A description of the genetic diversity present in both the wild and hatchery populations can be used to determine whether the broodstock will potentially suffer from inbreeding depression and if they have the maximum genetic potential (Ha et al., 2009). Excluding the genetically differentiated population of Hokitika, the wild-caught broodstock and their F1 generation at NIWA's Bream Bay Aquaculture Park are representative of all the major wild gene variants that were reported in Chapter Three suggesting that there was an appropriate number of individuals within the founding broodstock (Symonds et al., 2012). Successful capture of genetic variation from the wild was most likely because the wild population appears to be largely genetically homogenous, especially where the initial broodstock individuals were sourced: Northland, Whitianga and Cook Strait. In order to maintain this genetic base over successive generations, ongoing genetic management will need to be undertaken. Typically within a broodstock, many strains may be used within breeding programs, however, the precise genetic relationship among strains is frequently unknown (Liu and Cordes 2004). The application of microsatellite DNA markers has been used to successfully determine the parentage of offspring and enable the parental contribution of individuals to be more precisely managed (Symonds et al., 2012). Maintenance of a highly genetically effective population size is a key parameter for determining the long-term persistence of genetic diversity within a hatchery population (Ha et al., 2009).

A proper description of the levels of wild genetic diversity can be used to define sampling efforts (numbers and locations) that are required to capture an appropriate amount of genetic diversity when establishing a broodstock. There is no single correct value for the frequency of alleles that should be captured within a broodstock because it is dependent on the goal of the broodstock manager (FAO 2008). Besides supplying food directly for human consumption, aquaculture is increasingly being used for restocking wild populations (Waples and Drake 2004). In this case, the genetic integrity of the population needs to be maintained, with wild alleles at frequencies of 0.1 - 1\% needing to be captured within the founding broodstock. Failure to do so can have negative consequences on the wild populations as documented by Araki et al., (2007). On the other 
hand, farming fish for food i.e. P. oxygeneios (Symonds et al., 2012), alleles less than $5 \%$ in frequency in the wild are not considered important because they provide fewer genetic gains and would be difficult to capture during sampling. Therefore, in utilising the wild genetic data set, the most efficient form of sampling can be considered depending on the breeding purpose.

The genetic markers used in this thesis research were selectively neutral. A lack of genetic differentiation at neutral loci may not be reflective of potential differences at genes under selection, which may be of interest to selective breeding programs i.e. disease resistance, growth rate, cold tolerance, etc. The development of higher resolution genomic markers will enable the detection of variation at functional genes could be used to identify traits in the wild and in the captive populations that are important in the successful development of $P$. oxygeneios as a premium market product.

\section{$\underline{5.4 \text { Conclusions }}$}

This thesis has characterised the whole mitochondrial genome of $P$. oxygeneios and applied molecular markers to describe the population genetic structure of $P$. oxygeneios. Results from this research has identified genetic differentiation between Hokitika and the remaining New Zealand sample sites, which may be representative of two independent stocks. This needs to be taken into consideration when undertaking a stock assessment and applying management boundaries. Management recommendations were made, with a suggestion to maintain HPB7 as an independent management area as well as to revise the Cook Strait management boundaries. A description of the levels of genetic diversity within the P. oxygeneios broodstock was similar to the levels found in the wild populations. Nevertheless, continual genetic management is required to maximise the productivity of this species in culture moving forward. It is hoped that this research will contribute to the growing body of data that can be successfully applied to future management decisions for both the development of a new New Zealand aquaculture opportunity and the sustainability of an iconic New Zealand fishery. 


\section{$\underline{\text { References }}$}

Aboim, M. A. (2005) Population genetics and evolutionary history of some deepsea demersal fishes from the Azores - North Atlantic. PhD dissertation, University of Southampton, Southampton, United Kingdom

Aboim, M. A., Menezes, G. M., Schlitt, T., Rogers, A. D. (2005) Genetic structure and history of populations of the deep-sea fish Helicolenus dactylopterus (Delaroche, 1809) inferred from mtDNA sequence analysis. Molecular Ecology 14: $1343-1354$

Allendorf, F. W., England, P. R., Luikart, G., Ritchie, P. A., Ryman, N. (2008) Genetic effects of harvest on wild animal populations. Trends in Ecology and Evolution 23: $327-336$

Anderson, S., Bankier, A. T., Barrell, B. G., De Bruijn, M. H. L., Coulson, A. R., Drouin, J., Eperon, I. C., Nierlich, D. P., Roe, B. A., Sanger, F., Schreier, P. H., Smith, A. J. H., Staden, R., Young, I. G. (1981) Sequence and organisation of the human mitochondrial genome. Nature 290: 457 - 465

Anderson, S. A., Salinar, I., Walker, S. P., Gublin, Y., Pether, S., Kohn, Y. Y., Symonds, J. E. (2012) Early development of New Zealand hapuku Polyprion oxygeneios eggs and larvae. Journal of Fish Biology doi:10.1111/j.10958649.2011.03191.x

Antao, T., Lopes, A., Lopes, R. J., Beja-Pereira, A., Luikart (2008) LOSITAN: A workbench to detect molecular adaptation based on a $F_{s t}-$ outlier method. Bioinformatics 9: 323

Araki, H., Cooper, B., Blouin, M. S. (2007) Genetic effects of captive breeding cause a rapid, cumulative fitness decline in the wild. Science 318: $100-103$

Ashford, J. R., Jones, C. M., Hofmann, E. E., Everson, I., Moreno, C. A., Duhamel, G., Williams, R. (2008) Otolith microchemistry indicates population structure by the Antarctic Circumpolar Current. Canadian Journal of Fisheries and Aquatic Sciences 65: $135-146$

Austreng, E. (1993) Historical development of feed for salmon. Institute of Aquaculture Research Ltd. Annual report with English summary. 17 p

Ball, A. O., Sedberry, G. R., Zatcoff, M. S., Chapman, R. W., Carlin, J. L. (2000) Population structure of the wreckfish Polyprion americanus determined with microsatellite genetic markers. Marine Biology 137: 1077 - 1090 
Beaumont, M. A. and Nichols, R. A. (1996) Evaluating loci for use in the genetic analysis of population structure. Proceedings of the Royal Society of London B 263: $1619-1626$

Beentjes, M. P. and Francis, M. P. (1999) Movement of hapuku (Polyprion oxygeneios) determined from tagging studies. New Zealand Journal of Marine and Freshwater Research 33: 1 - 12

Begg, G. A. and Waldman, J. R. (1999) An holistic approproach to fish stock identification. Fisheries Research 43: 35 - 44

Begg, G. A., Hare, J. A., Sheehan, D. D. (1999) The role of life history parameters as indicators of stock structure. Fisheries Research 43: 141 - 163

Bentzen, P., Taggart, C. T., Ruzzante, D. E., Cook, D. (1996) Microsatellite polymorphism and the population structure of Atlantic cod (Gadhus morhua) in the northwestern Atlantic. Canadian Journal of Fish and Aquatic Sciences 53: $2706-2721$

Bibb, M. J., Van Etten, R. A., Wright, C. T., Walberg, M. W., Clayton, D. A. (1981) Sequence and gene organization of mouse mitochondrial DNA. Cell 26: 167 - 180

Borrell, Y., Carleos, C., Asturiano, J., Bernardo, D. V. E., Corral, N. Sanchez, J. A., Blanco, G. (2007) Use of microsatellites and a combinatorial optimization approach in the acquisition of gilthead seabream (Sparus aurata) broodstocks for hatcheries. Aquaculture 269: 200 - 210

Botsford, L. W., Castilla, J. C., Peterson, C. H. (1997) The management of fisheries and marine ecosystems. Nature 277: 509 - 515

Brown, W. M., George Jr., M., Wilson, A. C. (1979) Rapid evolution of animal mitochondrial DNA. Proceedings of the National Academy of Sciences of the United States of America 76: 1967 - 1971

Brummett, R. E., Angoni, D. E., Pouomogne, V. (2004) On-farm and on-station comparison of wild and domesticated Cameroonian populaitons of Oreochromis niloticus. Aquaculture 242: 157 - 164

Carr, S. M., Snellen, A. J., Howse, K. A., Wroblewski, J. S. (1995) Mitochondrial DNA sequence variation and genetic stock structure of Atlantic cod (Gadhus morhua) from bay and offshore locations on the Newfoundland continental shelf. Molecular Ecology 4: 79 - 88 
Carvalho, G. R. and Hauser, L. (1994) Molecular genetics and the stock concept in fisheries. Reviews in Fish Biology and Fisheries 4: 326 - 350

Catanese, G., Infante, C., Manchado, M., (2008) Complete mitochondrial DNA sequences of the frigate tune Auxis thazard and the bullet tuna Auxis rochei. DNA Sequences 19: 159 - 166

Chapius, M-P. and Estoup, A. (2007) Microsatellite null alleles and estimation of population differentiation. Molecular Biology and Evolution 24: 621 - 631

Chen, I-S., Hsu, C-H., Hui, C.F., Shao, K-T., Miller, P. J., Fang, L. S. (1998) Sequence length and variation in the mitochondrial control region of two freshwater gobiid fishes belonging to Rhinogobius (Teleostei: Gobioidei). Journal of Fish Biology 53: $179-191$

Chybicki, I. J. and Burczyk, J. (2009) Simultaneous estimation of null alleles and inbreeding co-efficients. Journal of Heredity 100: 106 - 113

Clark, S. H., Overholtz, W. J., Hennermuth, R. C. (1982) Review and assessment of the Georges Bank and Gulf of Maine haddock fishery. Journal of Northwestern Atlantic Fishery Science 3: 1 - 27

Coughlan, J. P., Imsland, A. K., Galvin, P. T., Fitzgerald, R. D., Naevdal, G., Cross, T. F. (1998) Microsatellite DNA variation in wild populations and farmed strains of turbot from Iceland and Norway: a preliminary study. Journal of Fish Biology 52: $916-922$

Crawford, N. G. (2010) SMOGD: software for the measurement of genetic diversity. Molecular Ecology Resources 10: 556 - 557

Dammannagoda, S. T., Hurwood, D. A., Mather, P. B (2011) Genetic analysis reveals two stocks of skipjack tuna (Katsuwonus pelamis) in the northwestern Indian Ocean. Canadian Journal of Fish and Aquatic Sciences 68: 210 - 223

Davidson, W. S., Koop, B. F., Jones, S. J., Ihurra, P., Vidal, R., Maass, A., Jonassen, I., Lien, S., Omholt, S. W. (2010) Sequencing the genome of the Atlantic salmon (Salmo salar). Genome Biology 11: 403

Earl, D. A. and vonHoldt, B. M. (2012) STRUCTURE HARVESTER: a website and program for visualizing STRUCTURE output and implementing the Evanno method. Conservation Genetics Resources 4: 359 - 361 
Donaldson, K. A. and Wilson, Jr., R.R. (1999) Amphi-Panamic Geminates of Snook (Percoideii-Centropomidae) provide a calibration of the divergence rate in the mtDNA control region of fishes. Molecular Phylogenetics Evolution 13: 208 - 213

Drummond, A. J. and Rambaut, A. (2007) BEAST: Bayesian evolutionary analysis by sampling trees. BMC Evolutionary Biology 7: 214

Drummond, A. J., Ashton, B., Buxton, S., Cheung, M., Cooper, A., Heled, J., Kearse, M., Moir, R., Stones-Havas, S., Sturrock, S., Thierer, T., Wilson, A. (2010) Geneious v5.6.4, available from http://www.geneious.com

Estoup, A., Tailiez, C., Cornuet, J.-M., Solignac, M. (1995) Size homoplasy and mutational processes of interrupted microsatellites in two bee species, Apis melligera and Bombus terrestris (Apidae). Molecular Biology Evolution 12: 1074 1084

Excoffier, L., Larval, G., Schneider, S. (2005) Arlequin ver. 3.0. An intergrated software package for population genetics data analysis. Evolutionary Bioinformatics Online 1: 47 - 50

Faurby, S. and Barber, D. H. (2012) Theoretical limits to the correlation between pelagic larval duration and population genetic structure. Molecular Ecology 21: $3419-3432$

FAO (2008) Aquaculture development 3, genetic resource management. FAO technical guidelines for responsible fisheries. No. 5 Suppl. 3. Rome, FAO 125 p.

FAO (2012) Part 1, World review of fisheries and aquaculture in: The state of world fisheries and aquaculture. Food and Agricultural Organisation of the United Nations, Rome

Forrest, B., Hopkins, G., Webb, S., Tremblay, L. (2011) Overview of marine biosecurity risks from finfish aquaculture development in the Waikato region. Prepared for Waikato Region Council. Cawthorn Report No. 187178 p.

Francis, M. P., Mulligan, K. P., Davies, N. M. and Beentjes, M. P. (1999). Age and growth estimates for New Zealand hapuku, Polyprion oxygeneios. Fishery Bulletin 97: $227-242$

Friess, C. and Sedberry, G. R. (2011) Genetic evidence for a single stock of the deep-sea teleost Beryx decadactylus in the North Atlantic Ocean as inferred from mtDNA control region analysis. Journal of Fisheries Biology 78: 466 - 478 
Frost, L. A., Evan, B. S., Jerry, D. R. (2006) Loss of genetic diversity due to hatchery culture practices in barramundi (Lates calcarifer) 261: 1056 - 1064

Fu, Y. X. (1997) Statistical tests of neutrality of mutations against population growth, hitchhiking and background selection. Genetics 147: 915 - 925

Gaither, M. R., Jones, S. A., Kelley, C., Newman, S. J., Sorenson, L., Bowen, B. W. (2011) High connectivity in the deepwater snapper Pristipomoides filamentosus (Lutjanidae) across the Indo-Pacific with isolation of the Hawaiian archipelago. PLOS ONE 6: e28913

Garcia De Leon, F. J., Chikhi, L., Bonhomme (1997) Microsatellite polymorphism and population subdivision in natural populations of European sea bass Dicentrarchus labrax (Linnaeus, 1758). Molecular Ecology 6: 51 - 62

Gjedrem, T. (1985) Improvement of production through breeding scheme. GeoJournal 10: 233 - 241.

Gjedrem, T. (2012) Genetic improvement for the development of efficient global aquaculture: A personal opinion review. Aquaculture 344: 12 - 22

Gjerde, B., Gunnes, K., Gjedrem, T. (1983) Effects of inbreeding on survival and growth in rainbow trout. Aquaculture 34: 327 - 332

Glover, D. C., Dettmers, J. M., Wahl, D. H., Clapp, D. F. (2008) Yellow Perch (Perca flacescens) stock structure in Lake Michigan: an analysis using mark-recapture data. Canadian Journal of Fisheries and Aquatic Sciences 65: 1919 - 1930

Godfray, H. C. J., Beddington, J. R., Crute,. I. R., Haddard, L., Lawrence, D., Muir, J. F., Pretty, J., Robinson, S., Thomas, S. M., Toulim, C (2010) Food security: the challenge of feeding 9 billion people. Science 327: 812 - 818

Goldberg, T. L., Grant, E. C., Inendine, K. R., Kassler, T. W., Claussen, J. E., Philipp, D. P. (2005) Increased infectious disease susceptibility resulting from outbreeding depression. Conservation Biology 19: 455 - 462

Gonzalez, E., Nagasawa, K., Umino, T. (2008) Stock enhancement program for black sea bream (Acanthopagrus schlegelii) in Hiroshima Bay: Minitoring the genetic effects. Aquaculture 276: 36 - 43

Goudet, J. (2001) FSTAT, a Program to Estimate and Test Gene Diversities and Fixation Indices, Version 2.9.3. Available from www.unil.ch/ izea/softwares/fstat.html 
Goudet, J., Raymond, M., de Meeus, T., Rousset, F. (1996) Testing differentiation in diploid populations. Genetics 144: 1933 - 1940

Grant, W. S. and Bowen, B. W. (1998) Shallow population histories in deep evolutionary lineages of marine fishes: insights from sardines and anchovies and lessons from conservation. Journal of Heredity 89: 415 - 426

Grant, W. S. and Waples, R. S. (2000) Spatial and temporal scales of genetic variability in marine and anadromous species: implications for fisheries oceanography. In: Fisheries Oceanography: an Integrative Approach to Fisheries Ecology and Management (eds Harrison, P., Parsons, T. R.), pp. 61-93. Blackwell Science Ltd, Oxford

Guindon, S., Dufayard, J. F., Lefort, V., Anisimova, M., Hordijk, W., Gasavel, 0. (2010) New algorithms and methods to estimate maximum-likelihood phylogenies: assessing the performance of PhyML 3.0. Systematic Biology 59: 307 $-321$

Ha, H. P., Nguyen, T. T. T., Poompuang, S. Na-Nakorn, U. (2009) Microsatellite revealed no genetic differentiation between hatchery and contemporary wild populations of striped catfish, Pangasianodon hypophthalmus (Sauvage 1878) in Vietnam. Aquaculture 291: 154 - 160

Hauser, L. and Carvalho, G. R. (2008) Paradigm shifts in marine genetics: ugly hypotheses slain by beautiful facts. Fish and Fisheries 9: 333 - 362

Hauser, L., Adcock, G. J., Smith, P. J., Bernal-Ramirez, J. H., Carvalho, G. R. (2002) Loss of microsatellite diversity and low effective population size in an over exploited population of New Zealand snapper (Pagrus auratus). Proceedings of the National Academy of Sciences of the United States of America 99: 11742 11747

Heath, R. A. (1985) A review of the physical oceanography of the sea around New Zealand - 1982. New Zealand Journal of Marine and Freshwater Research 19: 79 124

Hemmer-Hansen, J., Nielsen, E., Frydenberg, J., Loeschcke, V. (2007) Adaptive divergence in a high gene flow environment: $H s c 70$ variation in the European flounder (Platichthys flesus L.). Heredity 99: 592 - 600

Hoarau, G., Boon, E. Jongma, D. N., Ferber, S., Palsson, J. Van der Veer, H. W., Rijnsdorp, A. D., Stam, W. T., Olsen, J. L. (2005) Low effective population size and 
evidence for inbreeding in an overexploited flatfish, plaice (Pleuronecles platessa) Proceedings of Biological Sciences 272: 497 - 503

Houston, R., Haley, C., Hamilton, A., Guy, D., Tinch, A., Taggart, J., McAndrew, B., Bishop, S. (2008) Major quantitative trait loci affect resistance to infectious pancreatic necrosis in Atlantic salmon (Salmo salar). Genetics 178

Huang, C. M. and Liao, I. C. (1990) Response to mass selection for growth rate in Oreochromis niloticus. Aquaculture 85: 199 - 205

Hurst, G. D. D and Jiggins, F. M. (2005) Problems with mitochondrial DNA as a marker in population, phylogeographic and phylogenetic studies: the effects of inherited symbionts. Proceeding the Royal Society B 272: 1525 - 1534

Hutchings, J. A. (1996) Spatial and temporal variation in the density of northern cod and a review of hypotheses for the stock's collapse. Canadian Journal of Fisheries and Aquatic Sciences 53: 943 - 962

Ihaka, R. and Gentleman, R. (1996) R: A language for data analysis and graphics. 5: $299-314$

Ihsesen, P. E., Booke, H. E., Casselman, J. M., McGlade, J. M., Payne, N. R., Utter, F. M. (1981) Stock identification: materials and methods. Canadian Journal of Fisheries and Aquatic Sciences 38: 1838 - 1855

Imsland, A., Brix, O., Naevdal, G., Samuelson, E (1997) Haemoglobin genotypes in turbot (Scophthalmus maximum Rafinesque) their oxygen affinity properties and relation with growth. Comparative Biochemistry and Physiology 116A: 157 - 165

Inoue, J. G., Miya, M., Tsukamoto, K., Nishida, M. (2001) Complete mtDNA sequence of the Japanese anchovy Engraulis japonicas. Fisheries Science 67: 828 835

Jennings, S. and Beverton, R. J. H. (1991) Intraspecific variation in the life history tactics of Atlantic herring (Clupea harengus L.) stocks. ICES Journal of Marine Sciences 48: 117 - 125

Jerry, D. R., Preston, N. P., Crocos, P. J., Keys, S., Meadows, J. R., Li, Y (2004) Parentage determination of Karuma shrimp Penaeus (Marsupenaeus) japonicas using microsatellite markers (Bale). Aquaculture 235: 237 - 247

Johansen, S. D., Coucheron, D. H., Andreassen, M., Karlsen, B. D., Furmanek, T., Jorgensen, T. E., Emblem, A., Breines, R.,Nordeide, J. T., Moum, T., Nederbragt, A. 
J., Stenseth, N. C., Jakobsen, K. S. (2009) large-scale sequence analysis of Atlantic cod New Biotechnology 25: 263 - 271

Jost, L. (2008) $\mathrm{G}_{\mathrm{st}}$ and its relatives do not measure differentiation. Molecular Ecology 17: 4015 - 4026

Kalinowski, S. T. (2005) HP-Rare: a computer program for performing rarefaction on measures of allelic diversity. Molecular Ecology Notes 5: 187 189

Kim, S-G., Morrishima, K., Satoh, N., Fujioka, T., Saito, S., Arai, K. (2007) Parentage assignment in hatchery population of brown sole Pleuronectes herzensteini by microsatellite DNA markers. Fisheries Science 73: 1087 - 1093

Laikre, L., Palm, S., Ryman, N. (2005) Genetic population structure of fishes: implications for coastal zone management. AMBIO 34: 111- 119

Langella, 0. (2010) Populations 1.2.31. Available at http://bioinformatics.org/ tryphon/populations/

Lavoue, S., Miya, M., Inoue, J. G., Saitoh, K., Ishiguro, N. B., Nishida, M. (2005) Molecular systematics of the gonorynchiform fishes (Teleostei) absed on whole mitochondrial sequences: Implications for higher-level relationships within the Otocephala. Molecular Phylogenetics Evolution 37: 165 - 177

Law, R. (2007) Fisheries-induced evolution: present status and future direction. Marine Ecology Progress Series 335: 271 - 277

Le Corre, V. and Kremer, A. (2003) Genetic variability at neutral markers, quantitative trait loci and trait in a subdivided population under selection. Genetics 164: 1205 - 1219

Lee, T., Clarke, M. E., Williams, E., Szmant, A. F., Berger, T. (1994) Evolution of the Tortugas Gyre and its influence on recruitment in the Florida Keys. Bulletin of Marine Science 54:621 - 646

Li, G., Hubert, S., Bucklin, K., Ribes, V., Hedgecock, D. (2003) Characterisation of 79 microsatellite DNA markers in the Pacific oyster Crassostrea gigas. Molecular Ecology Notes 3: 228 - 232

Librado, P. and Rozas, J. (2009) DnsSP v5: a software for comprehensive analysis of DNA polymorphism data. Bioinformatics 25: 1451 - 1452 
Limouzy-Paris, C. B., Graber, H. C., Jones, D. L., Ropke, A. W., Richards, W. J. (1997)

Translocation of larval coral reef fishes via sub-mesoscale spin-off eddies from the Florida current. Bulletin of Marine Science 60:966 - 983

Liu, Z. J., Cordes, J. F. (2004) DNA markers technologies and their applications in aquaculture genetics. Aquaculture 238: 1 - 37

Lowe, W. H. Allendorf, F. W. (2010) What can genetics tell us about population connectivity? Molecular Ecology 19: 3038 - 3051

Lynch, M. (1991) The genetic interpretation of inbreeding depression and outbreeding depression. Evolution 45: 622 - 629

McClelland, E. K. and Naish, K. A. (2007) What is the fitness outcome of crossing unrelated fish populations? A meta-analysis and an evaluation of future research directions. Conservation Genetics 8: 397 - 416

McComish, B. J., Hills, S. F. K., Biggs, P. J., Penny, D. (2010) Index-free de-novo assembly and deconvolution of mixed mitochondrial genomes. Genome Biology Evolution 2: 410 - 424

Maxwell, K. (2011) A hundred years of the Otago groper fishery. Draft final research report for scientific objective 3 (milestone 18) of project ZBD2005/05 long-term effects of climate variation and human impacts of the structural functioning of the New Zealand shelf ecosystem.

Mills, L. S. and Allendorf, F. W. (1996) The one-migrant-per-generation rule in conservation and management. Conservation Biology 10: 1509 - 1518

Miller, P. A., Fitch, A. J., Gardner, M., Hutson, K. S., Mair, G. (2011) Genetic population structure of Yellowtail Kingfish (Seriola lalandi) in temperate Australiasian waters inferred from microsatellite markers and mitochondrial DNA. Aquaculture 319: 328 - 336

Ministry for Primary Industries (2012). Fisheries Assessment Plenary, November 2012: stock assessments and yield estimates. Compiled by the Fisheries Science Group, Ministry for Primary Industries, Wellington, New Zealand. $531 \mathrm{p}$.

Miya, M. and Nishida, M. (2000) Use of mitogenome information in teleostan molecular phylogenetics: a tree bases exploration under the maximumparsimony optimality criterion. Molecular Phylogenetics Evolution 17: 437 - 455 
Mora, C., Myers, R. A., Coll, M., Libralato, S., Pitcher, T. J., Sumail, R. U., Zellers, D., Watson, R., Gaston, K. J., Worm, B. (2009) Management effectiveness of the world's marine fisheries. PLoS Biology 7: e1000131

Nagata, J., Masuda, R., Kaji, K., Kaneko, M., Yoshida, M. C. (1998) Genetic variation and population structure of the Japanese sika deer (Cervus nippon) in Hokkaido Island based on mitochondrial D-loop sequences. Molecular Ecology 7: 871 - 877

Nakadate, M., Shikano, T., Taniguchi, N. (2003) Inbreeding depression and heterosis in various quantitative traits of the guppy, Poecilia reticulata. Aquaculture 220: 219 - 226

Neff, B. D. (2001) Genetic paternity analysis and breeding success in bluegill sunfish (Lepomis macrochirus). Journal of Heredity 92: 111 - 119

Norris, A.T., Bradley, D.G., Cunningham, E.P. (1999) Microsatellite genetic variation between and within/farmed and wild Atlantic salmon Salmo salar populations. Aquaculture 180: 247 - 264

Norris, A. T., Bradley, D. G., Cunningham, E. P. (2000) Parentage and relatedness determination in farmed Atlantic Salmon (Salmo salar) using microsatellite markers. Aquaculture 182: 73 - 83

NZIER (2010) Value of kingfish and hapuku farming. A preliminary analysis. New Zealand Institute of Economic Research Authoritative Analysis 24p.

O'Connell, M. and Wright, J. M. Microsatellite DNA in fishes. Review in Fish Biology and Fisheries 7: $331-363$

Oosterhout, C. V., Hutchinson, W. F., Wills, D. P. M., Shipley, P. (2004) Microchecker: software for identifying and correcting genotyping errors in microsatellite data. Molecular Ecology Notes 4: 535 - 538

Paetkau, D., Slade, R., Burden, M., Estoup, A. (2004) Genetic assignment methods for the direct, real-time estimation of migration rate: a simulation-based exploration of accuracy and power. Molecular Ecology 13: 55 - 65

Palm, S., Dannewitz, J., Jarvi, T., Peterson, E., Prestegaard, T., Ryman, N. (2003) Lack of molecular genetic divergence between sea-ranched and wild sea trout (Salmo trutta). Molecular Ecology 12: 2057 - 2071

Palumbi, S. R. (2003) Population genetics, demographic connectivity and the design of marine reserves. Ecological Application 13: S146 - S158 
Pampoulie, C., Jorundsdottir, T. D., Steinarsson, A., Petursdottir, G., Stefansson, M. O., Danielson, A. K. (2006) Genetic comparison of farmed strains and farmed Icelandic populations of Atlantic cod (Gadhus morhua L.). Aquaculture 261: 556 564

Paul, L. J. (2002a) Can existing data describe the stock structure of the two New Zealand groper species, hapuku (Polyprion oxygeneios) and bass (P. americanus)? New Zealand Fisheries Assessment Report 2002/14. 24p

Paul, L. J. (2002b) A description of the New Zealand fisheries for the two groper species, hapuku (Polyprion oxygeneios) and bass (P. americanus). New Zealand Fisheries Assessment Report 2002/13. 47p

Pawson, M. G. and Jennings, S. (1996) A critique of methods for stock identification in marine capture fisheries. Fisheries Research 25: 203 - 217

Paxton, J. R., Hoese, D. F., Allen, G. R., Hanley J. E. (1989) Pisces. Petromyzontidae to Carangidae. In: Walton, D. W. and Longmore, R. (eds) Zoological catalogue of Australia. Vol 7. Brown Prior Anderson Pty Ltd, Burwood, Victoria

Peakall, R. and Smouse, P.E. (2012) Genalex 6.5: genetic analysis in Excel. Population genetic software for teaching and research-an update. Bioinformatics 28: $2537-2539$

Peres, M. B. and Klippel, S. (2003) Reproductive Biology of the southwestern Atlantic wreckfish Polyprion americanus (Teleosti:Polyprionidae). Environmental Biology of Fishes 68: 163 - 173

Piry, S., Luikart, G., Cornuet, J. M. (1999) BOTTLENECK: A computer program for detecting recent reductions in the effective popu- lation size using allele frequency data. Journal of Heredity 90: 502 - 503

Piry, S., Alapetite, A., Cornuet, J.-M., Paetkau, D., Baudouin, L., Estoup, A. (2004) GeneClass2: A Software for Genetic Assignment and First-Generation Migrant Detection. Journal of Heredity 95: 536 - 539

Pogson, G., Taggart, C., Messa, K., Boutilier, R. (2001) Isolation by distance in the Atlantic cod, Gadus morhua, at large and small geographic scales. Evolution 55: $131-146$

Porta, J., Porta, J., Canavate, P., Martinz-Rodrigeuz, G., Alvarez, M. (2007)

Substantial loss of genetic variation in a single generation of Senegalese sole 
(Solea senegalensis) culture: implications in the domestication process. Journal of Fish Biology 71B: 223 - 234

Posada, D. (2008) jModelTest: phylogenetic model averaging. Molecular Biology and Evolution 25: 1253 - 1256

Powers, D., Lauerman, T., Crawford, D., Smith, M., Gonzalez-Villasenor, I., Dimichele, L. (1991) The evolutionary significance of genetic variation at enzyme synthesizing loci in the teleost Fundulus heteroclitus. Journal of Fish Biology 39A: $169-184$

Pritchard, J. K., Stephens, M., Donnelly, P. (2000) Inference of population structure using multilocus genotype data. Genetics 155: 945 - 959

R Development Core Team (2011). R: A language and environment for statistical computing. R Foundation for Statistical Computing, Vienna, Austria. ISBN 3-900051-07-0, URL http://www.R-project.org/

Rambaut, A. and Drummond, A. J. (2007) Tracer v1.4. Available from http://beast.bio.ed.ac.uk/Tracer

Ramos-Onsins, S. E and Rozas, J. (2002) Statistical properties of new neutrality tests against population growth. Molecular, Biology and Evolution 19: 2092 2100

Raymond, M. and Rousset, F. (1995) GENEPOP (version 1.2): population genetics software for exact tests and ecumenicism. Journal of Heredity 86: 248 - 249

Rice, W. R. (1989) Analysing tables of statistical tests. Evolution 48: 223 - 225

Rioux Paquette, Sebastien (2011) Popgenkit package for 'R'

Roberts, C. D. (1986) Systematics of the percomorph fish genus Polyprion Oken, 1917. PhD dissertation. Victoria University of Wellington, Wellington, New Zealand

Rogers, A. R. and Harpending, H. (1992) Population growth makes waves in the distribution of pairwise genetic differences. Molecular Biology Evolution 9: 552 569

Rogers, A. D., Morely, S., Fitzcharles, E., Jarvis, K., Belchier, M. (2006) Genetic structure of Patagonian toothfish (Dissostichus eleginoides) populations on the Patagonian Shelf and Atlantic and western Indian Ocean sectors of the Southern 
Ross, P. M., Hogg, I. D., Pilditch, C. A., Lundquist, C. J. (2009) Phylogeography of New Zealand's coastal benthos. New Zealand Journal of Marine and Freshwater Research 43: 1009 - 1027

Rousset, F. and Raymond, M. (1995) Testing heterozygosity excess and deficiency. Genetics 140: 1413 - 1419

Rozen, S._and Skaletsky, H. J. (2000) Primer3 on the WWW for general users and for biologist programmers. In: Krawetz S, Misener S (eds) Bioinformatics Methods and Protocols: Methods in Molecular Biology. Humana Press, Totowa, NJ, pp 365 386

Ruzzante, D. E., Taggart, T. E., Cook, D. (1998) A nuclear DNA basis for shelf- and bank-scale population structure in northwest Atlantic cod (Gadus morhua): Labrador to Geogres Bank. Molecular Ecology 7: 1663 - 1680

Ryman, N. and Palm, S. (2006) POWSIM: a computer program for assessing statistical power when testing for genetic differentiation. Molecular Ecology Notes 6: $600-602$

Salzburger, W., Ewing, G. B., von Haeseler, A. (2011) The performance of phylogenetic algorithms in estimating haplotype genealogies with migration. Molecular Ecology 20: 1952 - 1963

Sambrook, J., Fritsch, E. F., Maniatis, T. (1989) Molecular cloning: a lab manual, vol. 3. Cold Spring Harbour Laboratory Press, Cool Spring Harbour, New York

Sanger, F., Nicklen, S., Coulson, A. K. (1977) DNA sequencing with chainterminating inhibitors. Proceedings of the National Academy of Sciences of the United States of America 74: 5463 - 5467

Sauvage, C., Derome, N., Normandeau, E., St.-Cyr, J., Audet, C., Bernatchez, L. (2010) Fast transcriptional responses to domestication in the Brook Charr Salvelinus faontinalis. Genetics 185: 105 - 112

Schatz, M. C., Delcher, A. L., Salzberg, S. L. (2010) Assembly of large genomes using second-generation sequencing. Genome Research 20: 1165 - 1173

Sedberry, G. R., Carlin, J. L., Chapman, R. W., Eleby, B. (1996) Population structure in the pan-oceanix wreckfish, Polyprion americanus (Teleosti:Polyprionidae), as indicated by mtDNA variation. Journal of Fish Biology 49(Suppl A): 318 - 329 
Sekino, M., Hara, M., Taniguchi, N. (2003) Los of microsatellite and mitochondrial DNA variation in hatchery strains of Japanese flounder Paralichthys olivaceus. Aquaculture 213: 101 - 122

Seligmann, H. (2010) Mitochondrial tRNAs as light strand replication origins: similarity between anticodon loops and the loop of the light strand replication origin predicts initiation of DNA replication. BioSystems 99: 85 - 93

Skaala, O., Hoyheim, B., Glover, K., Dahle, G. (2004) Microsatellite analysis in domesticated and wild Atlantic salmon (Salmo salar L.): allelic diversity and identification of individuals. Aquaculture 240: 131 - 143

Smith, P. J. (1990) Protein electrophoresis for identification of Australasian fish stocks. Australian Journal of Marine and Freshwater Research 41: 823 - 833

Smith, P. J., McVeagh, S. M., Ede, A. (1996) Genetically isolated stocks of orange roughy (Hoplostethus atlanticus), but not of hoki (Macruronus novaezelandiae), in the Tasman Sea and southwestern Pacific Ocean and around New Zealand. Marine Biology 125: 783 - 793

Smith, P.J., McMillan, P.J., Bull, B., McVeagh, S.M., Gaffney, P.M., Chow, S. (2002) Genetic and meristic variation in black and smooth oreos in the New Zealand exclusive economic zone. New Zealand Journal of Marine and Freshwater Research 36:737-750

Smith, P. J. (2008) Population biology and genetics of paua, hapuku and kingfish: sourcing fish for broodstock development. NIWA Technical Report 132. 44 p.

Smith, H. M. (2012) Characterisation of the mitochondrial genome and the phylogeographic structure of blue cod (Parapercis colias). MSc dissertation, Victoria University of Wellington, Wellington, New Zealand.

Smith, P. J. and Johnson, A. D. (1985) Glucosephosphate isomerase and $\alpha$ glycerophospjhate dehyfrogenase electromorph frequencies in groper Polyprion oxygeneios from central New Zealand. New Zealand Journal of Marine and Freshwater Research 19: 173 - 177

Smith, P. J. and Conroy, A. M. (1992) Loss of genetic variation in hatcheryproduced abalone, Haliotis iris. New Zealand Journal of Marine and Freshwater Research 26: 81 - 85

Smith, P. J., Francis, R. I. C. C., McVeagh, M. (1991) Loss of genetic diversity due to fishing pressure. Fisheries Research 10: 309 - 316 
Su, G-S., Liljedahl, L-E., Gall, G. A. E. (1996) effects of inbreeding on growth and reproductive traits in rainbow trout (Oncorhynchus mykiss). Aquaculture 142: $139-148$

Swearer, S. E., Shima, J. S., Hellberg, M. E., Thorrold, S. R., Jones, G. P., Robertson, D. R., Morgan, S. G., Selkoe, K. A., Ruiz, G. M., Warner, R. R. (2002) Evidence of selfrecruitment in demersal marine populations. Bulletin of Marine Science 70: 251 271

Symonds, J. E. (2009) New Zealand breeding expansion addresses high-value species. Global aquaculture advocate May/June 27 - 28

Symonds, J. E., Walker, S. P., van de Ven, I., Marchant, A., Irvine, G., Pether, S., Gublin, Y., Bruce, M., Anderson, R. M., McEwan, K. M. (2012) Developing broodstock resources for farmed marine fish. Proceedings of the New Zealand Society of Animal Production 72: 222 - 226

Tajima, F. (1989) Statistical-method for testing the neutral mutation hypothesis by DNA polymorphism. Genetics 123: 585 - 595

Tankersley, R. A., McKelvey, L. M., Forward, R. B. (1995) Responses of estuarine crab megalopae to pressure, salinity and light: implications for flood-tide transport. Marine Biology 122: 391 - 400.

Teichert-Coddington, D. R. and Smitherman, R. O. (1988) Lack of response by Tilipia nilotica to mass selection for rapid early growth. Transactions of the American Fisheries Society 117: 297 - 300

Tidewell, J. H. and Allan, G. L (2001) Fish as food: aquaculture's contribution. EMBO reports 2: $958-963$

Trippel, E. A., Rideout, R. M., O'Reilly, P. T., Herbinger, C. M., Neil, S. R. E., Hamilton, L. (2009) Communal spawning leads to high potential for inbreeding in gadoid aquaculture. Aquaculture 296: 27 - 35

Tseng, M-C. and Smith, P. J. (2012) Lack of genetic differentiation observed in Pacific Bluefin tune (Thunnus orientalis) from Taiwanese and New Zealand waters using mitochondrial and nuclear DNA markers. Marine and Freshwater Research 63: 198 - 209

Tzeng, C. S., Hui, C. F., Shen, S. C., Huang, P. C. (1992) The complete nucleotide sequence of the Crossostima lacustre mitochondrial genome: conservation and variation among vertebrates. Nucleic Acids Research 20: 4853 - 4858 
Varela, A. I., Ritchie, P. A., Smith, P. J. (2012) Low level of global genetic differentiation and population expansion in the deep-sea teleost Hoplostethus atlanticus revealed by mitochondrial DNA sequences. Marine Biology 159: 1049 1060

Wakefield, C. B., Newman, S. J., Molony, B. W. (2010) Age-based demography and reproduction of hapuku, Polyprion oxygeneios, from the south coast of Western Australia: implications for management. ICES Journal of Marine Science 67: 1164 $-1174$

Waldman, J. R., Richards, R. A., Schill, W. B., Wirgin, I., Fabrizio, M. C. (1997) An empirical comparison of stock identification techniques applied to striped bass. Transactions of the American Fisheries Society 2: 144 - 176

Wang, C., Wang, J., Yang, J., Lu, G., Song, X., Chen, Q., Xu, J., Yang, Q., Li, S. (2012) Complete mitogenome sequence of black carp (Mylopharyngodon piceus) and its use for molecular phylogeny of leuciscine fishes. Molecular Biology Reports 39: $6337-6342$

Waples, R. S. and Drake, J. (2004) Risk/benefit considerations for marine stock enhancement: a Pacific salmon perspective. Pp. 260 - 306 in Leber, K. M., Kitada, S., Blankenship, H. L., Svasand, T., eds. Stock enhancement and sea ranching: developments, pitfalls and opportunities. Blackwell publishing, Oxford, U.K.

Waples, R. S. and Gaggiotti, O. (2006) What is a population? An empirical evaluation of some genetic methods for identifying the number of gene pools and their degree of connectivity. Marine Ecology 15: 1419 - 1439

Weir, B. S. and Cockerham, C. C. (1914) Estimating F-statistics for the analysis of population structure. Evolution 38: 1358 - 1370

Xiao, Y., Gao, T., Zhang, Y., Yanagimoto, T. (2010) Demographic history and population structure of blackfin flounder (Glyptocephalus stelleri) in Japan revealed by mitochondrial control region sequences. Biochemical Genetics 48: $402-417$

Zardoya, R. and Meyer, A. (1996) The complete nucleotide sequence of the mitogenome of the lungfish (Protopterus dolloi) supports its phylogenetic position as a close relative of land vertebrates. Genetics 142: $1249-1263$

Zeldis, J., Broekhuizen, N., Forsythe, A., Morrissey, D. Stenton-Dozey, J. (2011) Waikato marine fish-farmiing: production and ecological guidance. NIWA climate 
report CHC2010-147. National Institute of Water and Atmosphere Research Ltd. $112 \mathrm{p}$. 